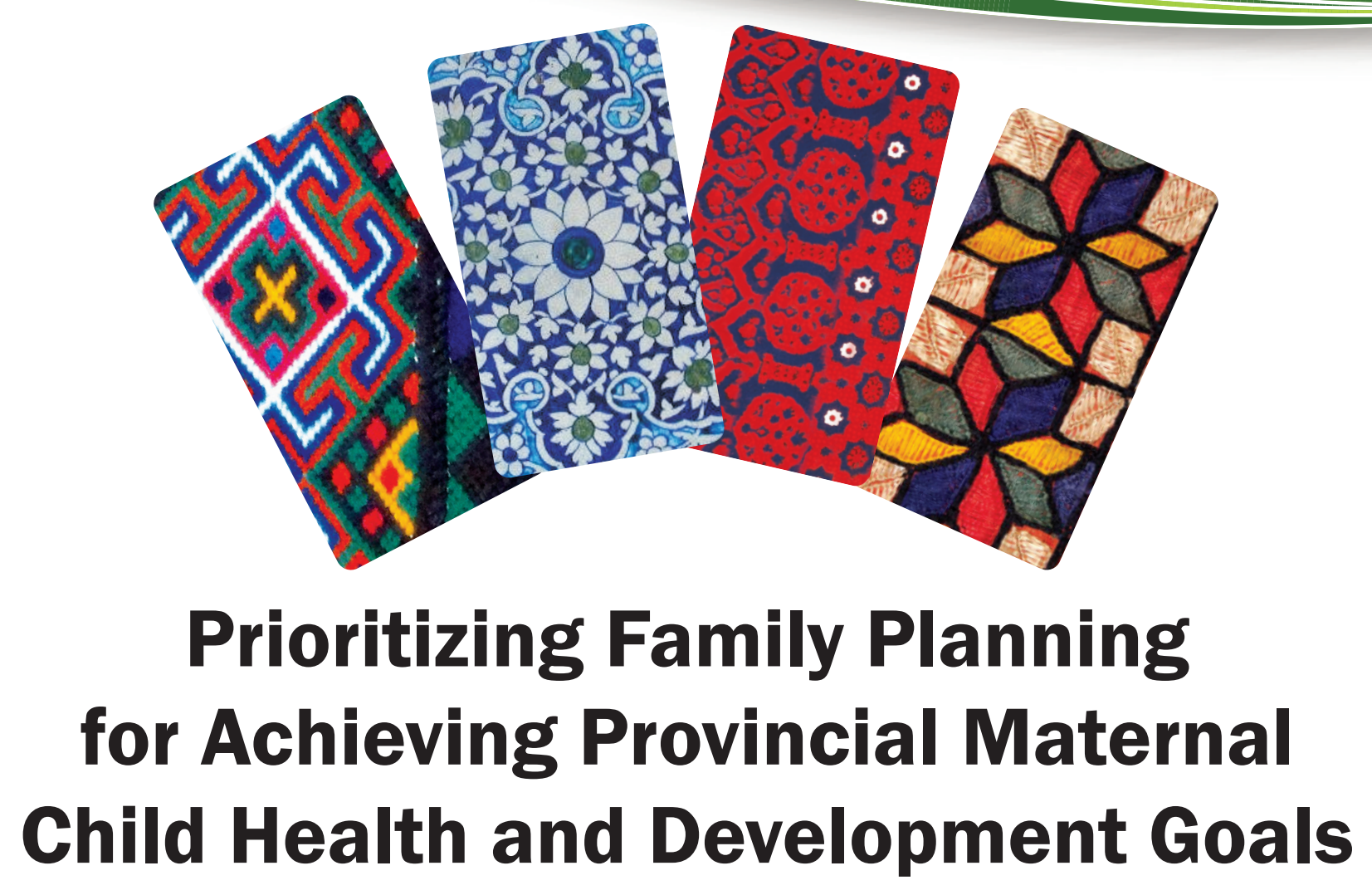

A Study Funded by

The Maternal and Newborn Health Programme

Research and Advocacy Fund (RAF)

Implemented by

The Population Council

March 2014

Authors:

Dr. Zeba A. Sathar

Dr. Muhammad Asif Wazir

Maqsood Sadiq 



\title{
Prioritizing Family Planning for Achieving Provincial Maternal Child Health and Development Goals
}

\author{
A Study Funded by \\ The Maternal and Newborn Health Programme \\ Research and Advocacy Fund (RAF)
}

Implemented by

The Population Council

March 2014

Authors:

Dr. Zeba A. Sathar

Dr. Muhammad Asif Wazir

Maqsood Sadiq 


\section{POPULATION}

COUNCIL

Ideas. Evidence. Impact.

The Population Council confronts critical health and development issues - from stopping the spread of HIV to improving reproductive health and ensuring that young people lead full and productive lives. Through biomedical, social science, and public health research in 50 countries, we work with our partners to deliver solutions that lead to more effective policies, programmes, and technologies that improve lives

(C) 2013 The Population Council, Inc.

Declaration

"I have read the report titled 'Prioritizing Family Planning for Achieving Provincial Maternal Child Health and Development Goals', and acknowledge and agree with the information, data and findings contained".

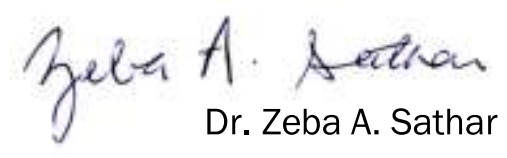

Country Director, Population Council

Islamabad

\section{Acknowledgment}

'Prioritizing Family Planning for Achieving Provincial Maternal Child Health and Development Goals' is a project funded by the Maternal and Newborn Health Programme- Research and Advocacy Fund (RAF), and is implemented by the Population Council, Pakistan.

Disclaimer

This document is an output from a project funded by the UK Department for International Development (DFID) and the Australian Department of Foreign Affairs and Trade (DFAT) for the benefit of developing countries. The views expressed and information contained in it are not necessarily those of or endorsed by DFID, DFAT or the Maternal and Newborn Health Programme- Research and Advocacy Fund (RAF), which can accept no responsibility or liability for such views, for completeness or accuracy of the information, or for any reliance placed on them. 


\section{Table of Contents}

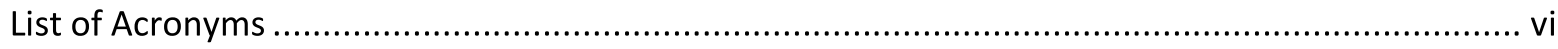

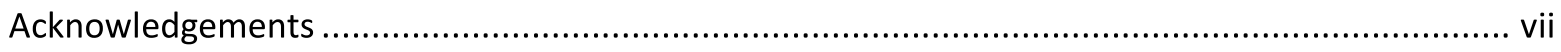

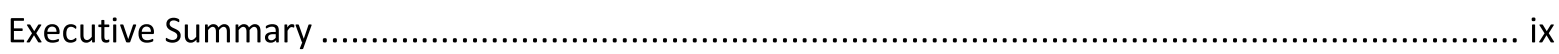

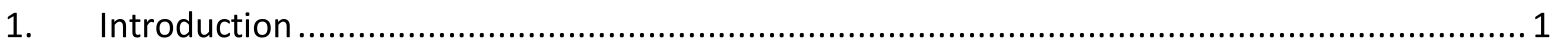

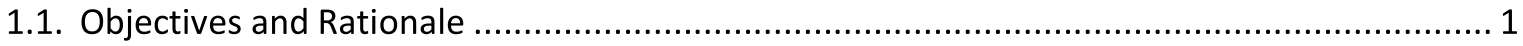

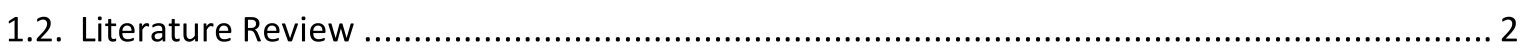

1.2.1. Family Planning: A Priority for Development ..................................................... 2

1.2.2. Reaffirming the Health Benefits of Family Planning for MDGs 4 and 5.................... 4

1.2.3. Socioeconomic Benefits of Family Planning........................................................ 7

1.2.4. Women's Empowerment and Labour Force Participation.......................................... 7

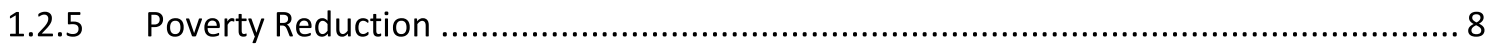

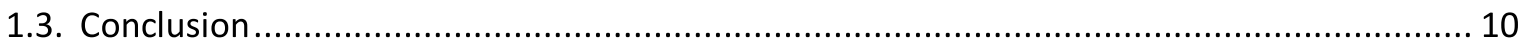

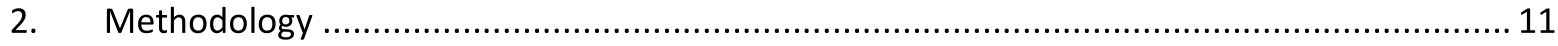

2.1. Generating Provincial Population Projections............................................................ 11

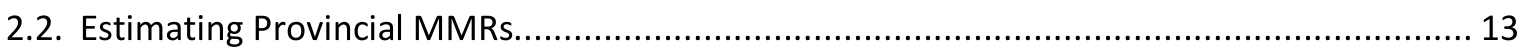

2.3. Estimating the Impact of Family Planning on Maternal and Infant and Child Mortality ....... 15

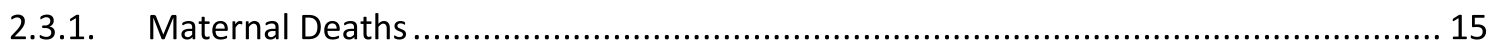

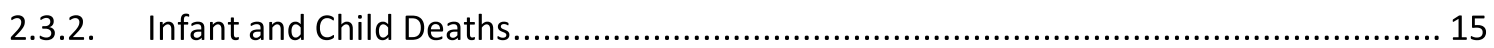

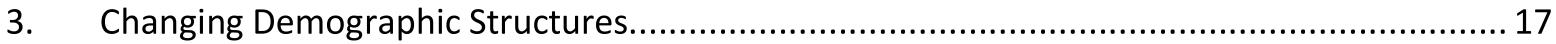

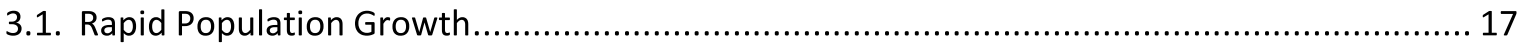

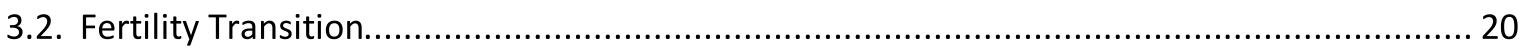

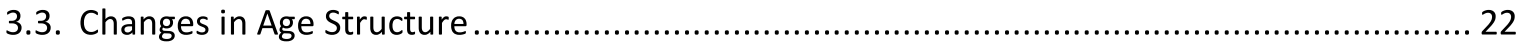

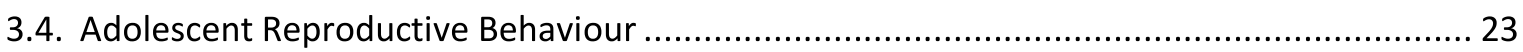

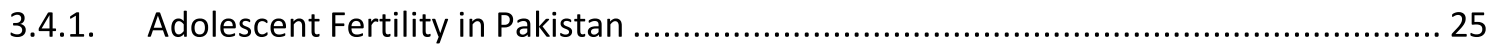

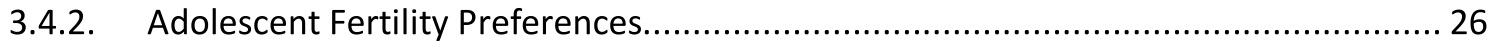

3.4.3. High Neonatal Mortality among Adolescent Mothers............................................ 28

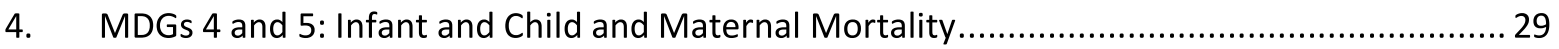

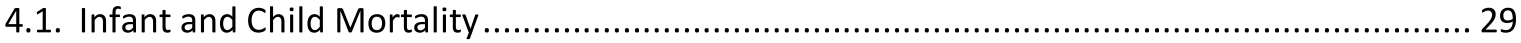

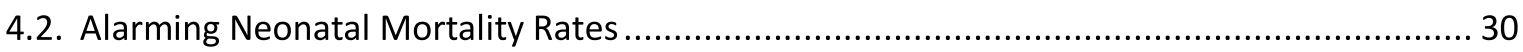

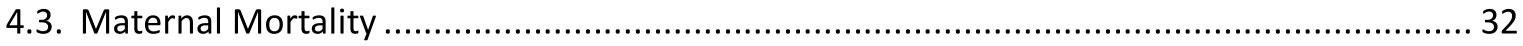

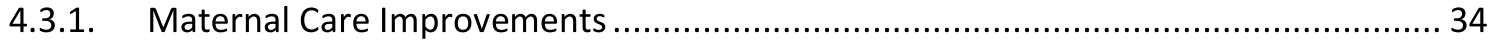

5. The Opportunity to Expedite Fertility Decline and Reduce Maternal and Infant Mortality..... 37

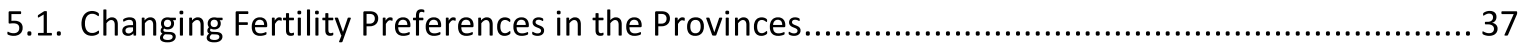

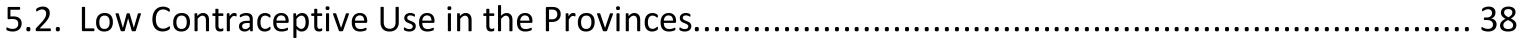

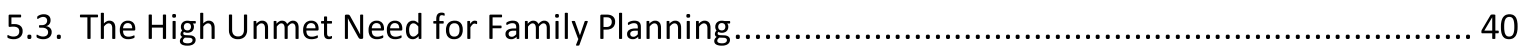

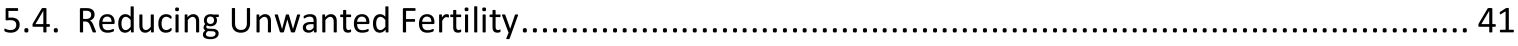


6. The Role of Family Planning in Reducing Maternal and Child Mortality..............................43

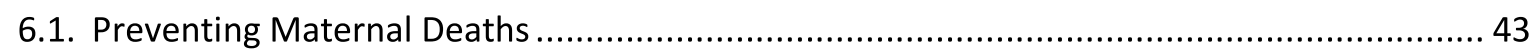

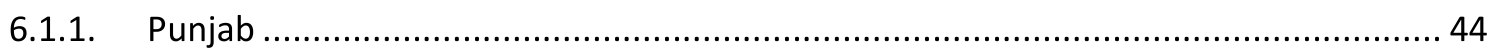

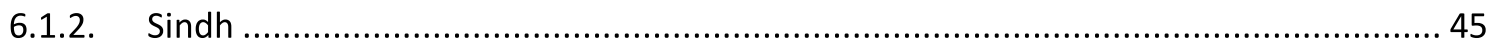

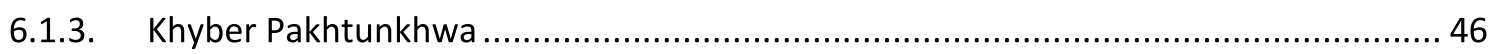

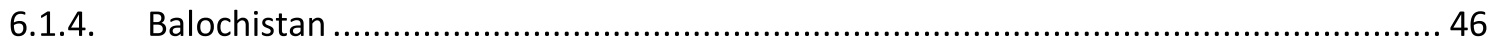

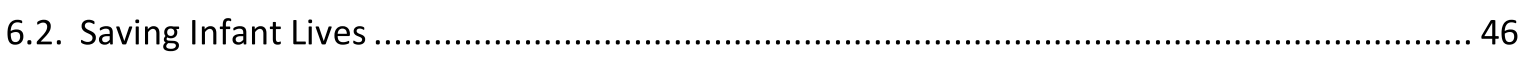

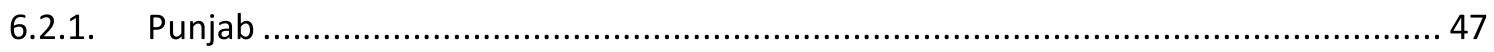

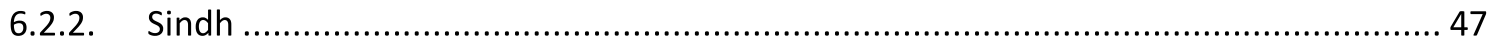

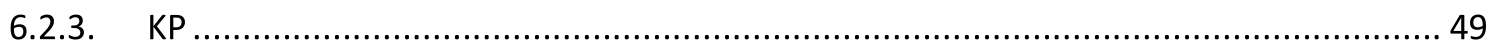

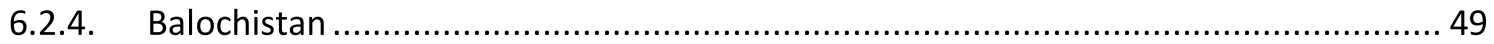

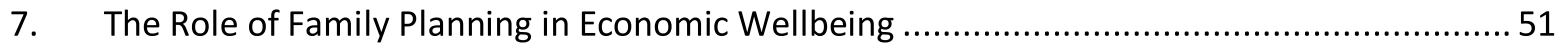

7.1. Establishing the Link between Fertility, Family Planning and Poverty ............................... 51

7.2. The Impact of Fertility Decline on Overall Age Structure .............................................. 53

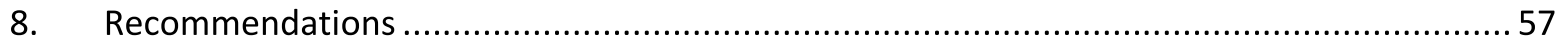

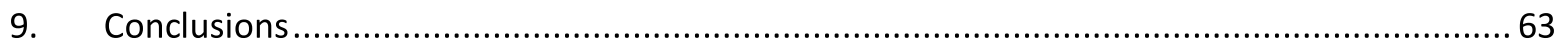

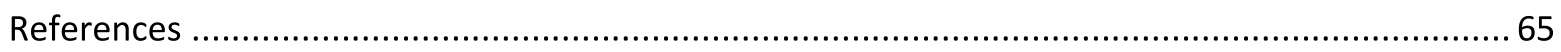

\section{List of Tables}

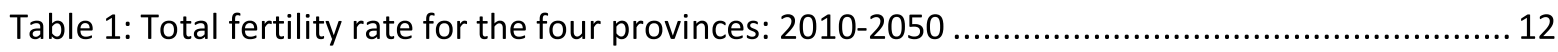

Table 3.1: Median age at marriage and percentage of women aged 25-29 married by age 18

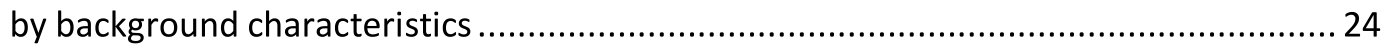

Table 3.2: ASFR for adolescent girls at the national level, 1990-2012 ..................................... 25

Table 7.1: Average household size, mean number of children under 15, and dependency ratios by poverty status, at national and provincial levels. 2001-02 and 2010-11 ..........55

Table 7.2: Household Savings Income Ratio by poverty status $\&$ by number of children at the provincial level in Pakistan: 2005-2010. 56 


\section{List of Figures}

Figure 3.1: Estimated and projected population of Pakistan, 1951-2050 ........................... 18

Figure 3.2: Estimated and projected population at the provincial level, 1951-2050 .................. 19

Figure 3.3: TFR levels and trends at the provincial level, 1990-2012 ................................. 21

Figure 3.4: TFR levels and trends by place of residence at the provincial level, $2006-12$

Figure 3:5: Age structure changes in Pakistan \& at the provincial level, 1972-2050 ................... 22

Figure 3.6: Adolescent contraceptive use in Punjab, Sindh and KP, 2006-07-2012-13 ............... 26

Figure 3.7: Adolescent fertility preferences at the provincial level ................................... 27

Figure 3.8: Met and unmet need for family planning services among adolescents at the

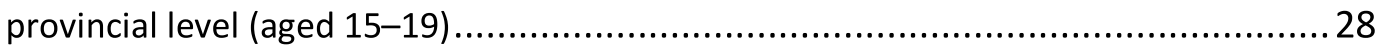

Figure 3.9: Neonatal mortality for mothers aged $<20$ at birth at the provincial level.................. 28

Figure 4.1: Levels of and trends in IMR and U5MR at the provincial level, 1990-2012 ...............30

Figure 4.2: Levels of and trends in neonatal and post-neonatal mortality at the provincial

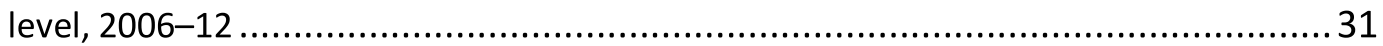

Figure 4.3: MMR levels and trends for Pakistan, 2001-12 ................................................ 33

Figure 4.4: MMR levels and trends for Pakistan and at the provincial level, 2001-12. ................33

Figure 4.5: Levels of and trends in ANC and SBA services at the provincial level ,

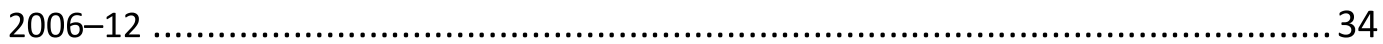

Figure 4.6: Percentage of deliveries at home by province, $2006-12$..................................... 35

Figure 5.1: Preferences for limiting and spacing family size for men and women at the

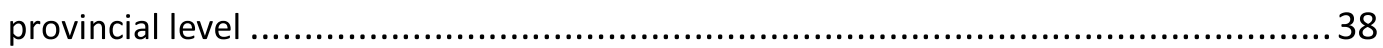

Figure 5.2: Contraceptive prevalence by provinces................................................ 38

Figure 5.3: Provincial Contraceptive prevalence rates................................................... 39

Figure 5.4: Contraceptive methods mix for Pakistan................................................. 40

Figure 5.5: Unmet need for family planning by provinces, 2006-12 .................................. 41

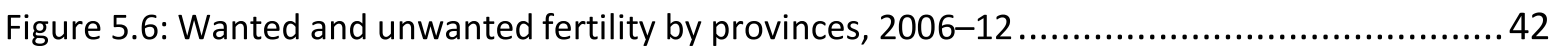

Figure 6.1: Impact of family planning on number of maternal deaths in Pakistan...................... 44

Figure 6.2: Impact of family planning on maternal mortality by provinces............................. 45

Figure 6.3: Impact of family planning on infant and children (aged 1-4) deaths in Pakistan .......... 47

Figure 7.1: TFR by poverty status by province.................................................... 51

Figure 7.2: Contraceptive prevalence rates by three wealth quintiles by province ....................5 52

Figure 7.3: Unmet need for family planning by women's socioeconomic status by province ......... 53

Figure 7.4: Population pyramids for the poorest and richest households at the provincial level, 2010-11 


\section{List of Acronyms}

\begin{tabular}{|c|c|}
\hline ANC & Antenatal Care \\
\hline ASFR & Age-Specific Fertility Rate \\
\hline CPR & Contraceptive Prevalence Rate \\
\hline DHS & Demographic and Health Surveys \\
\hline FALAH & Family Advancement for Life and Health \\
\hline FP & Family Planning \\
\hline GFR & General Fertility Rate \\
\hline IEC & Information, Education, and Communication (campaign) \\
\hline IMR & Infant Mortality Rate \\
\hline IUD & Intra-Uterine Device \\
\hline $\mathrm{KPK} / \mathrm{KP}$ & Khyber Pakhtunkhwa \\
\hline LHW & Lady Health Worker \\
\hline MDG & Millennium Development Goal \\
\hline MICS & Multiple Indicator Cluster Survey \\
\hline MMR & Maternal Mortality Ratio \\
\hline PDHS & Pakistan Demographic and Health Survey \\
\hline PIHS & Pakistan Integrated Household Survey \\
\hline PMDF & $\begin{array}{l}\text { Proportion of deaths of women of reproductive age that are due to maternal } \\
\text { causes }\end{array}$ \\
\hline PPHI & People's Primary Healthcare Initiative \\
\hline PRHFPS & Pakistan Reproductive Health and Family Planning Survey \\
\hline PSLMS & Pakistan Social and Living Standards Measurement Survey \\
\hline RAF & Research and Advocacy Fund \\
\hline SBA & Skilled Birth Attendance \\
\hline SWRHFPS & Status of Women, Reproductive Health, and Family Planning Survey \\
\hline TFR & Total Fertility Rate \\
\hline U5MR & Under-Five Mortality Rate \\
\hline UN & United Nations \\
\hline UNDP & United Nations Development Programme \\
\hline UNFPA & United Nations Population Fund \\
\hline UNICEF & United Nations International Children's Emergency Fund \\
\hline USAID & United States Agency for International Development \\
\hline WHO & World Health Organization \\
\hline
\end{tabular}




\section{Acknowledgements}

The Population Council is grateful to the Maternal and Newborn Health Programme- Research and Advocacy Fund (RAF), the Department for International Development (DFID) and the Australian Department of Foreign Affairs and Trade (DFAT) for generous funding of this project "Prioritizing Family Planning for Achieving Provincial Maternal Child health and Development Goals". This report comprises the analysis and results which have been presented to the provincial governments to make the case for accelerating family planning efforts. We would like to thank the provincial governments and their representatives that provided feedback and suggestions on earlier versions and presentations that are now included in the report. We are grateful to the anonymous reviewers assigned by the Research and Advocacy Fund who gave extremely valuable comments on an earlier draft of the report.

We acknowledge many Population Council colleagues who assisted in finalizing this report and particularly those who helped in the production of the briefs. Dr. Karen Hardee, Dr. Ali Mir, Ms. Seemin Ashfaq, Dr. John Townsend all provided comments at various stages. Mr. Muhammad Khalil and Ms. Seemin Ashfaq have really been most critically involved in the finalization of the report. We are grateful to Ms. Maheen Pracha for the careful editing of the report. Mr. Ali Ammad has been responsible for its layout. And finally, the authors accept responsibility for any errors that they failed to catch and correct in the report. 



\section{Executive Summary}

Addressing the four major provinces, this report presents an argument for prioritizing family planning to achieve their maternal child and development goals. The argument has been made effectively at the international level, culminating in the London Family Planning Summit 2012. This is after a large part of the decline in worldwide maternal mortality was attributed to declines in fertility. Strong links between birth spacing and contraceptive use and infant and child mortality are now widely accepted in the form of the World Health Organization's Healthy Timing and Spacing of Pregnancies initiative.

The report uses the latest available provincial data, especially the Pakistan Demographic and Health Survey for 2012-13. The analysis is based on a realistic set of provincial projections generated by the Population Council for each province. The authors identify opportunities for enhancing family planning use in the form of changing fertility preferences, which reflect the high unmet need across Pakistan, and point out the disconnect between the demand for spacing and limiting and actual use of contraception. Using this gap as a basis for projecting higher contraceptive use, we estimate the number of maternal, infant, and child lives that could be saved in each province through an accelerated family planning programme.

The analysis establishes that none of the provinces are on track to meeting the Millennium Development Goals 4 or 5 . The latest trends in maternal mortality are slightly more favourable but certainly childhood and neonatal mortality do not present a similar improvement. Current trends need to accelerate to set the trajectory towards further reducing maternal and child mortality in all the provinces.

The increase in size of population in each province is presented in the form of three scenarios a slow fertility decline, a slightly faster fertility decline, and a sharper decline-that could be brought about by an accelerated family planning programme. The associated advantages of fewer school-going children and schools, and of smaller infrastructure and food requirements, etc., are not presented here. However, what are highlighted are the changes in age structure and reduced dependency ratios linked with improvements in the economic status of households. Dependency ratios and the poverty status of households are presented separately for each province.

The report's key message across all provinces relates categorically to the need for an accelerated family planning programme. However, there are significant differences that need to be focused on. Punjab, for instance, faces rising child mortality and north and south differences. Balochistan has to confront extremely high and rising maternal mortality. Sindh shows stark differences between urban and rural areas in all indicators, while KP faces inter-district variations.

Essential steps towards an accelerated family planning programme include an increase in access to services to fill the rising gap between fertility preferences and the availability of services. The health sector in general and health departments in particular will have to step up the delivery of family planning services at their outlets and hospitals, and provide referrals and 
outreach in conjunction with the population welfare departments. The report also strongly recommends revitalizing the Lady Health Workers Programme in each province, enabling it to return to its original mandate of providing family planning services and making household visits. Finally, there is a need to focus on areas not covered by the population welfare and health departments or by lady health workers. These need to be identified and new services deliberately placed there. 


\section{Introduction}

There is an opportunity today to make a difference in Pakistan, given the country's new and emerging priorities since the 18th Amendment. The arguments presented using provincial data are more likely to strike a chord with provincial policymakers. The case for allocating resources and priorities for family planning has to be made with a renewed emphasis in each province, given its role in improving maternal and child health as well as in poverty reduction and economic growth.

This report aims to clarify the policies and direction relevant to each province in prioritizing family planning as an essential part of improving maternal and child health indicators and attaining the Millennium Development Goals (MDGs) and beyond. Current levels and trends in fertility, family planning and maternal and child mortality are not sufficiently on track to meet either MDG 4 or 5. Given the provinces' new responsibilities post-18th Amendment, there is a need to review and build up evidence at the provincial level of the links between family planning, fertility, and maternal and neonatal health. In particular, it is important to consider how the unmet need for family planning among younger women strongly influences maternal and neonatal health. The capacity to translate this knowledge into policies and evidence-based programmes for action also needs to be strengthened.

While there is a general awareness of the magnitude of these health and development issues, national and provincial governments and civil society have not responded adequately. ${ }^{1}$ Consequently, there is a gap between the demand for reproductive health services and their availability. The result is that Pakistan is one of the six countries classified as major contributors to the world's maternal deaths (Hogan et al., 2010). The links between successful family planning and reductions in maternal and child mortality have not been fully understood and appreciated by the health sector. One reason for this is that family planning has been seen as the sole responsibility of population welfare departments, which has virtually absolved the health sector of the responsibility of delivering family planning services, with the exception of the Lady Health Workers Programme.

\subsection{Objectives and Rationale}

The report's objective is to identify and reassert the importance of correcting this strategy. The main way of convincing policymakers is to trace the basic relationships that demonstrate the link between increased uptakes of family planning for birth spacing and improved maternal and child health and other development outcomes. We have established these relationships using the latest data available at the provincial level.

\footnotetext{
1: Population Council. (2009).Examining fertility change and its impact on household poverty and welfare(Background paper for the World Bank Pakistan Poverty Assessment Report).Islamabad: World Bank. Available at http://siteresources.worldbank.org/INTPRH/Resources/3763741278599377733/Pakistan62810PRINT.pdf
} 
The evidence generated has been shared with key stakeholders in the provinces over the course of interactive sessions, allowing them to comprehend and agree with the findings, and to understand the importance of according family planning services the priority they deserve.

\subsection{Literature Review}

\subsubsection{Family Planning: A Priority for Development}

Family planning programmes provide a win-win solution for development. The evidence is compelling: voluntary family planning programmes improve the health and survival of mothers and children, empower women, and help women and their families escape from poverty. Improving the welfare of individual women and children yields additional economic benefits. These issues are reflected in international an agreement such as the United Nations MDGs (until 2015) to which Pakistan is a signatory. However, progress has been slow and Pakistan lags behind, particularly in achieving its MDG 4 and 5 commitments, which focus on reducing child and maternal mortality and ensuring universal access to family planning and other reproductive health services (Centre for Poverty Reduction and Social Policy Development and Pakistan Planning Commission, 2010).

There is an urgent need for concrete action to reduce maternal mortality - Pakistan is one of the ten countries of the world with the highest number of maternal deaths (Hogan et al., 2010). Although family planning is an essential component of improving maternal and child health, it has been overlooked as a priority in the health sector (Sathar, 2013). Family planning helps reduce the number of unintended pregnancies and increases the prevalence of birth spacing. Maternal mortality in Pakistan is unacceptably high at 276 maternal deaths per 100,000 live births (Pakistan Demographic and Health Survey [PDHS], 2006/07). Moreover, among all female deaths in the reproductive age bracket in Pakistan, maternal complications are a leading cause of mortality (PDHS 2006/07). Family planning also helps reduce induced abortions and their complications - estimated at almost 700,000 annually - by reducing the number of unwanted pregnancies (Population Council, 2013).

Family planning plays a vital role in empowering women to contribute more to economic activities and enables them to invest better in their children's education (Habumuremyi and Zenawi, 2012). Women are able to decide their family size and to seek better reproductive health services for themselves and their children, which ultimately enhances their contribution to family wellbeing and overall national development. Additionally, "universal access to reproductive healthcare and modern methods of family planning is not only a powerful way to dramatically improve maternal and child health, but is also an essential component of sustainable development and poverty alleviation" (USAID, 2013). At the community level, family planning helps to reduce the cost of health services, since there will be fewer mothers seeking care for pregnancy complications, unsafe abortions, and delivery. Family planning can also play a significant role in curtailing high levels of population growth, thus improving the quality of life and accumulation of human capital, and reducing poverty and hunger (Bloom et al., 2006). 
The advantages of investing in family planning garnered global attention in the 1980s when many poor countries began to experience its development benefits. Perhaps the best-known example of the impact of family planning on fertility declines is the Matlab experiment in Bangladesh. In 1978, about half the villages in the Matlab district were categorized as experimental areas and the other half as control areas. The experimental areas received extensive and comprehensive high-quality family planning services, while the control areas received the same services as the rest of the country. The experimental areas were provided free services and a range of contraceptive methods. These services included regular home visits by well-educated female family planning workers to address health concerns.

The impact of these intensive services on reproductive behaviour was very significant. Within the first few years of the Matlab programme, the proportion of women using contraceptives rose substantially from 5 percent to 28 percent. Furthermore, fertility fell to levels that were 22 percent lower in the experimental areas that received the intensive family planning services compared to the control areas (Bongaarts et al., 2012).

A comparison of the fertility transition in Pakistan and Bangladesh is testimony to the gains that can be made by investing intensively in family planning programmes. In the early 1970s, the two countries had nearly the same high level of fertility - about 7 births per women. However, trends deviated significantly in subsequent decades. Fertility in Bangladesh had declined to 3.3 births per woman by the late 1990s, while Pakistan's fertility rate still stood at 5 births per woman. During the 1990s and after 2000, the pace of the fertility transition in Bangladesh continued to decline rapidly and reached about replacement-level fertility in $2011-2.3$ births per woman (NIPORT, Mitra, and ICF, 2012).

This distinct difference in fertility trends needs a comprehensive explanation: what factors account for the divergent fertility trends in Pakistan and Bangladesh even though both countries have similar social, economic, cultural, and religious characteristics? Bongaarts et al. (2012) evaluate the history of fertility transition in both countries and conclude that the difference lies in their respective family planning programmes. While "Pakistan's programme has been very weak and ineffective, lacking government funds and commitment. ... Bangladesh has implemented one of the world's most effective voluntary family planning programmes, using the experience and lessons from the Matlab experiment. A unique feature of the programme is its staff of literate female workers who advise women and distribute supplies at their doorsteps, thus overcoming the barriers posed by purdah" (Bongaarts, 2012). As a result of these groundbreaking efforts, the levels of unwanted fertility and unmet need are considerably lower in Bangladesh than in Pakistan. Fertility is, of course, a vital component of population change in developing countries. Any family planning-induced fertility decline will significantly change the future population growth trajectory. Thus, any delay in fertility transition will have important repercussions for future population growth.

Although Pakistan's family planning programme started in 1965, it failed at the outset to provide adequate and easily available services and counselling on family planning. Thus, Pakistan's decision to discourage family planning in the 1970 s and 1980 s led to much more rapid population growth than in Bangladesh. In 1980, the population of Pakistan was 8 million 
less than that of Bangladesh; by 2010, its population was 20 million more. Population projections show that, by 2050 , the population of Pakistan will be 51 percent larger than that of Bangladesh (222 million vs. 335 million) (UN, 2009).

Iran is another example of the benefits of a successful family planning programme. Until the 1980s, it had experienced a high level of fertility - more than 6 births per woman - and family planning had never been a government priority. However, in 1989, the Iranian government realized the negative consequences of the country's rapid population growth and abruptly reversed the population policy, strongly supporting family planning programmes (Roudi-Fahimi, 2002; Bongaarts et al., 2012). A vigorous information, education, and communication (IEC) campaign was initiated to introduce the benefits of small families and an extensive network was established through village health workers to provide free contraceptive services and deliveries. The impact of this rigorous family planning programme was immense. In about 12 years, a remarkable fertility decline was observed from more than 5 births in the late 1980s to 2 births per woman by 2000 . This family planning programme has, arguably, had a substantial impact on the fertility decline and other development outcomes in Iran (Abbasi-Shavazi and McDonald, 2006).

\subsubsection{Reaffirming the Health Benefits of Family Planning for MDGs 4 and 5}

\section{Maternal Mortality}

The MDGs related to reproductive health require a 75 percent reduction in the maternal mortality ratio (MMR) by 2015. Family planning would contribute to achieving this target in two ways. First, it would virtually eliminate the estimated 36 percent of maternal deaths caused by unintended pregnancies and help combat the estimated 13 percent of maternal deaths caused by unsafe abortions (Bongaarts et al., 2012). Second, family planning would reduce the proportion of risky pregnancies by preventing teenage and older-age (above 35 years) births and high-parities births. Recurring pregnancies affect the health of the mother due to which underweight babies are born; these babies are more likely to face the risk of neonatal and postneonatal death. In the event of a child's death, people tend to bear more children to meet their desired family size (Smith et al., 2009).

Declines in maternal mortality are generally attributed to successful "safe motherhood" initiatives. In 1987 in Nairobi, a group of international agencies launched the global "Safe Motherhood initiatives" movement, the aim of which was to reduce the burden of maternal morbidity and mortality in developing countries (Starrs, 2006). A major component of such initiatives is to enhance good-quality maternal health services that include skilled birth attendants for both routine and complicated pregnancies, and the improved availability and quality of comprehensive emergency obstetric care for life-threatening complications.

Overall, such initiatives have contributed significantly to the recent decline in maternal mortality. However, the literature has not closely examined the contribution of fertility declines to maternal mortality and this has yet to be demonstrated mathematically. Providing such evidence of this 
relationship would serve as an important reminder of the role that fertility reduction (and, consequently, family planning programmes that contribute significantly to fertility reduction) play in reducing the Maternal mortality ratio and reducing the total numbers of maternal deaths. Jain (2011) systematically explores the relationship between fertility and the MMR in three South Asian countries - Bangladesh, India, and Pakistan. The results show that fertility declines between 1990 and 2008 contributed significantly to the reduction in the MMR. About 22 percent of the MMR decline in Pakistan in this period can be attributed to fertility reduction and 78 percent to safe motherhood programmes. Therefore, despite the significant progress in safe motherhood initiatives, continued fertility reductions in the future will contribute substantially to achieving MDG 5.

Family planning has been a major contributor to reducing the number of maternal deaths worldwide: globally, maternal deaths declined by 47 percent between 1990 and 2010. South Asia (excluding India) has made the greatest progress in preventing maternal deaths: the MMR declined by 59 percent from 1990 to 2010 (WHO, 2012). In comparison, Pakistan has made only moderate progress in preventing maternal deaths in the last two decades; even so, about a 47 percent decline was observed between 1990 and 2010. The MMR declined from 490 in 1990 to 260 in 2008 (WHO, 2012), and estimates suggest that maternal deaths in Pakistan dropped by 2.3 percent annually from 1990 to 2010 (WHO, 2012). However, the country will need to reduce its MMR by 11 percent annually from 2010 to 2015 in order to achieve MDG 5, the target for which is to reduce the MMR by 75 percent between 1990 and 2015.

Fertility is an important factor in reducing maternal mortality. Several recent studies have examined the effect of the decline in fertility rate between 1990 and 2008 on maternal mortality (see Stover and Rose, 2010; Ross and Blanc, 2012; Jain, 2011). Pakistan's total fertility rate (TFR) was 5.4 in 1990/91 and about 3.9 in 2011/12 (PDHS 1990/91; Pakistan Social \& Living Standards Measurement Survey [PSLM] 2011/12). While fertility did not decline significantly before the 1990s, a fertility transition set in after this point and, consequently, maternal mortality also started to decline. The estimated net effect of the fertility decline on maternal mortality was about 22 percent between 1990 and 2008 (Jain, 2011).

The Lancet series on Family Planning (2012) has formulated a robust, persuasive, and timely case for increased investment in voluntary family planning. Leading up to the London Summit on Family planning 2012, the series provides compelling evidence that investment in family planning is a cost-effective investment that yields health, economic, and development benefits. In this series, Ahmed et al. (2012) anticipate that contraceptive use averted 44 percent of maternal deaths worldwide and 53 percent in South Asia in 2008. Furthermore, meeting the unmet need for contraception could prevent an additional 29 percent of maternal deaths per year (Ahmed et al., 2012). They estimate that, with a contraceptive prevalence rate (CPR) of 29.3 percent, 42 percent of maternal deaths were averted in Pakistan in 2008; the corresponding proportion with a CPR of 58 percent in Bangladesh was 57 percent (Ahmed et al., 2012).

It is increasingly recognized that family planning is an essential component of reproductive health and can accelerate the achievement of the MDGs related to reproductive health (Cates et 
al., 2010). Research shows that the use of contraception has a conspicuous impact on the lives and health of women. In developing countries, the use of contraception has accounted for about 40 percent of the reduction in the number of maternal deaths over two decades (Cleland et al., 2012). The increasing use of contraception has reduced the MMR by 26 percent in almost a decade by preventing high-risk pregnancies particularly at high parities in older women and by preventing unsafe abortions. Were the unmet need for contraception fulfilled, a further 30 percent reduction of maternal deaths could be achieved (Cleland et al., 2012). Family planning also improves prenatal outcomes and child survival, mainly by promoting birth spacing.

The use of family planning can also reduce the risk of abortion. Abortion is one of the most preventable causes of maternal injury and death and voluntary family planning could virtually eliminate the estimated 13 percent of maternal deaths that occur due to unsafe abortions, nearly all of them in developing countries (Bongaarts et al., 2012).

In 2000, about 90 percent of global abortion-related and 20 percent of obstetric-related mortality and morbidity could have been averted with the use of effective contraception by women wanting to postpone or cease further childbearing (Columbien et al., 2004). In many countries, general fertility rates and unwanted fertility rates are still high among women who are susceptible to mortality and morbidity risks during their reproductive years. Some women compound these risks by undergoing unsafe abortions. Recurrent unsafe abortions can be prevented through access to effective contraception (Ahmed et al., 2012).

A study in Egypt has found that, when healthcare workers were trained to broaden their treatment for complications resulting from unsafe abortion to include a discussion of contraception and provide a referral for family planning services, the proportion of patients who decided to use a contraceptive method increased from 37 percent to 62 percent (Huntington et al., 1995). Similar outcomes are reported in Mexico, Kenya, and Bangladesh (Huntington and Piet-Pelon, 1999; Vlassoff, 2012). The evidence is, therefore, convincing: women who want access to family planning and receive the counselling and services they need, avoid repeated abortions (Huntington and Piet-Pelon, 1999; HIP, 2012; WHO, 1997; Azmat et al., 2012; Tripney et al., 2010). Nearly 1 million women in Pakistan seek unsafe abortions every year - a decision determined by the high level of unwanted pregnancies. Improved access to quality services would reduce the number of abortions and maternal and child deaths (Sathar, 2013).

Most of the evidence on the relationship between child health and birth spacing has been drawn from demographic and health surveys (DHS). A comprehensive study encompassing the DHS from 52 countries over 2000-2005 found that infants were at higher risk of dying if the birth interval was less than 24 months, controlling for other confounding factors (Rutstein, 2008). In Pakistan's case, neonatal, infant, and child mortality almost doubles if the previous birth interval is less than two years compared with an interval of 4+ years (Rutstein, 2008). Family planning can prevent child deaths that occur as a result of pregnancy before the age of 18 and beyond 34 years. It provides the opportunity to space one's children, which also helps reduce maternal depletion and other pregnancy-related complications. An interval of 3-5 years between two children also lowers the risk of preeclampsia, haemorrhaging, and other complications to mothers (Population Action International, 2010). 
Having children too close together is dangerous for both mother and child. In 2005, the World Health Organization (WHO) convened an expert review of the evidence on pregnancy spacing, which recommended that a mother should wait at least 2 years after having had a baby before trying to become pregnant again (WHO, 2007). To reduce the risk for herself, her existing children, and her unborn baby, the mother should allow at least 33 months (almost 3 years) between each birth (Health Timing and Spacing of Pregnancy: USAID). If mothers were able to delay conceiving again for 24 months after giving birth, the under-five mortality rate would fall by 13 percent, i.e., averting nearly 900,000 deaths. If they delayed conceiving until 36 months after giving birth, 25 percent of under-five deaths ( 1.8 million children a year) could be averted merely through healthier spacing (Rutstein, 2008).

\subsubsection{Socioeconomic Benefits of Family Planning}

Apart from some of the overall development benefits and the direct positive impact on MDGs 4 and 5, family planning has spinoffs for many other social sectors such as education, employment, and poverty reduction.

\section{Education}

The evidence shows that children with fewer siblings tend to receive longer schooling than those with many siblings (Maralani, 2008; Falbo et al., 2008; Steelman et al., 2002; Shavit et al., 1991). A smaller family allows parents to spare a greater share of resources for their children and give them the opportunity of better-quality education. As a result of its successful family planning programme, Indonesia had achieved its target of almost universal primary education by the mid-1980s (Randall, 2012). This, in turn, also led to better accumulation of human capital, which played an effective role in the country's subsequent economic development. Female education also has a statistically significant delaying effect on marriage. The effect remains robust in the presence of a number of controls. The lower risk of early marriage among educated women may be due to the waiting time allocated to schooling, finding a match, or finding a white-collar job.

\subsubsection{Women's Empowerment and Labour Force Participation}

Family planning provides the opportunity to enhance female labour force participation by giving women more space to take part in the labour force; each birth prevents them from working for a certain time. Bloom et al. (2009) note that, "each birth can reduce a woman's involvement in the labour force by as much as two years. In Indonesia, a reduction of one birth on average over a period of 20 years increased the likelihood of female labour force participation by 20 percent." Additionally, a review of the impact of education on autonomy and reproductive behaviour reveals that education enhances women's knowledge of the outside world and increases their awareness of the importance of family health and hygiene and of the treatment and prevention of illness (Jejeebhoy, 1995; McCarthy, 1997).

A number of studies also show that family planning is a determinant of poverty reduction. Aassveet al. (2005) state that, "overall our analysis shows that both improved labour market 
and educational opportunities and improvements in family planning. The use of family planning enhances per capita share of income of household members and help reduce poverty in a country at macro level, strengthening the economy leading to political stability." Joshi (2012) has provided evidence from Bangladesh which suggests that declines in fertility and child mortality contributed to poverty alleviation. Women who space their children are more likely to seek employment and, as a result, can increase their household income, helping to reduce extreme poverty (Population Action International, 2010). Women with fewer children have more time to earn wages outside the home, which boosts family income and quality of life and reduces poverty. Such families are thus able to save more and begin to break the grip of poverty, while communities are able to make greater investments in education, healthcare, and infrastructure (Bongaarts et al., 2012). Kerala, India, is a good example of a case where policymakers identified excessive family size as a root cause of poverty and recognized the need to deal with it as an integral part of the general development strategy (Randall, 2012).

Improved reproductive health and family planning services give women more working time and help increase household income and savings. These savings, once invested, further enhance the family's income and prosperity. In Sri Lanka, "a 70 percent drop in maternal mortality risk between 1946 and 1953 created a 15 percent increase in life expectancy for school-age girls, which led to increasing the female literacy by 2.5 percent and female years of education by 4 percent" (Jayachandran and Llera-Muney, 2008).

\subsubsection{Poverty Reduction}

Rapid population growth is generally seen as eroding into economic gains, especially at the macro-level (Kelly, 1988). Internationally, the decline in fertility - a natural consequence of the demographic transition - is known to increase national savings and economic growth by reducing the overall number of people, especially those at younger ages, competing for resources (Schultz, 2005; Lewis, 1980, Hammer, 1986). Such savings from fertility declines have been known to be substantial in many developing countries, particularly in East Asia (Mason, 2008).

In their seminal study, Bloom et al. (1999) have illustrated that, overall, the rate of population growth had little effect on economic growth in Asia during 1965-90, but changes in life expectancy, age structure, and population density did have a significant impact on growth rates. Furthermore, a large body of literature suggests that demographic effects can explain most of the East Asian economic miracle and that population changes are relevant to poverty at the macro-and micro-levels (Bloom et al., 1999; Hobcraft, 2003). At the micro-level, household size is seen as the main driving factor of poverty while population age structures influence the dependency ratio and, consequently, the poverty trajectories of households (Jayaramman and Findeis, 2005; Sewanyana, 2009). Dependency ratios are linked to poverty dynamics because of their distinct economic consequences: "The young require intensive investment in health and education, prime-age adults supply labour and saving, and the aged require healthcare and retirement income" (Bloom, Canning, and Sevilla 2003). We examine which factors interplay with each other to adversely affect children in poorer households. As Eastwood and Lipton 
(1999) confirm, fertility affects the consumption of non-dependents through their savings and income.

While evidence on the link between fertility and poverty or economic growth is somewhat ambivalent, the association between high fertility and poverty at the household level appears to be more strongly established. Arif and Qureshi (2001) for Pakistan, Degraff et al. (1997) for the Philippines, and Lipton and Eastwood (1999) for 45 developing and transitional economies find that large households are generally associated with increased poverty. They argue that higher fertility increases the incidence and intensity of poverty by retarding economic growth and skewing the distribution of income consumption against the poor. An earlier study by the World Bank also examines the consequences of high fertility for poverty in Pakistan. However, it was carried out prior to the fertility transition and when the lack of rich economic and demographic data did not allow the level of analysis possible now (Cochrane et al., 1990).

Several studies have documented households' consumption behaviour by fertility. Eastwood and Lipton (1999) use survey data on transitional economies and find that fertility affects private consumption as well as the incidence and intensity of poverty. They argue that, in large households, there is less care per child, less access to healthcare, a greater risk of undernutrition, and more gender discrimination in food distribution. All these costs of high fertility to education, health, and gender equality goals often affect only those households that are already at risk of poverty. Other studies (Hemmi, 2003; Nana-Fabu, 2001; Okojie, 1989; Desai, 1992) have also found that high fertility negatively affects consumption, education, and health.

A strong impact of fertility decline is that of more favourable age structures among members of richer households. This is a combined effect of the greater fertility decline among the non-poor and the assumption that richer households will include more educated persons, thereby having better means and access to achieve lower fertility. Studies elsewhere find a direct relationship between fertility and family outcomes (Schultz, 2005). Grouping Pakistan Socioeconomic Survey (PSES) panel households into the chronically poor, transitory poor, and always non-poor, Arif and Bilquees (2006) in their study establish that increased household size increases the risk of falling into poverty or remaining chronically poor. In addition, the latter's monthly per capita expenditures are very low and they are unable to maintain their expenditure per capita as household size increases. 


\subsection{Conclusion}

With the passage of the 18th Amendment and associated emerging priorities, there is an opportunity to make a difference in Pakistan. Provincial policymakers must be persuaded of this on the basis of province-level data that makes a case for allocating resources and priorities to family planning with a renewed emphasis, given its role in improving maternal and child health, reducing poverty, and fostering economic growth.

The objective of this review is to empirically demonstrate the link between increased uptake of family planning for birth spacing and improved maternal and child health, and other development outcomes. This will reflect the potential benefits of investing in family planning programmes and fertility decline for each province. Women's health has not received the highest priority in Pakistan, and major changes in the age structure of the population have meant that there are a growing number of young women with unmet healthcare needs requiring special focus.

Family planning is a unique and cost-effective tool among development initiatives, with potential benefits that range from economic development, maternal and child health, and educational advances, to coping strategies for poverty, women's empowerment, and environmental protection. Some of these benefits are self-evident. For example, the contribution of family planning to lowering maternal mortality - mainly by preventing unintended pregnancies - and reducing infant and child mortality - largely through longer birth intervals - is well documented. Furthermore, achieving the other MDGs, such as those related to education, is more likely when the pressure of an increasing school-age population is reduced.

There is little debate on the need to reduce high maternal and child mortality risks across all four provinces. One of the most effective, albeit underrated, interventions to reduce maternal mortality and morbidity is the use of contraception to avoid high parity and closely spaced births. The unmet need for family planning is about 25 percent in Pakistan, but with large variations by province and sub-population. At the same time, nearly a million women in Pakistan seek illegal and unsafe abortions every year - a decision that represents a considerable risk to their health and social status (Population Council, 2004). Many cases of poor maternal health can be attributed to the large proportion of unwanted pregnancies that lead to unsafe abortions or unsafe deliveries, mainly due to poor access to quality family planning services (Singh et al., 2010; Singh et al., 2009). Effective reproductive health interventions are needed to ensure, first, that every pregnancy is wanted, through universal access to family planning, and second, that every birth is safe, attended by a skilled birth attendant. 


\section{Methodology}

The aim of this report is to address the opportunities and gaps in the Pakistan government's response to the issues highlighted in Chapter 1, and to increase levels of funding for family planning and adolescent health and services as a priority. We argue that prioritizing investment in family planning will present an opportunity to save several thousands of lives in each province.

Provincial data are utilized to establish that increasing family planning and reducing fertility is one of the most powerful means of improving maternal and child health and moving towards MDGs 4 and 5 . The second argument in favour of investments in family planning concerns the importance of adolescent and youth behaviour vis-à-vis marriage, age at first birth, and subsequent birth spacing, which would help slow down the population momentum and improve indicators among young women and families.

This report presents our main findings and a comparative picture of the provinces. The evidence has been collated into accompanying products (mainly policy briefs) and PowerPoint presentations for each province. This chapter describes the main analytical components of the briefs and estimates presented.

Data are drawn from a series of nationally and provincially representative datasets, including the PDHS for 1990/91, 2006/07, and 2012/13, and the PSLM for 2008/09 and 2011/12; the district-level graphs are based on the PSLM for 2008/09 and 2010/11 as well as Multiple Indicator Cluster Surveys where available. Together, these datasets present sufficient information to demonstrate the associations between family planning, fertility and maternal and child mortality, and poverty to help provincial and district decision-makers formulate policies that reflect basic realities.

We have tried to present a comparative perspective across time and province to identify trends in vital rates and associations, e.g., unmet need and gaps between demand and supply and by age group using the PDHS for 2006/07 and 2012/13.

\subsection{Generating Provincial Population Projections}

In the absence of a census, generating population counts is a challenging task in Pakistan. The census provides not only the basis of resource distribution but also plays a vital role in effective policy formulation. The household census - the basis of population headcounts - is overdue, the last census having been conducted in 1998. Although household counts were initiated in 2011, they were postponed due to several factors ranging from resource constraints to political interference. Thus, in the absence of the census, current estimates for population by age and sex at the provincial level were not available.

To overcome this constraint, we have carried out cohort component population projections for each province, spanning the period 1998 to 2013 in single years on the basis of age and sex

distribution from the 1998 census. TFR estimates have been extracted from existing sample 
surveys for the period 1998 to 2013, such as the PRHFPS 2000/01, SWRHFPS 2003, and PDHS 2006/07 and 2012/13. Spline smoothing techniques were used to smooth the TFR to yield a credible time series at the national as well as provincial level.

We have developed provincial population projections that should prove useful for policymakers and practitioners in the health, population welfare, education, and planning sectors, with the aim of persuading them of the role of rapid fertility decline in changing population sizes and age structures. Population projections are a strong tool that should be applied to all sectors when planning for the future needs of the population. However, the core of the argument is that additional investments in family planning programmes will yield huge savings and benefits to the provincial governments. Our projections are used to demonstrate the impact of different fertility decline scenarios.

The traditional cohort component population projection technique used to generate provincelevel estimates and projections uses the components of demographic change (births, deaths, and migration) to project the population by age and sex. The technique is applied to each province separately in its particular demographic context.

Future population trends are very sensitive to trends in fertility. This finding needs to be assessed further to specify the actual impact of the speed of fertility decline on population growth and its subsequent effect on various aspects of social and economic development. Bongaarts et al. (2013) comprehensively review the population projections for Pakistan produced by different institutions and discuss the demographic drivers of the country's phenomenal population growth. To construct population projections at the provincial level, we present three hypothetical projections for each province up to 2050. At the national level, we assume that the TFR is declining steadily and will reach two children per woman by 2050 (Bongaarts et al., 2013). We further assume that a similar pace of fertility decline applies to each province with different baseline indicators of fertility. Table 1 gives TFR levels and trends at the national and provincial level from 2005-10 to 2045-50.

Table 1: Total fertility rate for the four provinces: $2010-2050$

\begin{tabular}{lrrr}
\hline Region & $2005-2010$ & $2025-2030$ & $2045-2050$ \\
\hline Punjab & 3.73 & 2.56 & 1.89 \\
Sindh & 3.97 & 2.72 & 2.01 \\
KPK & 4.25 & 2.91 & 2.15 \\
Balochistan & 4.61 & 3.16 & 2.33 \\
Pakistan & 3.93 & 2.69 & 2.00 \\
\hline
\end{tabular}

Source: Population Council estimates and projections 
The three fertility scenarios are:

Medium fertility, which assumes that the TFR declines at a steady pace and reaches around two births per woman by 2050.

Low fertility, which assumes that the TFR is half a birth lower than under the medium fertility assumption throughout.

High fertility, which assumes that the TFR is half a birth higher than under the medium fertility assumption throughout.

Life tables are a prerequisite for developing population projections. We have constructed life tables for each province based on the UN's model life table for Pakistan (utilizing age and sexspecific mortality rates) and using the infant and under-5 mortality rates as inputs into the projections. Estimates for these rates have been extracted from various sample surveys for the period 1998-2013. The UN's (2012) estimate of net international migration for Pakistan has also been used and distributed proportionally among the provinces. An additional component of internal migration is required, however, given that the population projections are applied at the sub-national level. We have used several rounds of the Labour Force Survey for this purpose, calculating estimates of the number of in- and out-migrants for each province and converting these into proportions for the respective provinces.

\subsection{Estimating Provincial MMRs}

Estimating maternal mortality is a complex and costly task, particularly in developing countries. However, it is a key measure of the country's overall health system and helps gauge the extent of its success in saving maternal lives. Several developing countries have established comprehensive vital registration systems to assess maternal mortality, but in most cases maternal deaths are underreported or misclassified as non-maternal. In countries where vital registration systems are lacking or weak, household surveys are used to estimate maternal mortality. However, such surveys can be problematic because maternal deaths are relatively rare events and require a large sample for precise results.

Our main objective here is to estimate the national and provincial MMRs for Pakistan over the last decade. Several studies show that changes in maternal mortality can be attributed to two major factors: (i) a decline in fertility and (ii) successful safe motherhood initiatives. The probability of maternal death is reduced when skilled birth attendants handle deliveries at a health facility and when fertility falls.

Due to the unavailability of estimates of maternal mortality for the 1990s, it is difficult to assess the extent of progress towards achieving MDG 5 in Pakistan as well as many other countries where reliable data on maternal deaths is not available. In response, WHO, the United Nations Children's Fund (UNICEF), and the United Nations Population Fund (UNFPA) have developed statistical tools for estimating maternal mortality and produced internationally comparable MMR estimates at the national, regional, and global level for 1990-2010 (WHO, 2000). 
A dual strategy is used that involves adjusting the available data for underreporting and misclassification. For all countries, a statistical model is applied to estimate the proportion of deaths of women of reproductive age that are due to maternal causes (PMDF). The number of maternal deaths is then obtained by multiplying this proportion by the WHO estimate of the number of deaths of women of reproductive age. The PMDF is taken as a dependent variable in a logit function since it is a proportion with many other independent variables and regional dummies. The complete statistical model is estimated with coefficients as follows:

$\operatorname{logit}(P M D F)=-6.15+1.24 * \ln ($ GFR $)-0.014 * \operatorname{logit}(S A)-0.26 *$ GDP $+0.53 *$ LASSAME $0.62 *$ VRComplete

where GFR is the general fertility rate; logit (SA) is the percentage of births assisted by a skilled attendant; GDP/PPP is the gross domestic product per capita based on purchasing power parity conversion; LASSAME is a dummy variable representing countries of Latin America, sub-Saharan Africa, and the Middle East to North Africa (from Pakistan to Morocco); and VRComplete is a dummy variable for countries identified by WHO as having complete death registration.

We adopt this indirect method for estimating the provincial and national MMRs. Data on skilled birth attendance were obtained from the PDHS 2006/07 and 2012/13 and from the PIHS 2000/01. GFR estimates are calculated by applying the population projection exercise for 1998 to 2013 presented earlier. Keeping all other model variables constant, we then estimate the MMR for each province for 2013.

The rationale for deriving these estimates is to draw attention to the existence and likely dimensions of the problem of maternal mortality in Pakistan at the provincial level. They indicate the order of magnitude and are not intended to serve as precise estimates. In addition, these estimates should stimulate greater awareness of the challenge of measuring maternal mortality. The margins of uncertainty associated with the estimated MMRs are very large and the estimates should, therefore, be used cautiously. In addition, inter-provincial comparisons should be treated with considerable circumspection because the model is not intended to produce results at a sub-national level and ignores variations at the sub-national level. 


\subsection{Estimating the Impact of Family Planning on Maternal and Infant and Child Mortality}

\subsubsection{Maternal Deaths}

We estimate the impact of family planning on maternal mortality in two steps. In the first step, we use the established relationship (see equation 2) between contraceptive use and the GFR from Li Liu et al. (2008). Using this relationship, we run simulations based on the given CPR scenarios and obtain estimates for the GFR. In the second step, using equation 1 as described earlier and the estimated GFR, we obtain estimates for the MMR for each province.

$$
G F R=222.28-3.05 *(C P R)+0.012\left(C P R^{2}\right)
$$

Where GFR is the general fertility rate and CPR is the contraceptive prevalence rate.

\subsubsection{Infant and Child Deaths}

High-Risk Fertility Behaviour

There is a strong relationship between a child's risk of dying and certain fertility behaviours. The risk of infant and child death is much higher if children are born to mothers who are too young (under 18 years) or too old (over 35 years) or if they are born after a short birth interval (less than 24 months) or to mothers with high parity (3+ children).

Approximately 58 percent of the births in Pakistan are characterized as high-risk due to high fertility behaviour (PDHS 2012/13). Improving access to and use of modern family planning methods would enable women to limit early or late childbearing and closely spaced births, and thereby reduce the probability of infant and child mortality. The experience of developing countries suggests that, as contraceptive use increases, the percentage of risky births declines. Such births carry an elevated mortality rate and an increase in contraceptive use could, therefore, yield savings in infant and child deaths.

We use the established relationship between contraceptive use, high-risk fertility behaviour, and infant and child mortality to run simulations based on the FAMPLAN model for different contraceptive-use scenarios and captures the effect on infant and under-5 mortality. The methodology is relatively simple when using linear relationships. These links are established by using 141 DHS datasets for developing countries. The procedure involves (i) establishing the relationship between high-risk fertility behaviour and contraceptive use (equation 3), and (ii) based on this relationship, calculating the infant and under-5 mortality rates.

$$
\begin{aligned}
& H R F B_{t}=H R F B_{b}-0.55\left(C P R_{t}-C P R_{b}\right) \\
& I M R_{t}=I M R_{b}-2.31 *\left(H R F B_{b}-H R F B_{t}\right) \\
& U 5 M R_{t}=U 5 M R_{b}-3.54 *\left(H R F B_{b}-H R F B_{t}\right)
\end{aligned}
$$


Where HRFB is high-risk fertility behaviour, CPR is the contraceptive prevalence rate, IMR is the infant mortality rate, and U5MR is the under-5 mortality rate.

In order to assess the impact of contraceptive use on infant and child mortality, we run two different contraceptive scenarios for each province:

- $\quad$ Scenario 1: increase the CPR by 10 percent

- Scenario 2: eliminate the unmet need for family planning

The uncertainty associated with the estimated infant and child mortality rate is relatively large because it is not only the outcome of high-risk fertility behaviour, but also of immunization coverage, good nutrition, and maternal socio-demographic characteristics. The aim of this exercise is to calculate the potential impact of family planning programmes, which, from the perspective of provincial policymakers, could have a far-reaching impact on infant and child health in Pakistan. 


\section{Changing Demographic Structures}

At present, Pakistan faces significant demographic changes at both the national and provincial levels. This chapter focuses on the realities the provinces must confront in terms of population size, age structures, fertility decline, options for future change, the opportunity presented by the demographic dividend, and the large adolescent population whose reproductive patterns are critical in shaping future population growth momentum.

A rapidly growing population automatically compromises the country's basic healthcare system and its ability to provide education and economic opportunities to all. Pakistan's current population of 184 million has already put huge stress on its stability, governance, the already overburdened infrastructure, and scarce resources. Population estimates for each of the provinces indicate that all four provincial governments face the same responsibility (post-18th Amendment) for providing services to their respective populations within constrained resources. Investment in the social sectors and particularly the health sector budgets now fall squarely in the domain of the provinces and need to be urgently reviewed.

At the same time, the provinces currently have an opportunity to benefit from the particular stage of the demographic transition they have entered, which could result in improved maternal and child health as well as economic development. Changes in the age structure across all the provinces present a window of opportunity to benefit from the demographic dividend. The high concentration of the youth population and large portion of the working-age population could result in improved economic performance and a higher standard of living.

The demographic dividend refers to the outcome of these changes in age structure. During this phase, the share of the working-age population is higher and the dependency ratio is lower, i.e., there are more working adults than the number of dependent children. Taking advantage of the opportunity depends, however, on many important decisions that should be made immediately to determine whether these changes in age structure will yield a dividend or a disaster. Pakistan needs to address the problems of its extremely young age structure and high fertility by investing in development, education, health, and family planning strategies. Decisions about fertility and family planning policy made today could reduce a further population increase in the future, given that the next few decades will be crucial as the majority of the population reaches working age.

In particular, expected future growth will be driven by three main demographic factors, which are discussed below.

\subsection{Rapid Population Growth}

Population changes are driven by three major components: fertility, mortality, and migration. The most important of these is the TFR or the average number of children a woman will have over her reproductive life. The population in each of the four provinces will continue to grow over the next few decades largely due to continuing high levels of fertility and the population momentum built into the population. 
For decades, Pakistan's demographic trajectory has been marked by rapid population growth, largely because of declining mortality and longer life-spans. Decades after the mortality decline in Pakistan, fertility has begun to decline and continues to be the most important of the three major drivers of population change.

Pakistan's rapid population growth is likely to continue in the future, with the population having increased more than fivefold in the last 60 years. However, the pace of growth rose faster during the 1980 s and 1990 s as mortality rates declined and fertility remained high. The total population doubled from 65 million in 1972 to 132 million in 1998, and is estimated at 184 million in 2013 (see Figure 3.1).

Figure 3.1: Estimated and projected population of Pakistan, 1951-2050

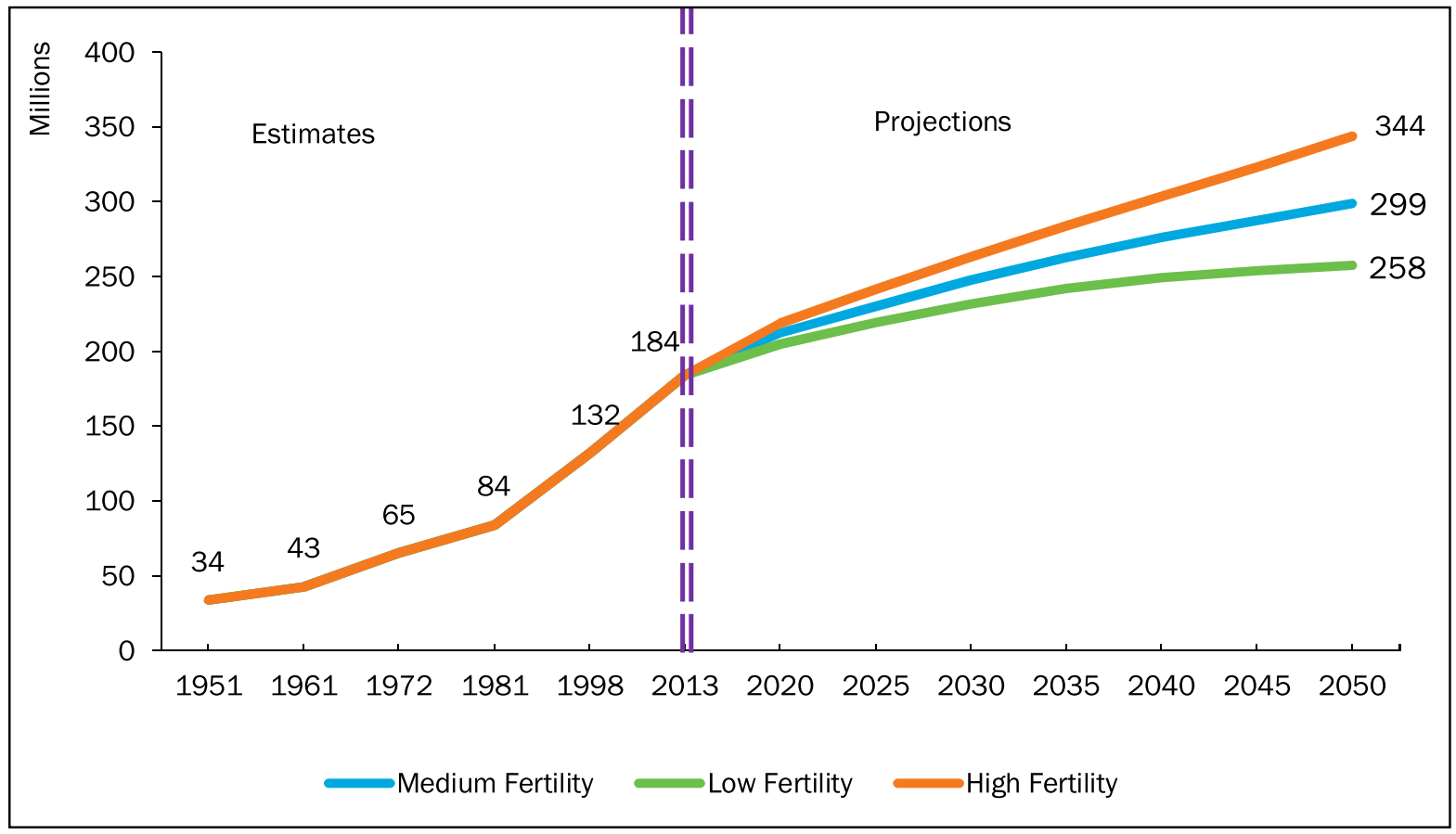

Source: Population Census 1951, 1961, 1972, and 1998; estimates and projections developed by the Population Council.

Figure 3.1 illustrates population projections for Pakistan based on three hypothetical fertility scenarios: medium, low, and high. Even though we assume that fertility will decline steadily over the next four decades and Pakistan will achieve replacement-level fertility by 2050 , the population could grow at a moderately rapid pace to reach 300 million by 2050 . According to the uncertainty range based on the low- and high-fertility variants, the total population could be as low as 258 million and as high as 344 million by that time. Most of this variation will be accounted for by present decisions about fertility and investment in family planning, which will have a significant impact on population growth over the next few decades.

In the absence of a census after 1998, we have relied on the best possible projections for each province. This study generates provincial projections that can be used by each province to 
analyse its options in the context of current age structures and needs based on the child, youth, working-age, and aged populations.

The population of Punjab has increased fivefold in the last 60 years, having doubled from 37 million in 1972 to 74 million in 1998 and now reached 100 million. Figure 3.2 gives population projections for the four provinces based on the three hypothetical fertility scenarios (medium, low, and high). Under the medium variant, the population of Punjab will grow from 100 million in 2014 to 163 million by 2050. Within the range between the low and high variants, the province's population falls between 140 million and 188 million, depending on how fast a fertility decline takes place. It is encouraging to note that Punjab's population growth rate has declined significantly since the 1960 s from 3.9 percent to 2.0 percent in 2013 . This change has been driven largely by the decline in growth in the more developed and wealthier districts in northern Punjab. At the same time, high population growth continues unabated in less developed districts (mostly in southern Punjab).

Figure 3.2: Estimated and projected population at the provincial level, 1951-2050
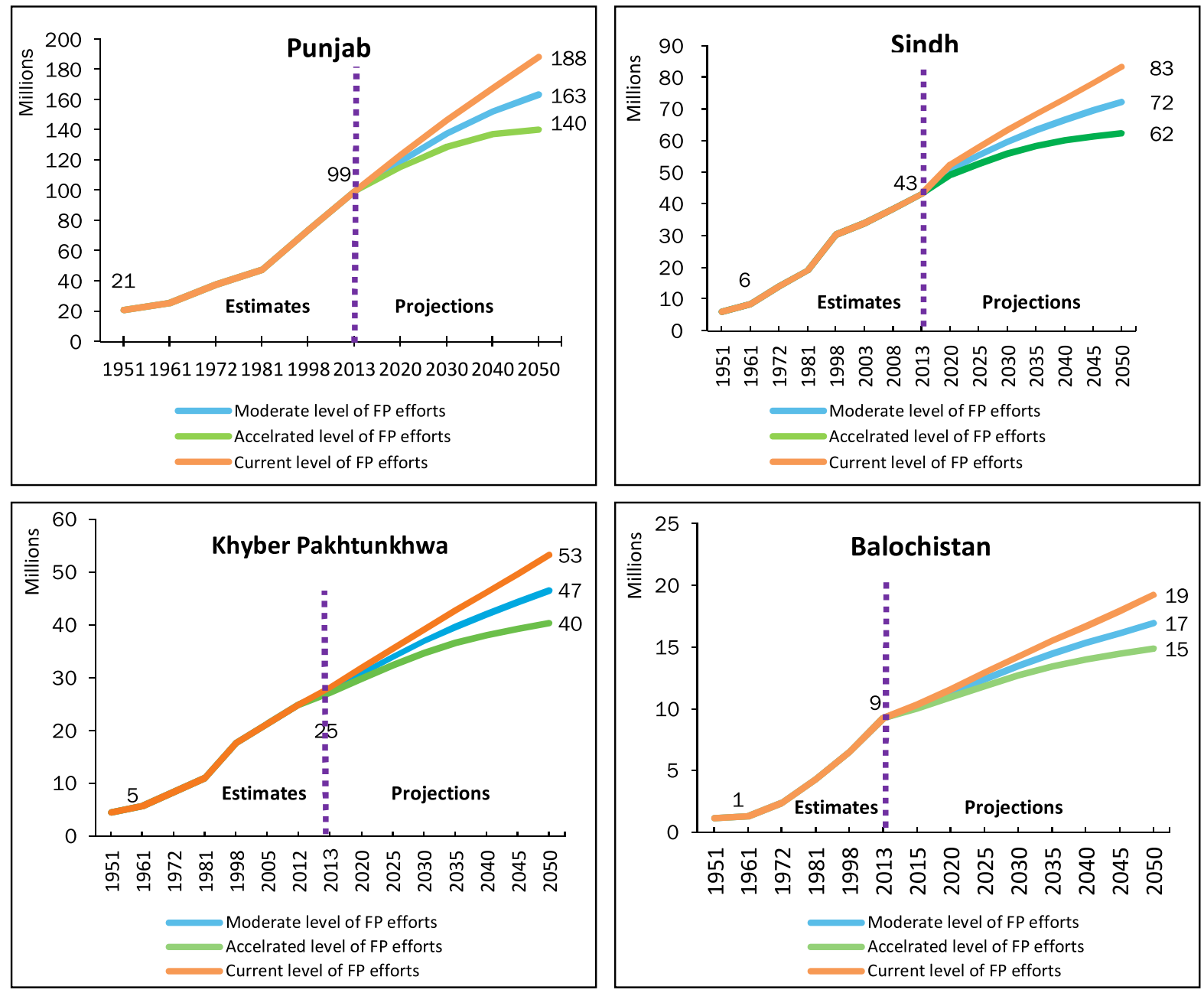

Source: Population Census 1951, 1961, 1972, and 1998; Population Council estimates and projections. 
The population of Sindh has increased sevenfold in the 60 years since independence. The population trebled from 6 million in 1951 to 19 million in 1981 and was estimated at 43 million in 2013. The population growth rate has declined since the 1960 s from 4.8 to 2.6 percent in 2013. Figure 3.2 gives population projections for Sindh based on future scenarios. If fertility declines at a moderate pace in the future, the total population will grow from 43 million to 72 million by 2050. If it continues to decline at its currently very slow pace, the population will grow to 83 million. If, however, the province invests in an accelerated family planning programme, the population will grow to only 62 million by 2050 .

KP's population has also increased significantly in the last 60 years and this trend will likely continue. The total population doubled from 5 million in 1951 to 11 million in 1981 and was estimated at 25 million in 2013. An accelerated family planning programme would bring KP's population up to 40 million, while the current pace of fertility decline would take it up to 53 million by 2050 .

Balochistan has experienced some decline in population growth over the last six decades, and this trend will likely continue. Its population has increased nine fold in 60 years: from 1 million in 1951 to 4 million by 1981 and to almost 9 million at present. Population growth rates have declined since the 1970 s from 5.3 to 2.8 percent in 2013. Given the anticipated fertility decline in the future, the province's total population will rise from 9 million in 2010 to 17 million by 2050.

\subsection{Fertility Transition}

After independence in 1947, Pakistan was among the developing countries that pioneered family planning programmes and warned against the consequences of rapid population growth. Despite this, the country experienced one of the highest fertility levels during the 1960 s to 1980s, which contributed significantly to its rapid population growth. Most other South Asian countries have experienced a drastic reduction in fertility over the last three decades, including Bangladesh, Iran, and India. Pakistan's demographic transition began relatively late, but once the fertility decline set in, it was termed one of the fastest in Asia (Feeney and Alam 2003). Unfortunately, this spurt did not continue and has stagnated in the first decades of the 21st century.

Figure 3.3 illustrates TFR levels and trends for Pakistan from 1990 to 2012. Between the early 1970s and mid-1980s, the TFR fluctuated between 6 to 7 children on average (data not shown). The 1990s saw a significant decline in fertility from 5.4 in 1990/91 to 4.8 in 2001. However, recent estimates from the PDHS 2006/07 and 2012/13 suggest that the TFR has stagnated at 3.8 children per woman.

Several studies carried out in the last two decades shed light on the determinants of the fertility decline in Pakistan; most of them observe that marital fertility has declined and thus contributed largely to the fertility transition. However, the decline has been mild and does not represent a major breakthrough. Contraception among married couples is used mainly to limit family size. The slight decline in overall fertility prior to the 1990 s is credited almost entirely to the increase in age at first marriage (United Nations, 1993). 
Fertility rates have declined across all four provinces from more than 6 births per woman in the 1970 s to over 5 in the 1990s and further to just under 4 (except Balochistan) by 2013. Clearly, a fertility transition is underway, but the pace of decline in the last five years has stagnated. While there is greater divergence in the TFR estimates (of almost one child, with 5.1 in Sindh and 5.8 in Balochistan), it is interesting to see that fertility rates show narrower variation. District-level surveys (the MICS, FALAH, and others) reveal dramatic interprovincial differences. Urban-rural differences in fertility within each province also indicate the uneven impact of the fertility transition (see Figure 3.4).

Figure 3.3: TFR levels and trends at the provincial level, 1990-2012

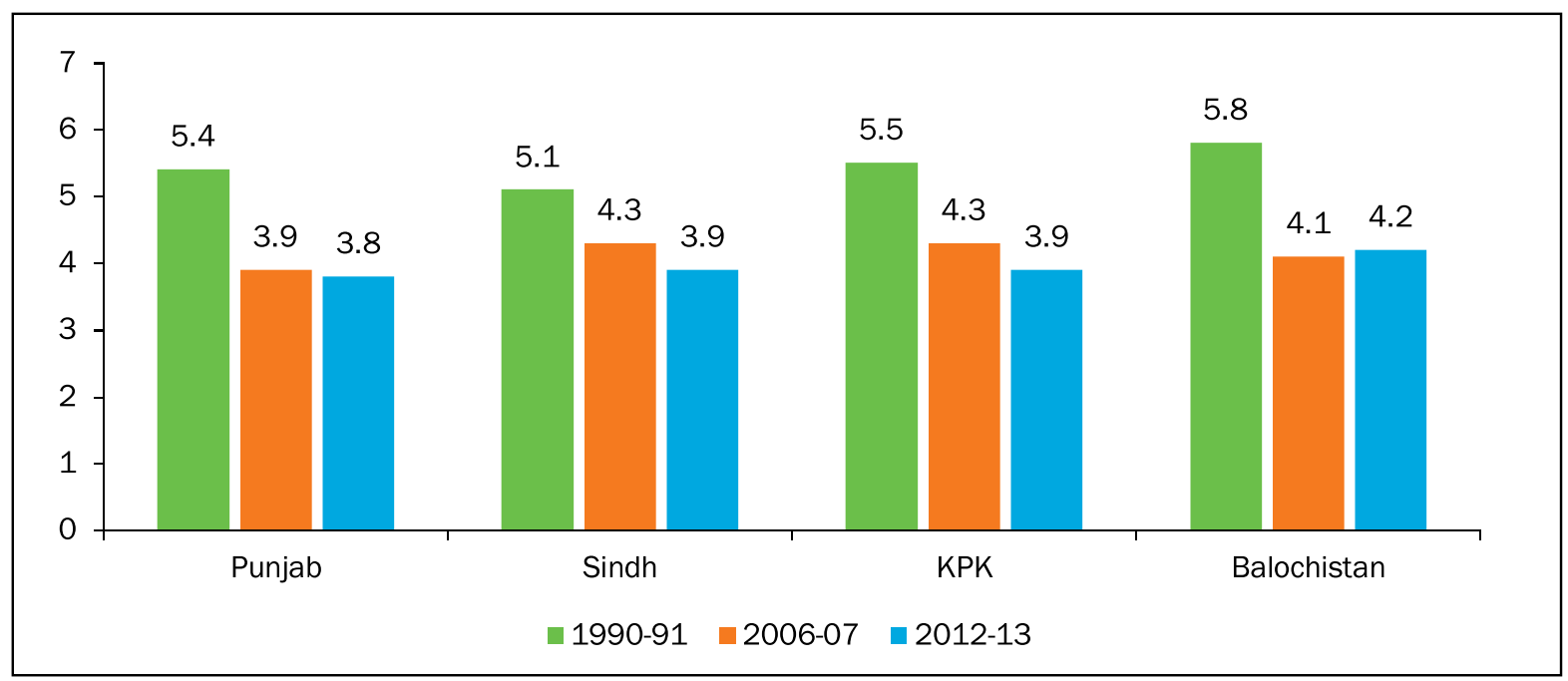

Source: PDHS 1990-91, 2006-07 \& 2012-13

Figure 3.4: TFR levels and trends by place of residence at the provincial level, 2006-12

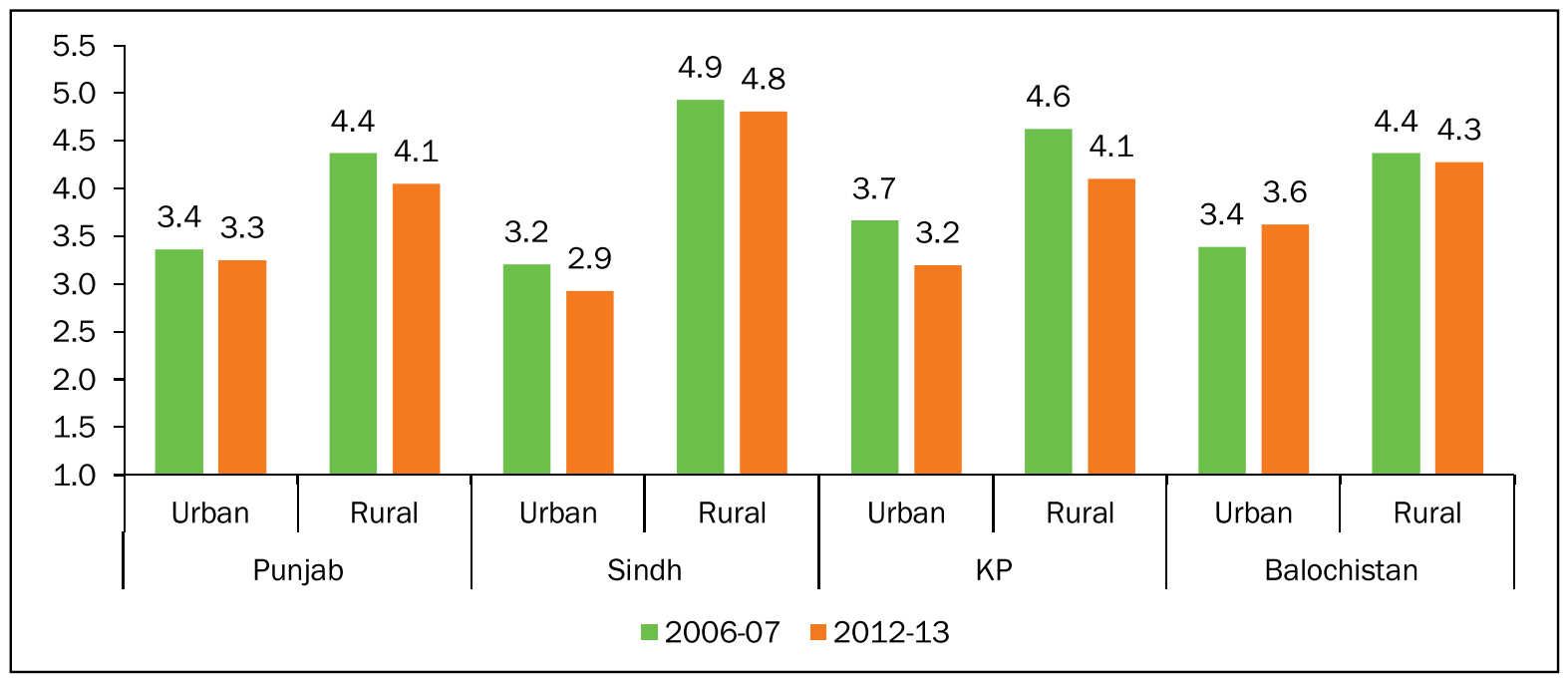

Source: PDHS 2006-07 \& 2012-13 


\subsection{Changes in Age Structure}

As the demographic transition proceeds - particularly due to declines in fertility - it leads to substantial changes in a population's age composition. Countries in the early to middle stages of the demographic transition have very young age structures and, as fertility declines, the population begins to age. Similar changes are observed in Pakistan's age structure from 1972 to 2050. In 1972, high fertility and mortality rates meant that the age structure was very young. Approximately 43 percent of the total population was under the age of 15 while 52 percent was of working age (aged 15 to 64 ). The share of the under-15 population declined to 36 percent in 2013 and will decline further to 21 percent by 2050 as a consequence of the assumed fertility decline over the next four decades. The working-age population had increased to 60 percent by 2013. We assume that, under the medium-fertility scenario, its share will increase further to 69 percent by 2050 .

We see similar changes in age structure for each of the provinces in Figure 3.5. To varying degrees, all four provinces are going through the same decrease in the number of children and increase in the working-age population - presenting the opportunity offered by the demographic dividend.

Figure 3:5: Age structure changes in Pakistan \& at the provincial level, 1972-2050
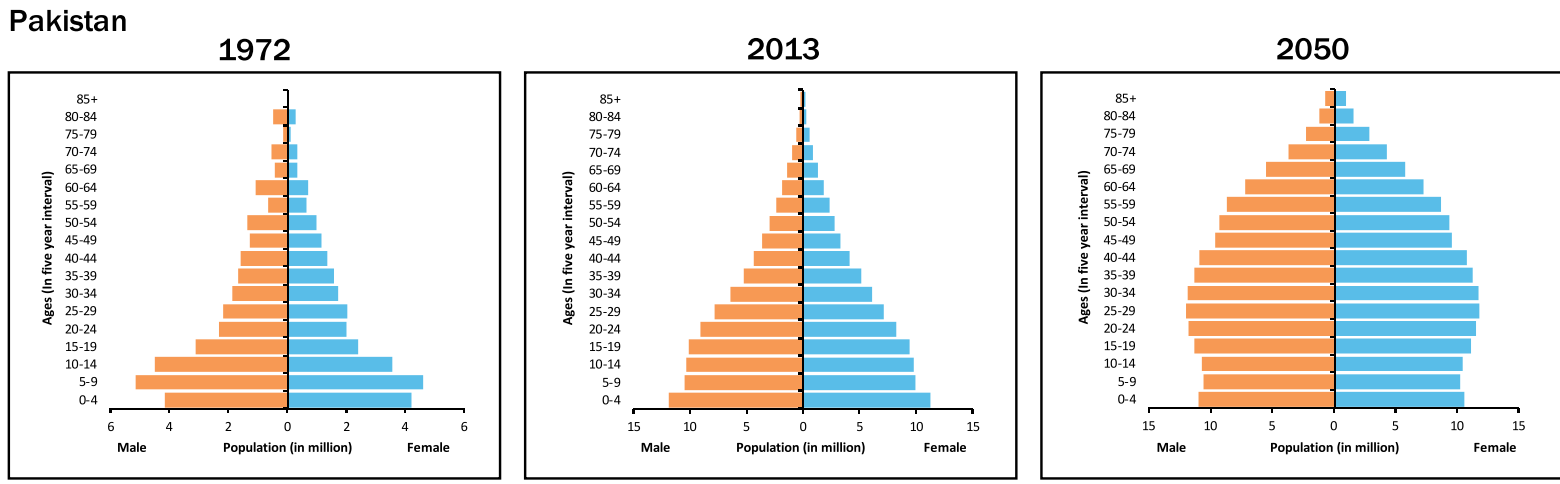

Punjab

1972

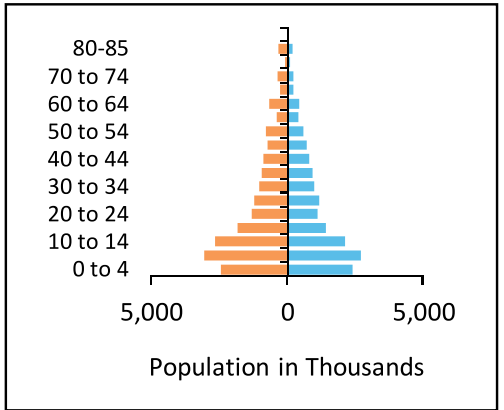

2013

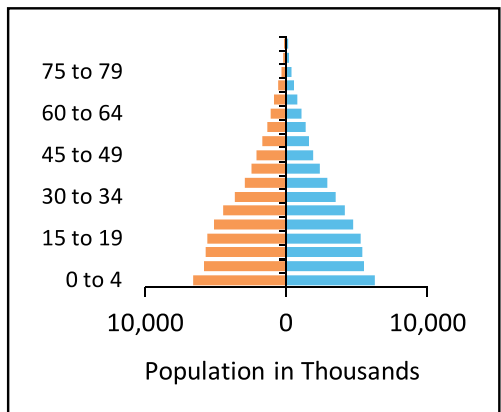

2050

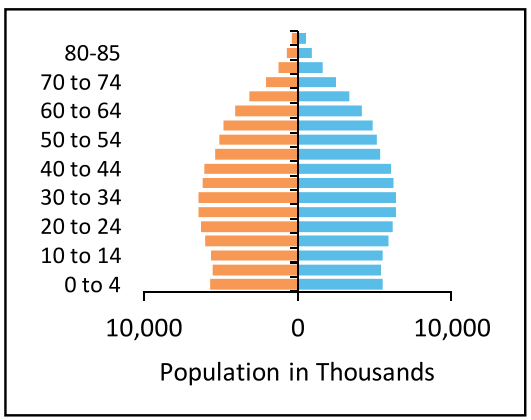


1972

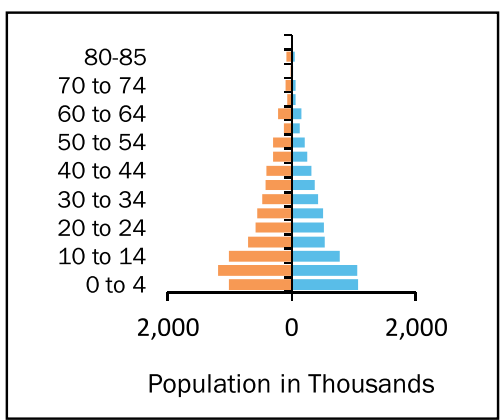

Khyber Pakhtunkhwa

1972
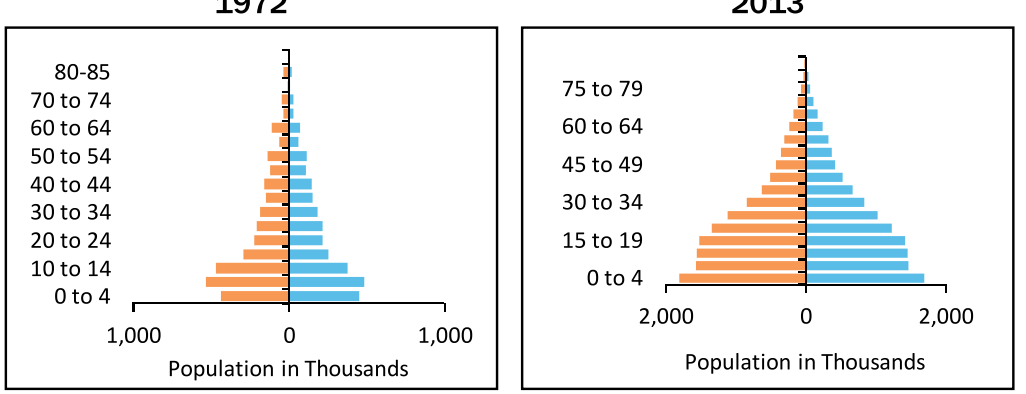

Population in Thousands
2050

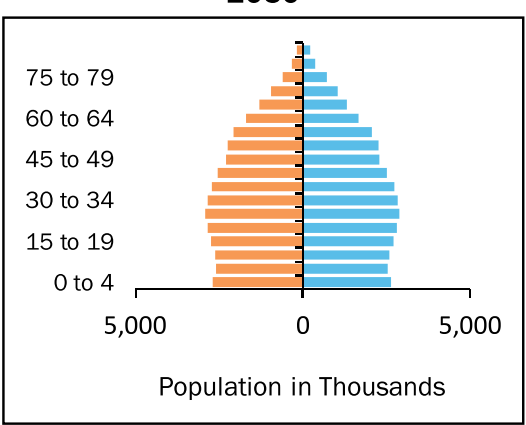

2050

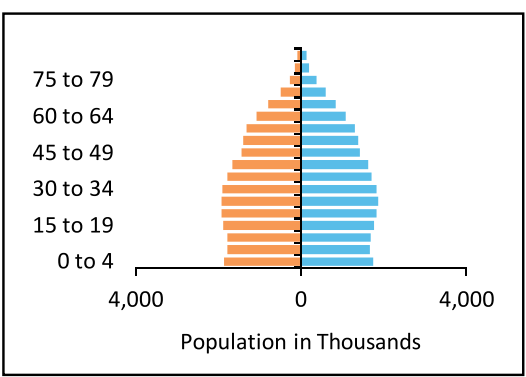

Balochistan
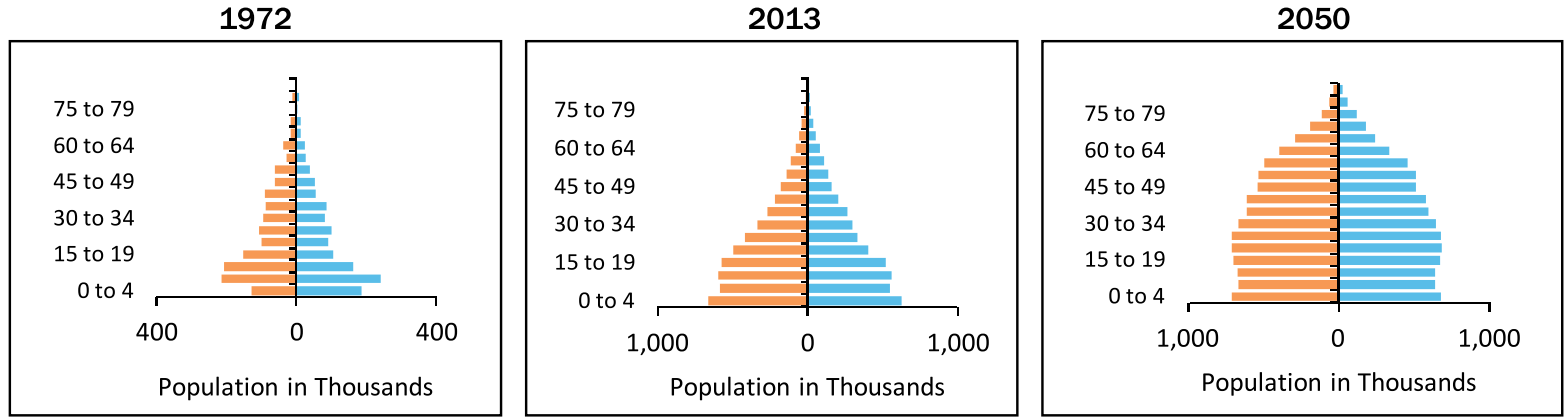

Source: Population Census 1972 and 1998; Population Council estimates and projections.

\subsection{Adolescent Reproductive Behaviour}

While the focus on youth entering the working-age demographic is important from an economic point of view, the reproductive behaviour of young women as they enter marriage is equally important from the perspective of the population momentum. Emerging demographic trends in marriage and fertility preferences and behaviour are presented below.

Marriage is a social compulsion and is considered the onset of childbearing in Pakistan. In spite of cultural diversity, marriage remains fundamental to the social identity of all women, regardless of their achievements in other spheres of life; pressure on women to marry persists. The timing of a woman's first marriage has a strong impact on her reproductive behaviour and patterns with far-reaching health consequences. Early marriage typically coincides with early 
childbearing at a young age. Early childbearing, therefore, has health consequences for young women, with the risks aggravated by poverty and inadequate access to maternal and child health services. It is widely argued that younger women are particularly excluded from such care.

The timing of first marriages is highly important in determining women's reproductive health and social status. To assess the most recent marriage patterns among teenage girls in Pakistan, we have used the latest PDHS for 2012/13 to compute women's median age at marriage and first birth by urban and rural areas for each province (Table 3.1). We find virtually the same gap of about 2.5 years between the median age at marriage and first birth across all areas. However, the data for Balochistan indicates an earlier median age at marriage, followed by KP, Sindh, and Punjab. Young women in urban areas have their first child at 25 compared to 22.5 in rural areas.

Another way of gauging marriage patterns is to look at the proportion of women who were married by a certain age. This varies substantially, with a quarter of women having married by the age of 18 in Punjab compared to 35 percent in Balochistan.

Table 3.1: Median age at marriage and percentage of women aged 25-29 married by age 18 by background characteristics

\begin{tabular}{|c|c|c|c|c|}
\hline \multirow[b]{2}{*}{ Region } & \multicolumn{2}{|c|}{ Median age at first (years) } & \multirow{2}{*}{$\begin{array}{c}\text { Married by age } 18 \\
\text { (\%) }\end{array}$} & \multirow{2}{*}{$\begin{array}{c}\text { Gave birth by age } 19 \\
(\%)\end{array}$} \\
\hline & Marriage & Birth & & \\
\hline Pakistan & 20.9 & 23.4 & 27.2 & 18.6 \\
\hline Urban & 22.9 & 25.3 & 17.8 & 17.1 \\
\hline Rural & 19.9 & 22.5 & 32.3 & 26.1 \\
\hline Punjab & 21.2 & 23.7 & 25.1 & 17.6 \\
\hline Sindh & 20.7 & 23.6 & 28.0 & 16.0 \\
\hline $\mathrm{KP}$ & 19.9 & 22.2 & 33.0 & 25.6 \\
\hline Balochistan & 19.4 & 21.7 & 35.2 & 24.9 \\
\hline
\end{tabular}

Source: PDHS 2012-13. 


\subsubsection{Adolescent Fertility in Pakistan}

Most of the fertility decline observed across Pakistan has occurred among women in the earlier (aged 15-19 years) and later (aged 35-49 years) phases of their reproductive years. The decline in adolescent fertility is a consequence of women's rising age at marriage. Consequently, the age-specific fertility rate (ASFR) for adolescent girls (aged 15-19) has dropped significantly over the last two decades. According to PDHS estimates for 1990/91 and 2012/13, the ASFR among women aged 15-19 years (ASFR ${ }_{15-19}$ ) has fallen from 84 births per 1,000 women in $1990 / 91$ to 44 births in $2012 / 13$. This translates into a 40 -percentage point decrease as compared to a 25 percent change in the rate of fertility decline among women aged 25-39. Table 3.2 shows the ASFR and total number of women aged 15-19 years. We see that adolescent fertility began to fall during the 1990s, but has declined only marginally in recent years.

Table 3.2: ASFR for adolescent girls at the national level, 1990-2012

\begin{tabular}{lcccc}
\hline & \multicolumn{4}{c}{ ASFR15-19 } \\
\cline { 2 - 5 } College & Total & Percent decline & Urban & Rural \\
\hline $1990 / 91$ & 84.0 & - & 54 & 84 \\
$2000 / 01$ & 65.0 & 23 & 41 & 79 \\
$2006 / 07$ & 51.1 & 22 & 29 & 47 \\
$2012 / 13$ & 44.0 & 14 & 27 & 53 \\
\hline
\end{tabular}

Source: PDHS 1990-91, 2006-07, and 2012-13; PRHFPS 2000-01.

A definite pattern emerges with respect to increasing reproductive choices and deliberate behaviour among adolescents. Whereas earlier, young couples appeared to have their first child as soon as possible, PDHS estimates suggest that contraceptive use has improved significantly among adolescents. We find that 10.3 percent of married adolescent girls (aged 15-19 years) reported having used any method of contraception in 2013 - a striking increase from 3 percent reported in 1991.

Contraceptive use among adolescent girls is about the same across Punjab, Sindh, and KP (a figure could not be computed for Balochistan where the sample was too small). This change in reproductive behaviour is notable (see Figure 3.6). 
Figure 3.6: Adolescent contraceptive use in Punjab, Sindh and KP, 2006-07-2012-13

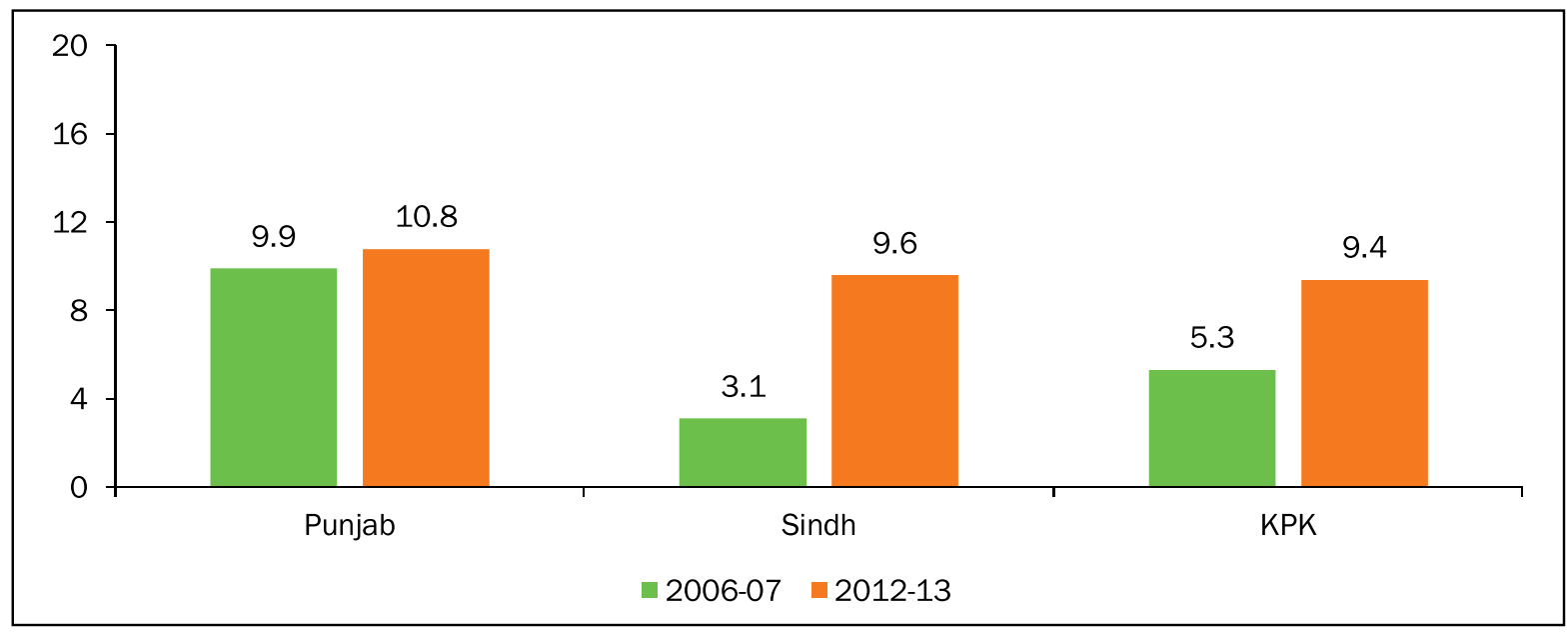

Source: PDHS 2006-07 \& 2012-13

Married adolescent girls aged 15-19 tend to use traditional contraceptive methods more commonly than modern ones. Estimates from the PDHS 2012/13 indicate that the most commonly used methods in this case are condoms (37 percent) followed by withdrawal (35 percent). Among modern methods, contraceptive pills are used the least ( 5 percent), followed by IUDs (9 percent); the use of injectables has declined from 17 percent in 1990 to 12 percent in 2012. Their preference for traditional methods implies that adolescent girls fear the side effects of modern contraceptive methods.

Despite the increasing rate of contraceptive use among adolescent girls in recent years, an unmet demand for family planning services seems to persist. Data from the PDHS 2012/13 shows that approximately 5 percent of all births across the country among women under 20 were unplanned. However, in the 1990s, only 2 percent of adolescents reported their most recent birth as being unplanned. Evidence from the DHS suggests that the unmet need for family planning has declined marginally in the last two decades. In 1990/91, 25 percent of adolescent girls reported an unmet need for family planning; this proportion declined to 20 percent in 2006/07 and 15 percent in 2012/13. It is encouraging to note, however, that the demand for contraceptives to space births is high among this younger age group. Birth spacing seems to be a greater issue among adolescents than limiting their family size, which is to be expected given that they are just starting their families.

\subsubsection{Adolescent Fertility Preferences}

Figure 3.7 illustrates adolescent fertility preferences in Pakistan. Approximately 40 percent of married adolescent girls want to delay having their next child (by at least two years) and 2 percent do not want any more children. There is, therefore, great potential for raising the rate of contraceptive use among adolescent girls. There is some difference across the provinces: 44 percent in Sindh, 38 percent in Punjab, and 40 percent in KP want to delay their next birth. The majority, not surprisingly, want another child soon. A significant proportion in Punjab, KP, and especially Balochistan, were undecided. 
Figure 3.7: Adolescent fertility preferences at the provincial level

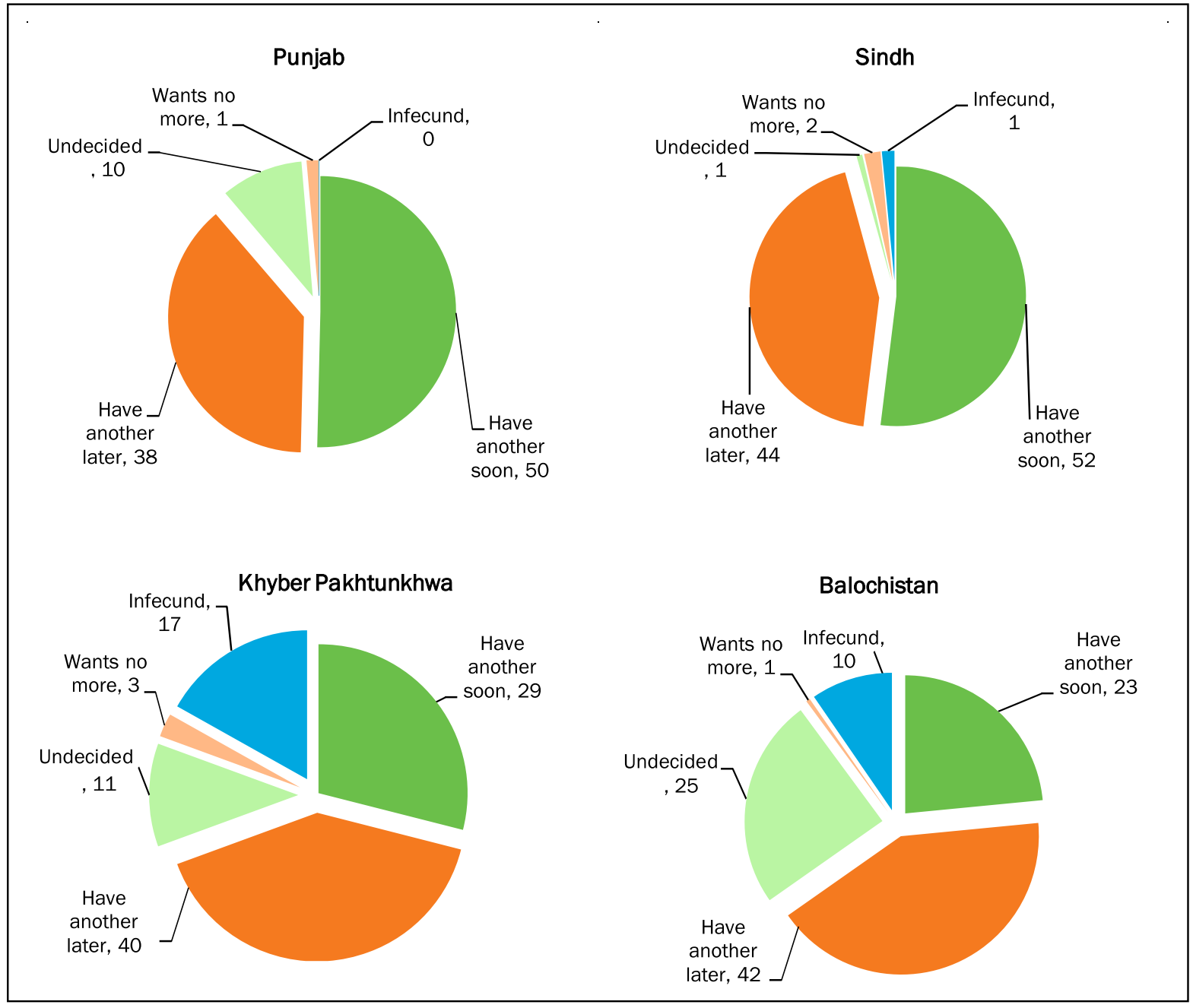

Source: PDHS 2012-13.

Given this emerging trend in fertility preferences among young married women - where they have expressed a desire to space births and even limit childbearing, and where about 10 percent are actually using contraception - it is interesting to measure their levels of unmet need. Figure 3.8 shows that a significant proportion (almost 20 percent) of young women aged 15-19 in Sindh report an unmet need for family planning; the corresponding figure for Punjab is only 10 percent. Surprisingly, young women in KP also reported levels of unmet need that exceeded the national figure. 
Figure 3.8: Met and unmet need for family planning services among adolescents at the provincial level (aged 15-19)

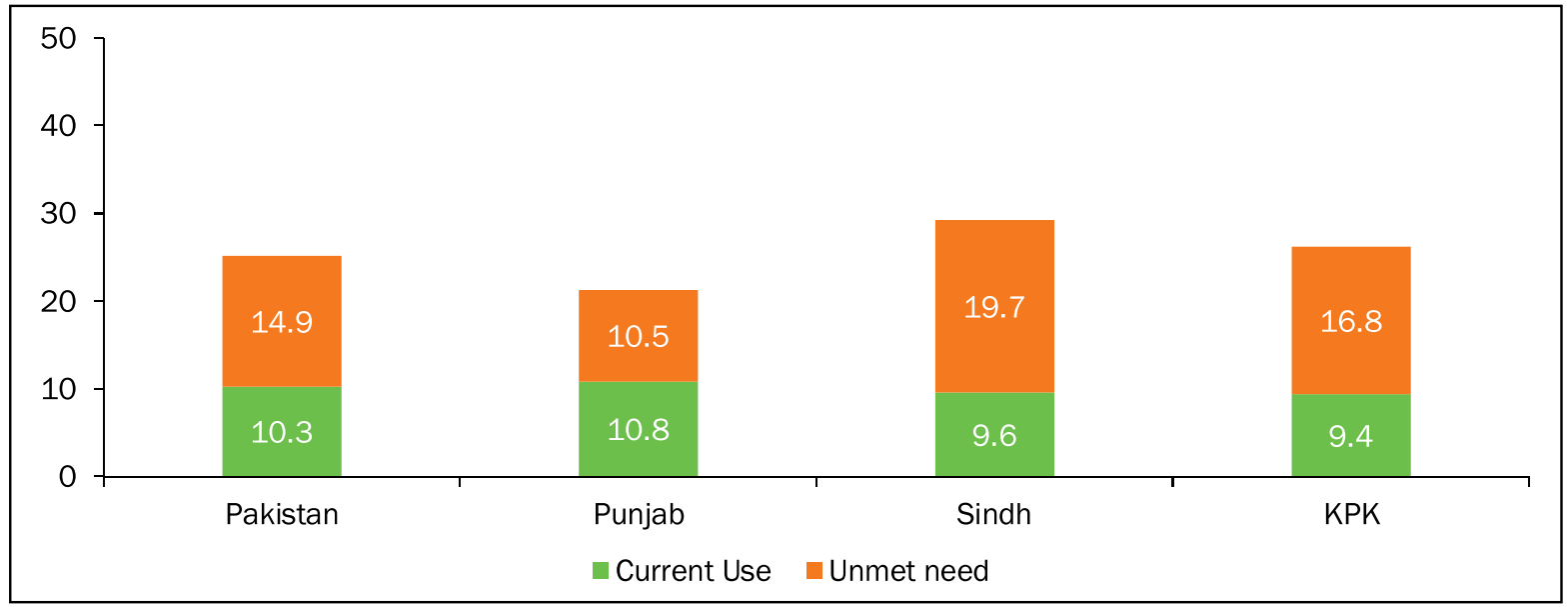

Source: PDHS 2012-13.

\subsubsection{High Neonatal Mortality among Adolescent Mothers}

Figure 3.9 illustrates the neonatal and post-neonatal mortality rate in Pakistan, where the mother's age emerges as an important factor determining both mortality rates. Data from the PDHS 2012-13 shows that neonatal mortality among younger women (under 20 years) is almost two-thirds higher than among women aged 20-29. Moreover, there are significant differentials in the post-neonatal mortality rate by mother's age. The strong correlation between maternal health and infant survival (particularly neonates) constitutes the basis of WHO's Healthy Spacing and Timing of Pregnancies initiative.

Figure 3.9: Neonatal mortality for mothers aged $<20$ at birth at the provincial level

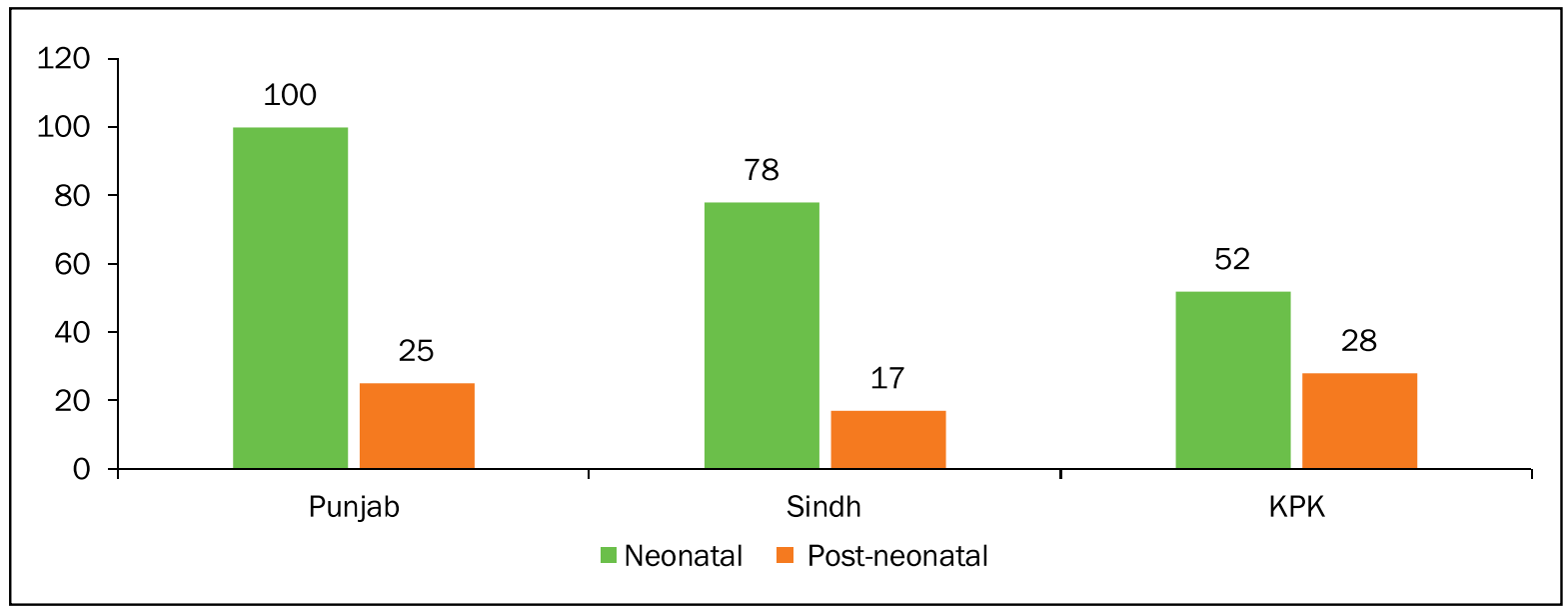

Source: PDHS 2012-13. 


\section{MDGs 4 and 5: Infant and Child and Maternal Mortality}

\subsection{Infant and Child Mortality}

Infant and child mortality indicators are often used to assess the efficiency of a country's health system and overall socioeconomic development. Accordingly, the child mortality rate (for children under the age of 5 years) and infant mortality rate were adopted as an MDG indicator (for MDG 4). MDG 4 aims to reduce infant and child mortality by two thirds by 2015 based on the 1990 level (UNDP, 2013). However, under-5 mortality in Pakistan has not declined substantially in recent years. Based on the indicators set for MDG 4 (UNDP, 2013), progress towards these targets has been slow. Despite some gains in infant and under-5 mortality, Pakistan is not on track to achieving MDG 4 (UNDP, 2013). The under-5 mortality rate (U5MR) has declined from 117 to 89 deaths per 1,000 live births from 1990 to 2012 - a rate of 1.1 percent per year against the required annual rate of 2.2 percent. The state of infant mortality is not very different: on average, 74 infants died for every 1,000 live births in 2012, compared with 91 infant deaths per 1,000 live births in the 1990s. This represents a decline in the infant mortality rate (IMR) of approximately 0.8 percent per year against the required annual rate of 2.2 percent.

Infant and child mortality rates are strongly correlated with poverty. Countries with very high poverty levels face substantially higher IMRs. Data from the latest PDHS 2012/13 confirms this finding: the IMR is almost two times as high in the lowest wealth quintile as in the highest wealth quintile (data not shown here). Thus, the IMR is clearly a function of poverty. Poor households that lack hygiene and sanitation facilities are more vulnerable to malnutrition and endemic infections, and have poor access to primary healthcare services.

Apart from poverty and the state of the health system, two other important factors that affect the likelihood of new born and infant deaths are the mother's age at first birth and the intervals between births. These are, in turn, strongly affected by family planning behaviour and women's use of contraceptive methods to control the number and timing of their births.

Figure 4.1 shows the trends in infant and child mortality across the four provinces. While the levels of infant and child mortality have declined, the pace of decline has slowed down and even been reversed in the case of Punjab and Balochistan. Perhaps the steadiest decline in both infant and child mortality has occurred in KP. In Sindh, the data indicates stagnation, while in Balochistan and Punjab, IMR and U5MR levels have risen in the last five years. 
Figure 4.1: Levels of and trends in IMR and U5MR at the provincial level, 1990-2012
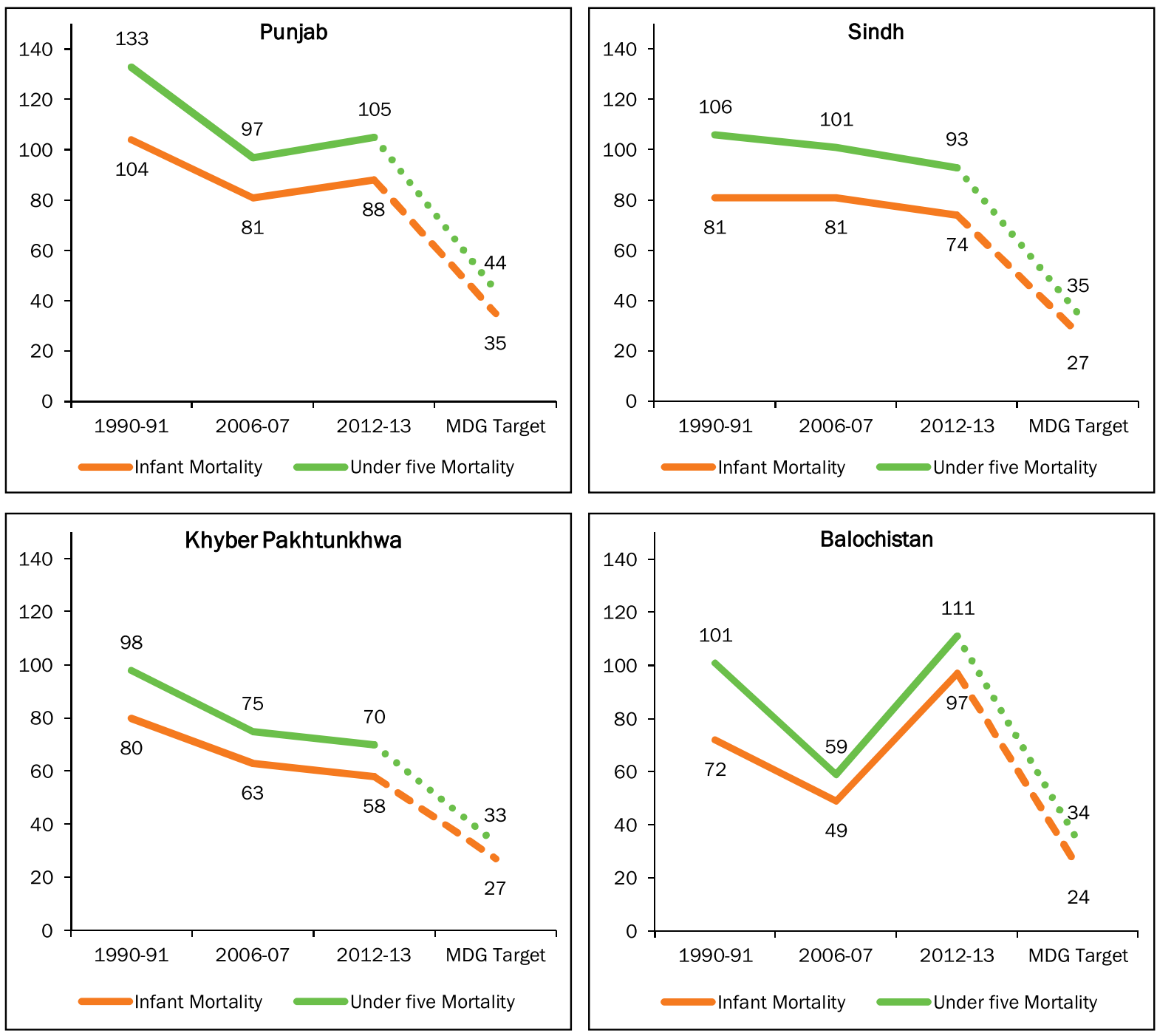

Source: PDHS.

\subsection{Alarming Neonatal Mortality Rates}

Neonatal mortality (death within the first 28 days of life) accounts for approximately 74 percent of infant deaths in Pakistan (PDHS 2012/13). Reducing neonatal mortality is, therefore, increasingly important for Pakistan to achieve a reduction in infant mortality. While infant mortality has fallen at a moderate pace, neonatal mortality has increased over the last two decades from 51 neonatal deaths per 1,000 live births in 1990 to 55 in 2012. This is chiefly the reason for the lack of reduction in overall infant and child mortality.

The issue of rising neonatal mortality needs to be addressed more effectively if progress in reducing overall infant and child mortality is to continue at a more rapid rate. Both the provincial governments and their partners must take systematic and effective action to ensure that every 
woman and baby is provided the basic and essential healthcare they need. Highly cost-effective interventions are feasible even at the community level, and most can be linked to preventive and curative initiatives for mothers and babies. For example, antenatal and early postnatal visits help promote healthy behaviour among mothers and are very effective is reducing neonatal mortality. Cases of neonatal infections can be managed alongside treatment for childhood pneumonia, diarrhoea, and malaria. Skilled birth attendance (SBA) yields significant returns on investment, saving mothers, new-borns, and unborn children.

The survival of neonates depends mostly on the socio-demographic and biological characteristics of their mothers. Neonates who face a higher risk of dying usually fall into one of four groups: (i) those born to very young mothers (under 18 years old), (ii) those born to older mothers (above 34 years), (iii) those born as closely spaced births, and (iv) those born to mothers of high parity (usually more than three children). Women who practice family planning can avoid high-risk births and reduce their chances of having a baby who will die in the neonatal or infancy period.

There is a strong correlation between contraceptive use and infant mortality. The IMR is approximately 50 percent lower in countries with a CPR of 30 percent or more compared to those where the CPR is less than 10 percent (Alan Guttmacher Institute, 2002).

Figure 4.2 compares neonatal and post-neonatal mortality rates by province. Clearly, neonatal mortality is greater than post-neonatal mortality across all the provinces. Furthermore, the lack of change or rise in neonatal mortality is very stark. In the case of post-neonatal mortality, both Sindh and KP have recorded a slight decline in the last five years. Balochistan has the highest neonatal and post-neonatal mortality rates.

Figure 4.2: Levels of and trends in neonatal and post-neonatal mortality at the provincial level, 2006-12

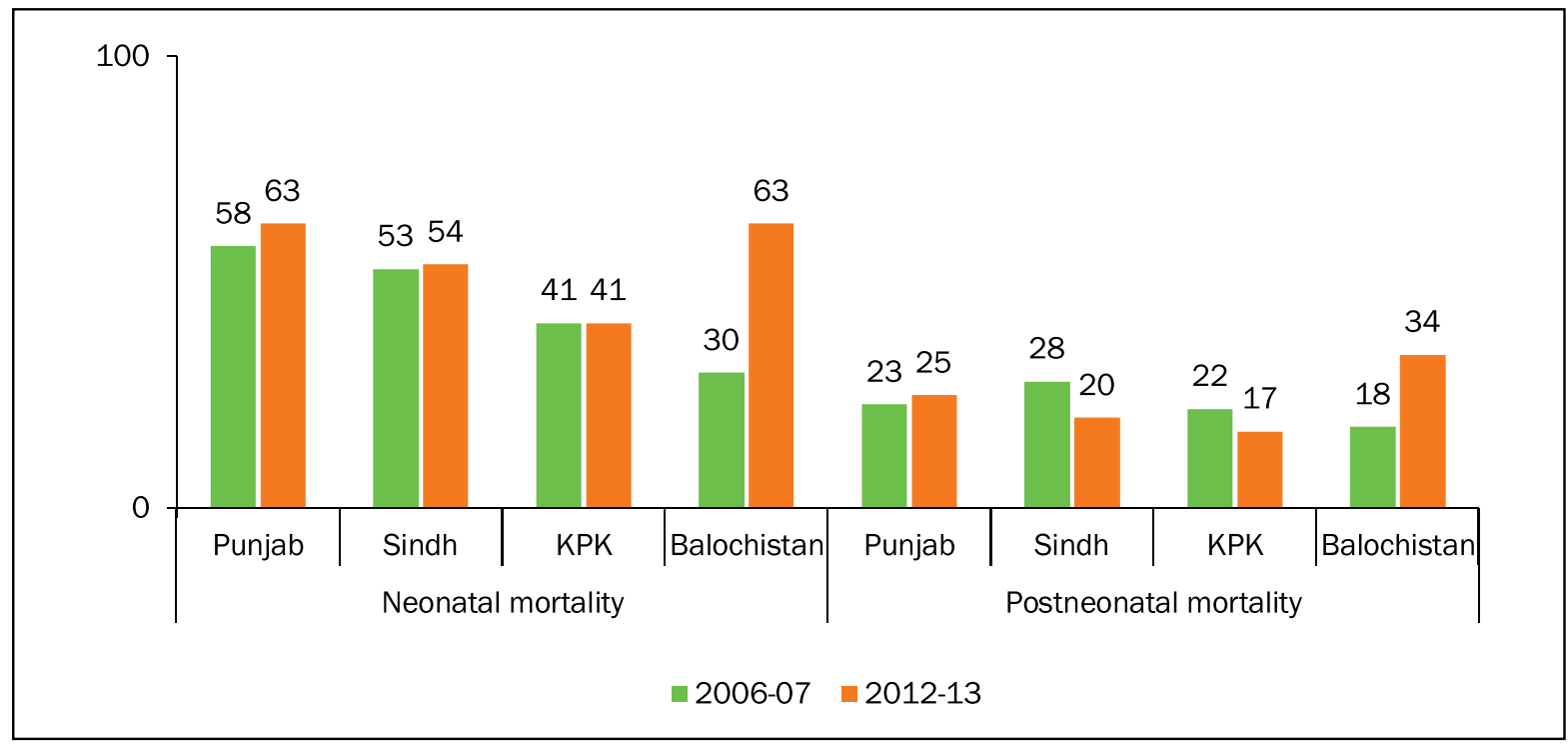

Source: PDHS 


\subsection{Maternal Mortality}

Maternal mortality is a leading cause of death among women of reproductive age in Pakistan: 20 percent of such deaths are due to pregnancy-related causes (PDHS 2006/07). Pregnancies that occur too early, too late, or too frequently can increase the risk of maternal death. Lowering fertility rates by increasing the use of family planning can, therefore, help reduce pregnancyrelated deaths.

Against this backdrop, the global community (including Pakistan) has adopted MDG 5, which aims to improve maternal health and sets the following targets for assessing progress: (i) reducing the MMR by 75 percent between 1990 and 2015, i.e., achieving a 5.5 percent annual decline in MMR in this period; and (ii) achieving universal access to reproductive health by 2015. Maternal mortality levels need to be more closely examined to inform reproductive health programme planning, to guide advocacy efforts and research at the national and international levels, and to inform decision making related to achieving MDG 5. Accordingly, country estimates must be internationally comparable if they are to be useful for the latter purpose. Estimates of maternal mortality indicate the extent of the problem and reflect the efforts made by successive governments to measure the MMR. Increased attention to developing and implementing policies and strategies targeting improved access to effective interventions likely accounts for the modest but encouraging progress made in reducing maternal mortality. Such efforts, however, need to be expanded and intensified to accelerate progress towards reducing disparities, which remain very wide.

The second round of the PDHS for 2006/07 provides consistent and reliable MMR estimates for Pakistan and the four provinces. In 2006/07, the national MMR was 276 maternal deaths per 100,000 live births - one of the highest in South Asia. Very high fertility rates, a high unmet need for family planning, and very low reproductive health indicators (antenatal care [ANC], SBA, and postnatal care) are three fundamental underlying causes of women's poor health in Pakistan.

Numerous additional factors contribute to high maternal mortality and morbidity, including lack of political commitment, poor governance (particularly in the health sector), a vastly underresourced public social sector, and a poorly functioning public sector health service delivery system, especially at the district level. Given the unavailability of MMR estimates during the 1990s, the WHO, United Nations Children's Fund (UNICEF), and United Nations Population Fund (UNFPA) developed statistical tools to produce internationally comparable estimates of maternal mortality at the national, regional, and global level from 1990 to 2010. These estimates have been revised and the earlier methodology used has been improved.

We have replicated this methodology for Pakistan and each of the provinces to produce current estimates of the MMR. Based on our findings, the average annual decline in the MMR between 1990 and 2012 was only 2.5 percent for Pakistan overall. The MMR therefore declined from an estimated level of 490 in 1990 to 220 in 2012 (see Figure 4.3). The significant decline estimated for the period 2001-06 reflects the rising use of SBA noted during the same period. 
The recent estimate of the MMR for 2012 suggests that approximately 13,000 women die every year due to pregnancy-related complications in Pakistan, i.e., 1 in every 5 women (currently married) of reproductive age die of maternal causes.

Figure 4.3: MMR levels and trends for Pakistan, 2001-12

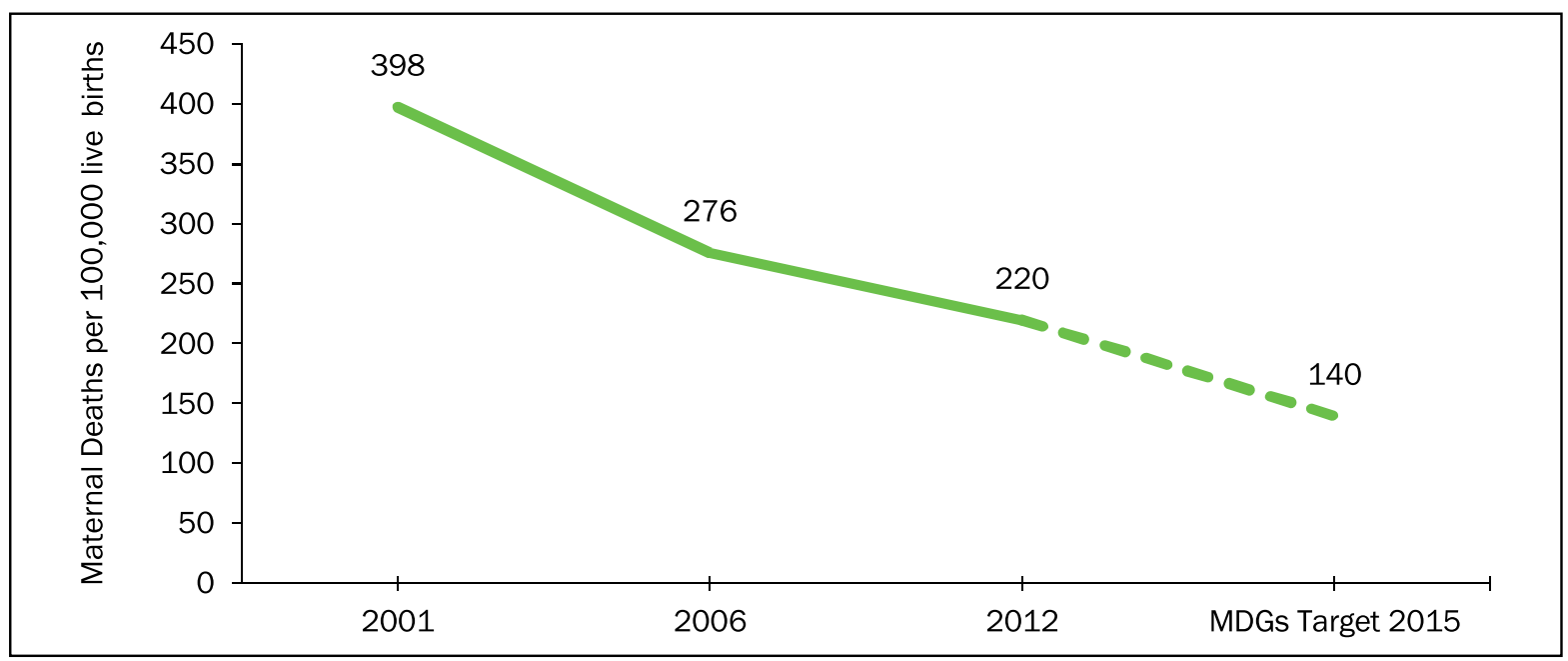

Source: PDHS 2006-07; Population Council estimates

Figure 4.4 presents MMR estimates for each of the provinces; the MMR appears to have improved steadily across all the provinces. Punjab has the lowest estimated MMR while Balochistan has a much higher MMR, recording an increase in the last five years. However, data accuracy may be an issue here.

Figure 4.4: MMR levels and trends for Pakistan and at the provincial level, 2001-12.

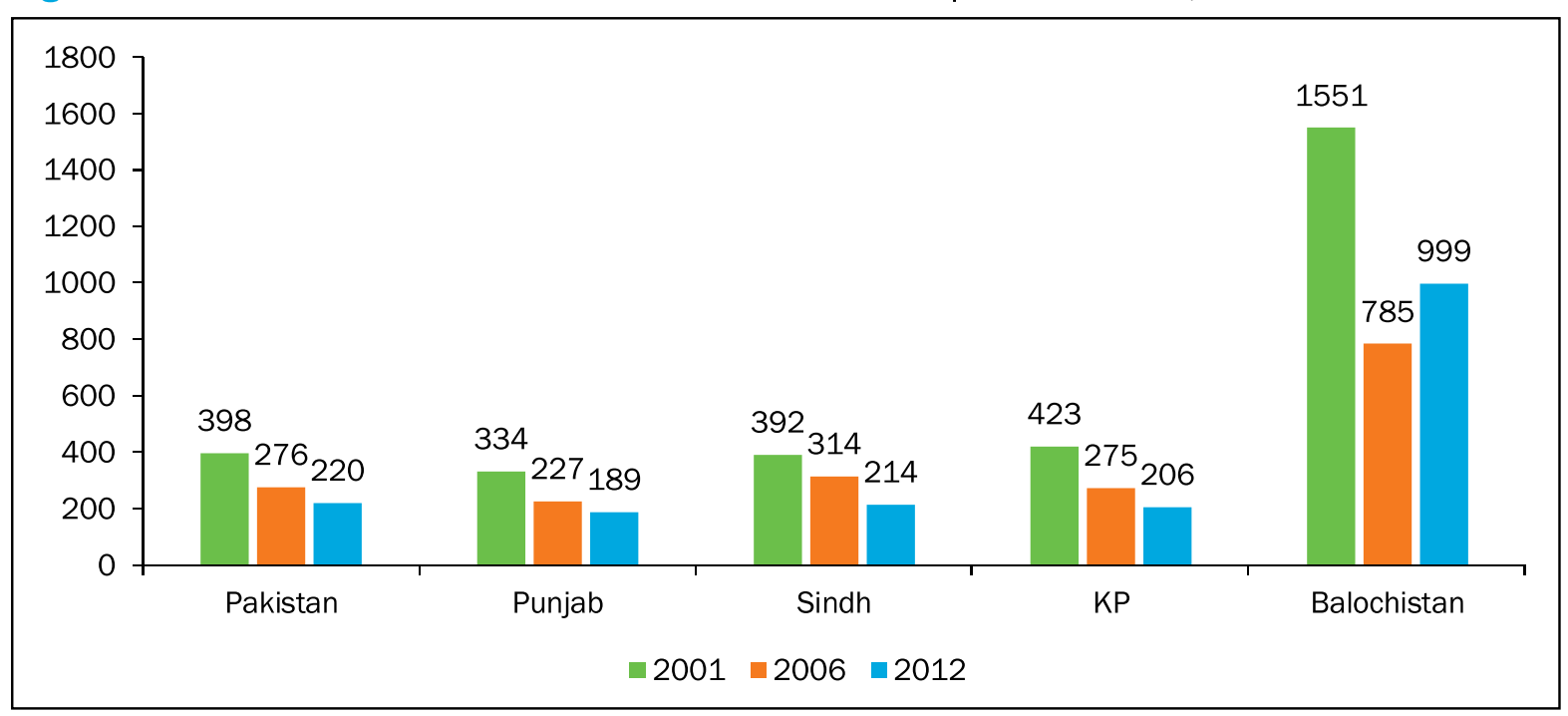

Source: PDHS 2006-07; Population Council estimates 


\subsubsection{Maternal Care Improvements}

Good nutrition and regular health check-up during pregnancy are very important for the health of the mother and her unborn baby. The WHO recommends that expectant mothers make at least four visits to a skilled healthcare provider during their pregnancy, suggesting that this promotes healthy behaviour and increases the probability of their using SBA (WHO, 2003, pp. 3). It also contributes to better maternal health through the mother's lifecycle. Inadequate care during this time breaks a critical link in the continuum of care, and affects both women and their babies. About 16 percent of maternal deaths in Pakistan are due to factors such as hypertension (pre-eclampsia and eclampsia) and antepartum haemorrhaging, which are directly related to inadequate care during pregnancy.

Against this backdrop, Pakistan initiated the National Programme for Maternal, Neonatal, and Child Health in 2006, which was then devolved to the provinces in 2010 under the 18th constitutional amendment. Under the umbrella of this programme, a new cadre of community midwives was launched and maternal and child health services strengthened in the public sector. Primary healthcare services were also extended through the LHWP, which provides essential reproductive health services through home visits in rural areas.

Figure 4.5 presents the levels and trends in ANC for each province from 2006 to 2012. The provision of ANC is, clearly, a success story in Pakistan's case. In the last 20 years, ANC (at least one visit to a healthcare provider) provided by skilled providers has improved substantially, from 26 percent in 1990 to 73 percent in 2012. This improvement was particularly rapid during the 1990s and early 2000s. However, there are dramatic differences across the provinces. While the data for Sindh and Punjab indicates that the majority of women have availed at least one antenatal visit, the corresponding proportion in Balochistan is 31 percent. KP, too, has not achieved the same level of ANC as the larger provinces.

Figure 4.5: Levels of and trends in ANC and SBA services at the provincial level , 2006-12
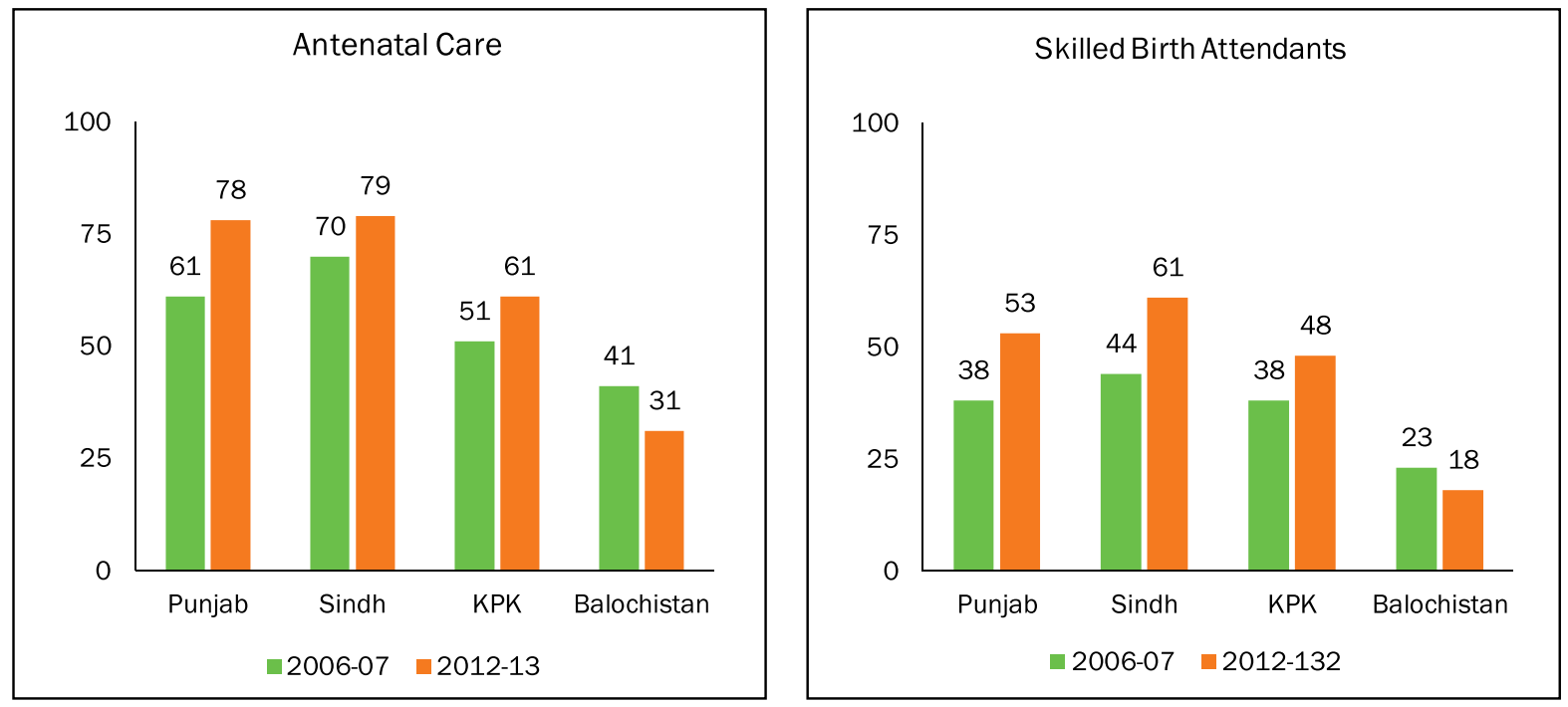

Source: PDHS. 
SBA at the time of delivery and subsequent care of the mother reduces the likelihood of maternal mortality and morbidity as complications that require urgent medical attention can be treated and/or referred to a healthcare centre. Thus, the proportion of babies delivered under the supervision of skilled health professionals ${ }^{2}$ is imperative to reduce maternal mortality and morbidity as well as serious illnesses in new-borns.

The PDHS 1990/91 reveals that only 19 percent of pregnant women were assisted by skilled health professionals during delivery. While the proportion of deliveries assisted by skilled providers increased to 52 percent in 2012, it should be noted that almost half of all women still deliver their babies with the help of an unskilled attendant, probably at home (see Figure 4.6). Also striking are provincial differences with Sindh recording a high 61 percent in SBA, followed by 53 percent in Punjab, and a mere 18 percent in Balochistan. KP recorded an impressive rise to 48 percent in SBA (Figure 4.5).

Figure 4.6: Percentage of deliveries at home by province, 2006-12

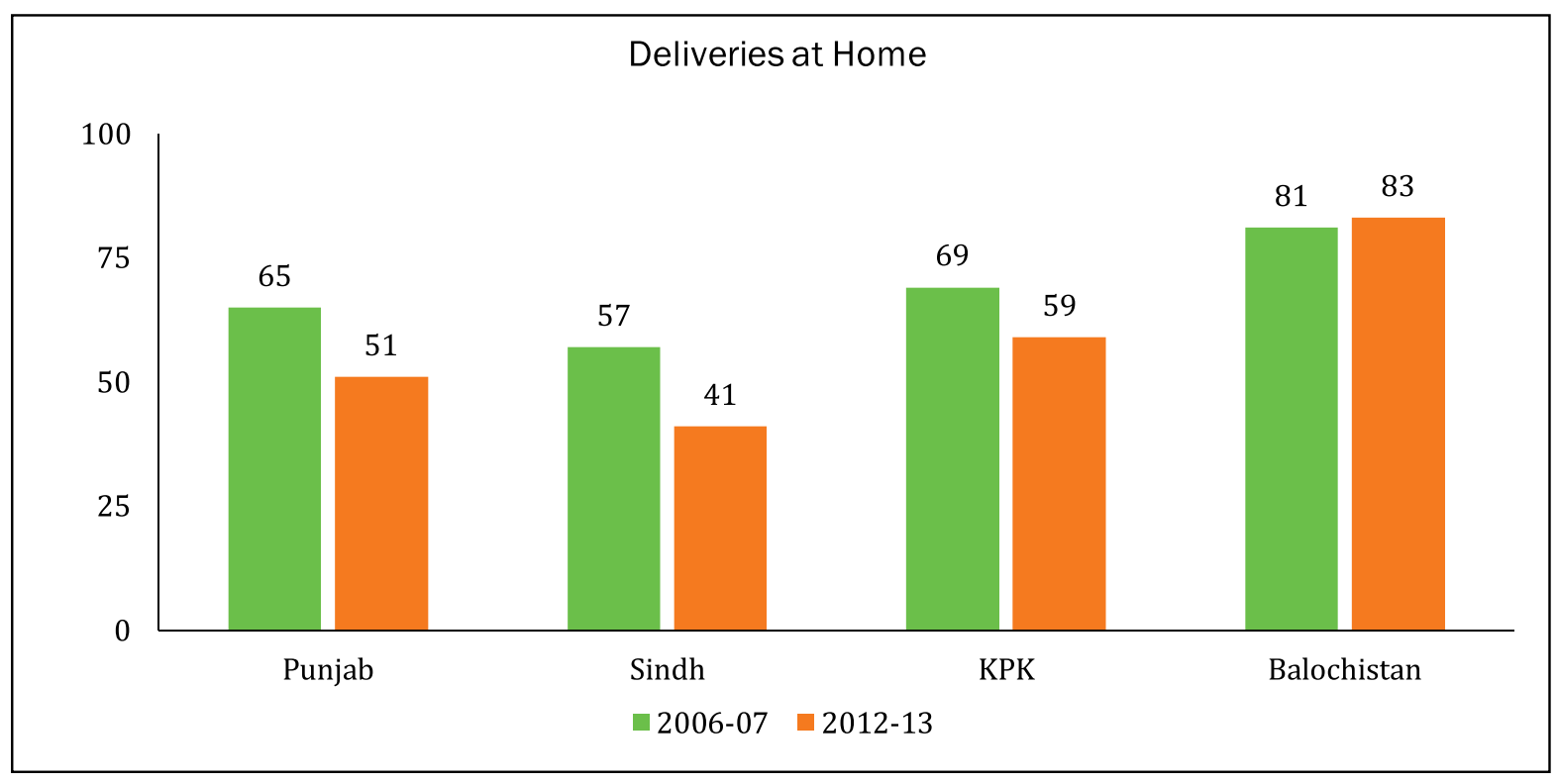

Source: PDHS.

2 Skilled providers include doctors, nurses, midwives, and lady health visitors. 



\section{The Opportunity to Expedite Fertility Decline and Reduce Maternal and Infant Mortality}

\subsection{Changing Fertility Preferences in the Provinces}

Chapter 1 has established that fertility declines brought about through an effective family planning programme and with sufficient human and financial resources can have a significant impact on MDGs 4 and 5 . Pakistan is currently experiencing a very slow fertility decline, which it will have to accelerate to hasten the decline in maternal and child mortality. What is important to note is that Pakistan and its provinces are going through a phase where fertility preferences are changing and there is a growing propensity for smaller families and well-spaced births. This is a key opportunity to target those women and men who have expressed their desire for change and provide them better access to the health sector and improved services to effectively utilize contraception. This chapter discusses the opportunity at hand in the context of each province.

Family size preference is an important indicator reflecting fertility norms and the intention to exercise control over fertility. It is, therefore, a useful predictor of the potential demand for family planning. In traditional and patriarchal societies such as Pakistan, men are believed to support large families and it is important to study their reproductive intentions as well. The distribution of married men and women aged $15-49$ by their desire for a given number of children and for spacing is depicted in Figure 5.1. Nationally, 70 percent of women - including 51 percent who want no more children and 19 percent who want to postpone their next child for two years - are interested in controlling their fertility (PDHS 2012/13). What is even more interesting is that 63 percent of married men also want to limit and space their children (PDHS 2012/13). This is more than enough evidence that family size norms are changing widely, with women in the lead and men following closely.

There are minor differences in this pattern across the provinces as shown in Figure 5.2. Our argument here is that efforts are required not so much to persuade women and men to change fertility norms, but instead to direct resources within the health system to providing more information and high-quality services aimed at changing fertility preference behaviours that lag behind. Policymakers must now ensure access to and availability of the required family planning methods, particularly in rural areas and to the poor in both urban and rural areas. 
Figure 5.1: Preferences for limiting and spacing family size for men and women at the provincial level

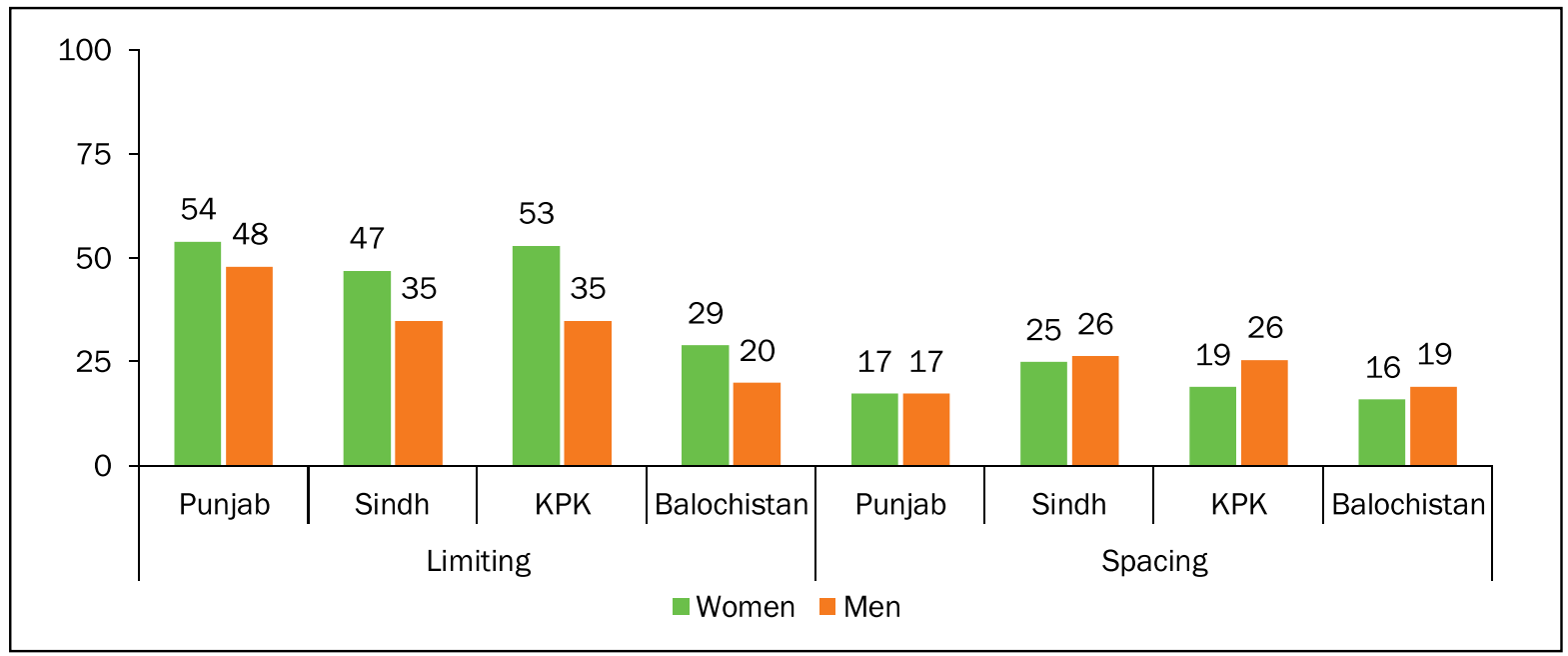

Source: PDHS 2012-13.

Figure 5.2: Contraceptive prevalence by provinces

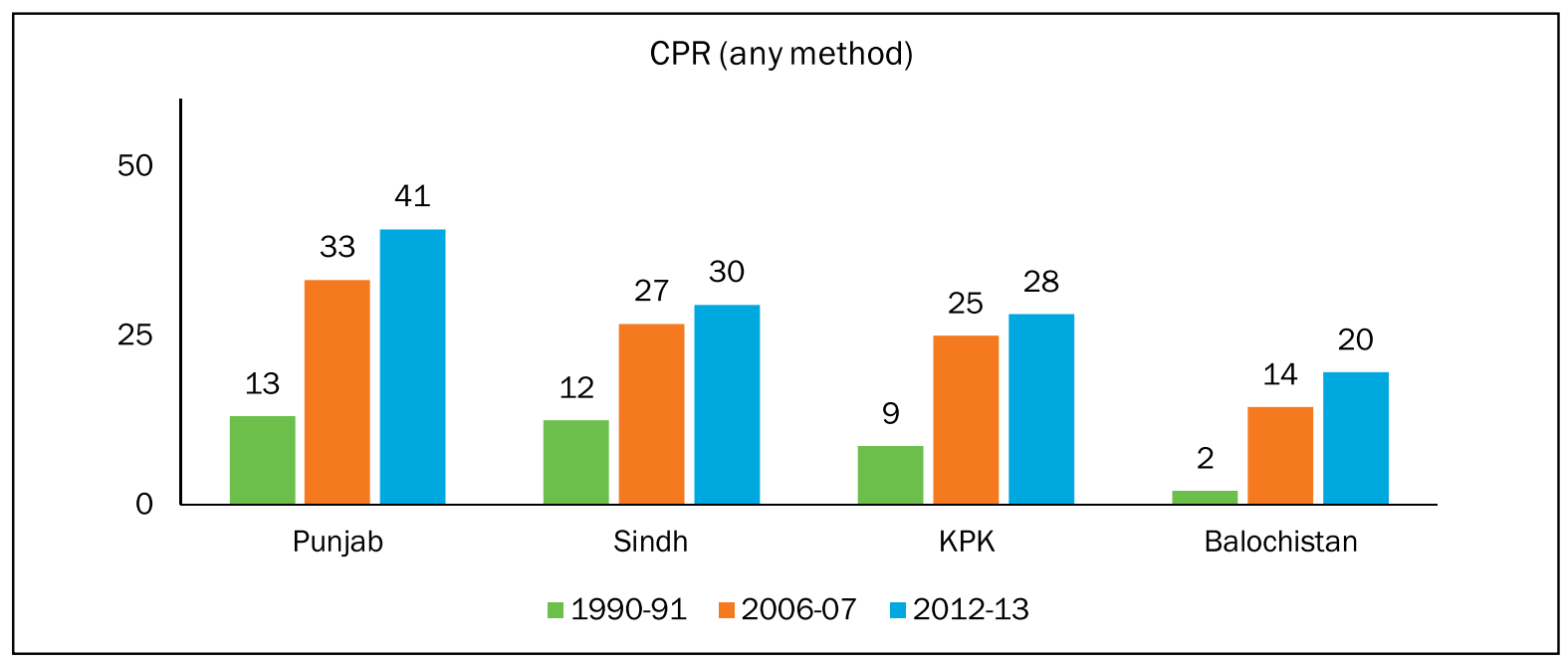

Source: PDHS 1990-91, 2006-07 \& 2012-13

\subsection{Low Contraceptive Use in the Provinces}

The primary objective of family planning is to allow women and couples to achieve their desired fertility so that they are able to delay, space, or limit pregnancies. In 2012, approximately, 35 percent of married women of reproductive age (15-49 years) used any method of contraception. Given that this proportion was 12 percent in 1990, the change represents a rise but with a very slow rate of uptake of family planning. In contrast, the CPR uptake during 19912000 was remarkable, rising from 12 percent to 28 percent. This is all the more worrying because it implies that, despite changing fertility preferences, the last 10 years have witnessed stagnation in the use of contraception. 
While Punjab shows some improvement in the last five years, this stagnation is evident across the other provinces (Figure 5.2). All four provinces experienced a real escalation in contraceptive use during 1990-2000 - on average, a rise of almost 2 percent a year. However, post-2000, this rate of change has been about 0.6 percent a year. If, in the past, progress was achieved in terms of family planning uptake, the same and more is still possible given that most men and women now favour smaller and better-spaced families.

Figure 5.3: Provincial Contraceptive prevalence rates
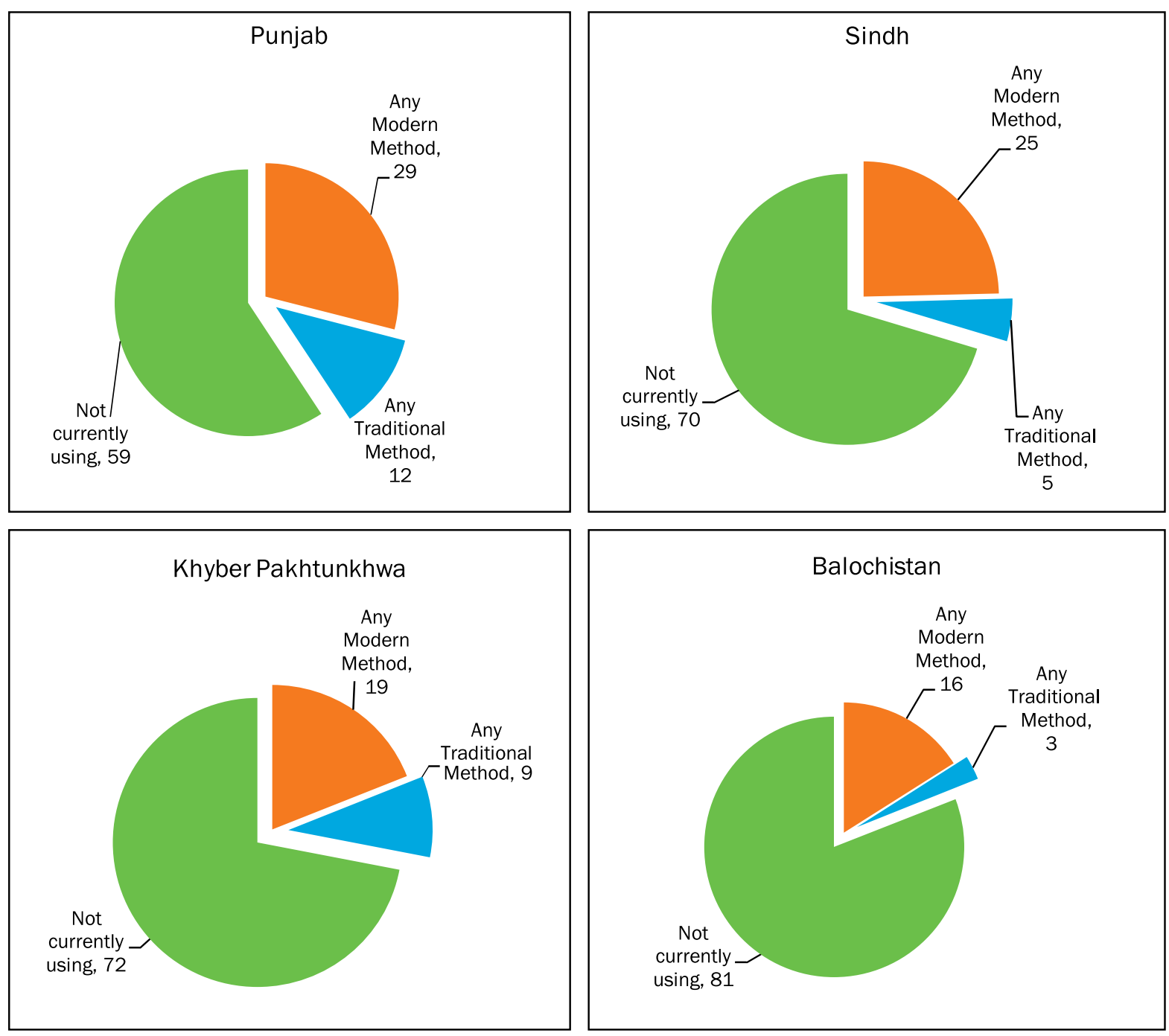

Source: PDHS 2012-13.

The use of modern contraceptives methods in Pakistan has improved over time, rising from 9 percent among married women in 1990 to 17 percent in 2000 and to 26 percent in 2012. A substantial proportion of this contraceptive use, however, still involves traditional methods. Patterns of modern versus traditional methods also vary across the provinces. In 2012, Punjab and KP had a much higher proportion of users adopting traditional methods than Sindh and Balochistan (Figure 5.3). 
Overall, in 2012, 73 percent of married women of reproductive age (7.7 million women) were using modern contraceptive methods, of which female sterilization was the most widely used. However, its share has declined in the last six years from 28 percent to 25 percent between 2007 and 2013. Condoms are the second most widely used method with its share having increased from 23 percent to 25 percent in the last six years.

Importantly, the use of all other modern methods has declined between 2006 and 2012. These include the IUD ( 7 percent), the Pill (5 percent), male sterilization ( 1 percent), and injectables ( 8 percent). In the meanwhile, the share of the withdrawal method has increased substantially from 14 percent in 2006 to 24 percent in 2012 - an increase of almost 70 percent.

Figure 5.4: Contraceptive methods mix for Pakistan

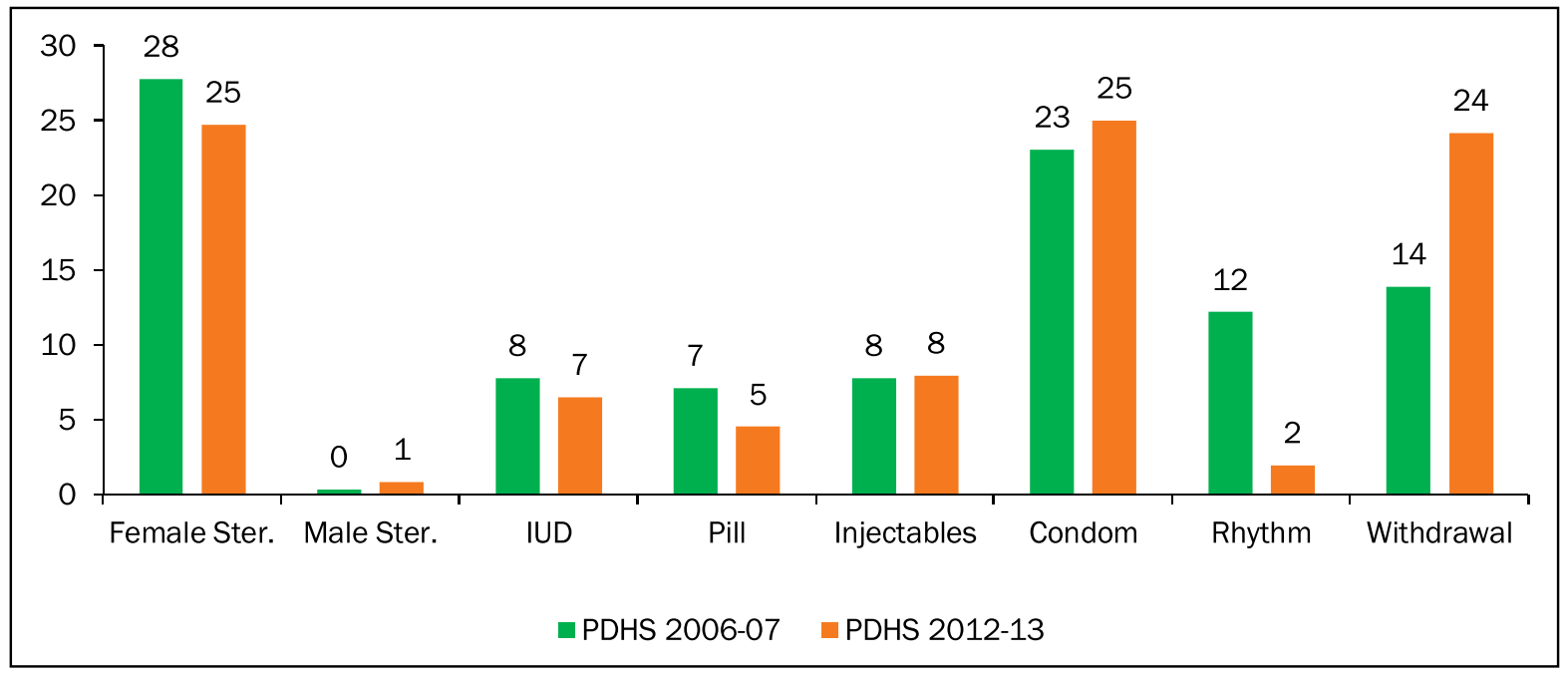

Source: PDHS 2006-07 and 2012-13.

\subsection{The High Unmet Need for Family Planning}

In 2012, approximately 5.9 million women wanting to avoid pregnancy were not using a family planning method; this is equivalent to an unmet need of 20 percent among married women aged $15-49$ years.

In the last two decades, the unmet need for family planning has decreased nationally from 30 percent in 1990 to 20 percent in 2012. Unmet need can be subdivided into (i) women who want to have another child after at least two years (for the purpose of spacing), and (ii) those who wish to stop childbearing (for the purpose of limiting family size). In 2012, an estimated 55 percent (11 percent with an unmet need for limiting family size) of those with an unmet need for family planning indicated the need to limit their family size while 45 percent indicated the need to space their children. In the 1990s, approximately 51 percent of women indicated an unmet need for family planning in terms of limiting family size; the remaining 49 percent accounted for the unmet need for spacing.

There are significant differences in this trend across the provinces. As seen in Figure 5.5, Punjab now registers the lowest unmet need, followed by Sindh. KP and Balochistan still have 
higher levels of unmet need and the latter has experienced hardly any change in unmet need in the last five years. Both the unmet need for spacing and limiting appear to have declined in Punjab and Sindh, while in KP the unmet need for spacing has declined.

Figure 5.5: Unmet need for family planning by provinces, 2006-12

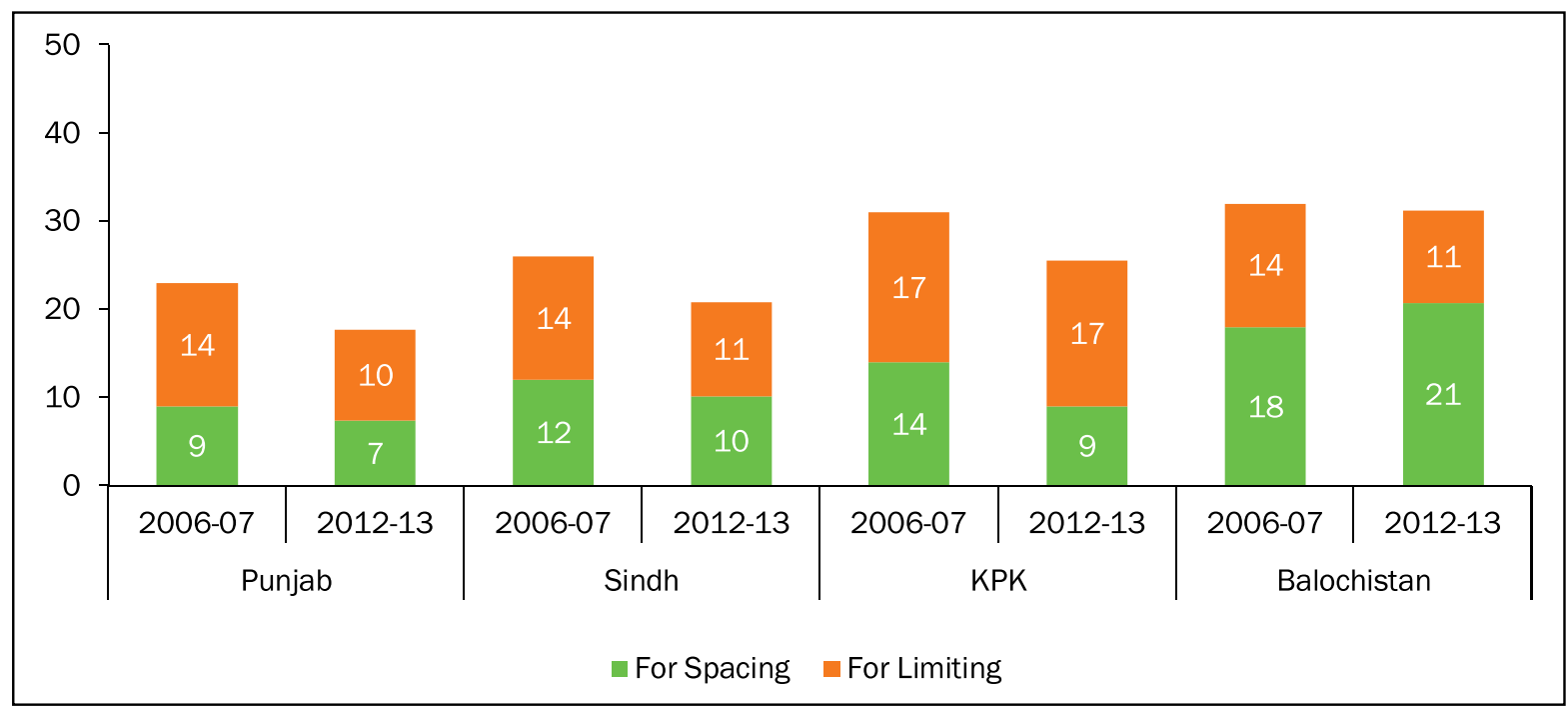

Source: PDHS 2006-07 \& 2012-13

There are several reasons for women's unmet need for family planning: lack of knowledge and access to family planning services; and financial, educational, social, and geographic barriers to obtaining family planning services. Generally, the primary reason for women not using contraception is the lack or high cost of family planning services. However, there are other reasons, the most common of which in Pakistan is women's concern about potential side effects and method failure. Approximately 22 percent of married women said they had discontinued their contraceptive method due to undesirable side effects (PDHS 2012/13), while 16 percent reported their contraceptive method had failed. Cost and access to family planning services represents a relatively small proportion of the reasons for discontinuing contraceptive methods -0.2 and 2 percent, respectively. Many of these barriers could be overcome through better information and counselling for both women and men.

\subsection{Reducing Unwanted Fertility}

One of the main consequences of high unmet need is unwanted pregnancies and unwanted and mistimed births. In DHS, women age 15-49 were asked as series of questions about each child born to them to determine whether the birth or pregnancy was wanted than or not wanted. According to the PDHS 2012-13, "A birth is considered wanted if the number of living children at the time of conception is less than the ideal number of children reported by the respondent. The gap between wanted and actual fertility shows the extent to which women are successful in achieving their reproductive intentions. This measure may be an underestimate to the extent that women may not report an ideal family size lower than their actual family size." (PDHS 201213, pp-89) 
This yields the wanted TFR and unwanted TFR. The unwanted fertility rate measures the potential impact of family planning programmes; wanted fertility is usually related to programmes, but more so to communications, modernization, and education etc. The levels of and trends in total wanted and unwanted fertility are presented in Figure 5.6. Overall, women in Pakistan had 0.9 children more than desired in 2012. This implies that, if unwanted births could be avoided, the TFR would drop by 31 percent. In the last six years, unwanted births have declined very slightly by 0.1 children. In 2006/07, about one child, on average, was unwanted. The prevention of unwanted births has many implications. It would reduce the population growth rate significantly, by decreasing the overall fertility rate. In addition, the incidence of unwanted fertility has a substantial impact on women's health and wellbeing in terms of abortions, postabortion complications, and additional morbidities.

Figure 5.6: Wanted and unwanted fertility by provinces, 2006-12

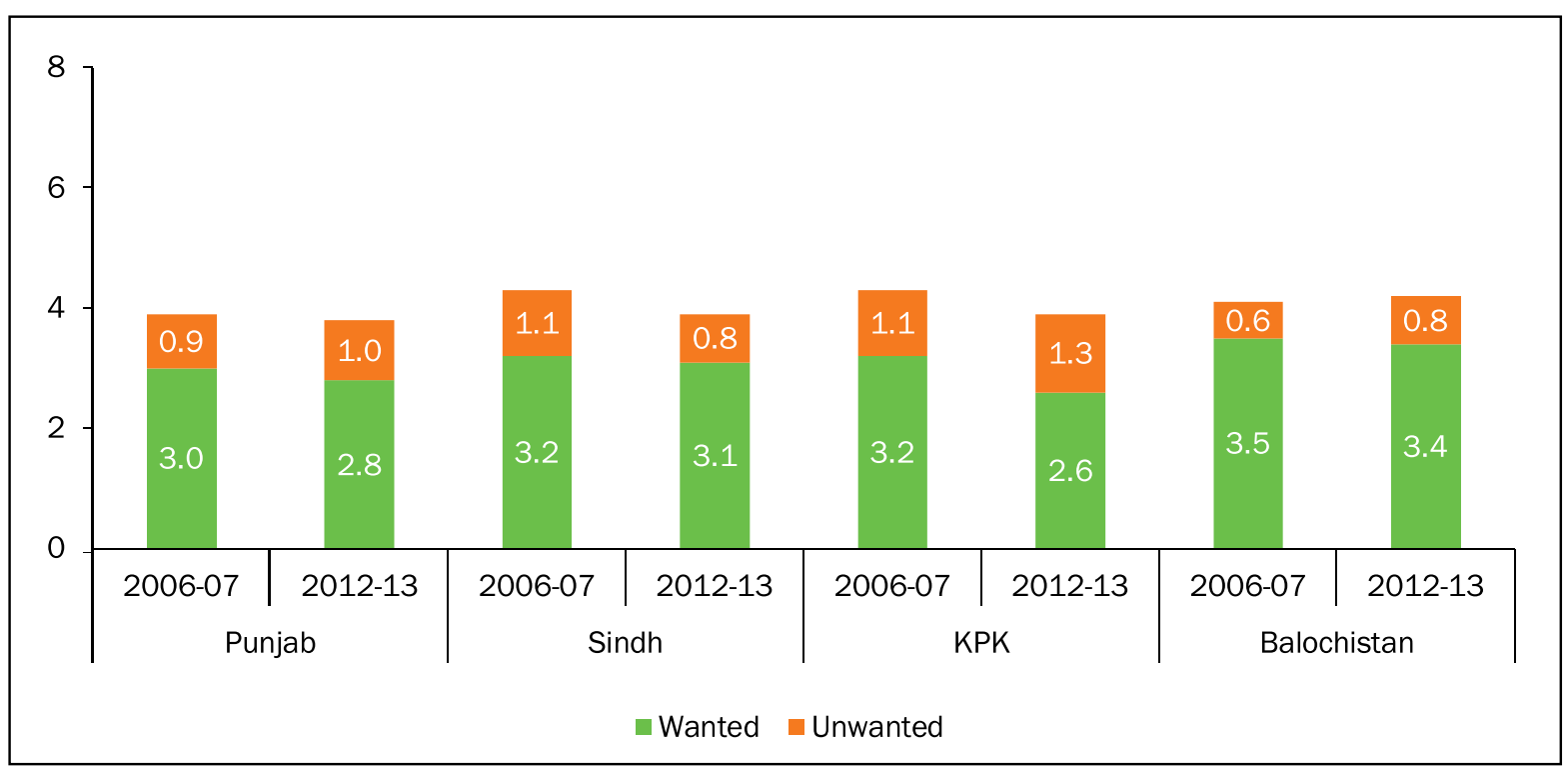

Source: PDHS 2006-07 \& 2012-13

The pattern of wanted and unwanted fertility across the provinces differs. While Punjab and Sindh have experienced a decline in unwanted fertility, KP and Balochistan currently have higher levels of unwanted fertility than they did in 2006/07. KP has the highest level of unwanted fertility on average at 1.3 children. While all the provinces have experienced some decline in wanted fertility, the biggest difference is seen in KP where the level dropped from 3.2 to 2.6 , reflecting a dramatic change in fertility preferences. 


\section{The Role of Family Planning in Reducing Maternal and Child Mortality}

\subsection{Preventing Maternal Deaths}

We have established the gap between provincial fertility preferences and the level of family planning use. If women's fertility levels and birth spacing reflected their preferences, i.e., their desired number of pregnancies and childbirth intervals, maternal mortality would certainly drop. The overall number of maternal deaths would also fall. This chapter shows how this logic applies to infant mortality levels.

The maternal mortality improvements depicted in Chapter 4 were driven largely by improvements in the level of SBA, ANC, and postnatal care as well as by declines in fertility. Despite these improvements in maternal health, more than 12,000 women in Pakistan die every year due to maternal complications. Addressing the high level of unmet need for family planning is a concrete and feasible policy option for preventing maternal deaths. By failing to fully address these unmet needs, family planning programme efforts stand to lose the opportunity to save several thousand lives a year.

Contraceptive use, which reduces fertility, in turn, directly reduces the number of maternal deaths because it lowers the chance of pregnancy (particularly unintended pregnancies and their associated complications). Contraception helps women to limit or space their pregnancies and the timing of each pregnancy. It also lowers the risk of teenage pregnancy and unsafe abortions. The high level of unmet need for contraception and resulting unplanned and unwanted pregnancies implies that many unintended pregnancies as well as induced abortions and maternal deaths were not prevented. Preventing such pregnancies would have a substantial impact on fertility decline: fertility rates and growth rates are directly influenced by the CPR.

This chapter assesses the impact of renewed and accelerated family planning programmes on maternal mortality. We use the methodology described in Chapter 2, i.e., a model based on the two core inputs of SBA and GFR (the total number of births per 1,000 women of reproductive age). Using the relationship between contraceptive use and the GFR (Chapter 2), we estimate the latter based on different contraceptive use scenarios. Contraceptive use goals are set based on the assumption of universal access (thus eliminating the unmet need for family planning). To gauge the impact of family planning on maternal deaths, we run different simulations based on this model, assuming different contraceptive prevalence scenarios.

Figure 6.1 presents the potential benefits of increased family planning use and SBA in terms of saving maternal lives in Pakistan. We present three scenarios based on different levels of contraceptive use and SBA. In the first scenario, if SBA increases to 80 percent from its current national level of 52 percent and the CPR remains at its current level of 35 percent, the number of maternal deaths falls from 12,351 to 8,309 - saving 4,042 maternal lives. This means that 
maternal deaths would decline by 33 percent. In the second scenario, which we particularly want to emphasize, eliminating the 20 percent unmet need for family planning, increasing the CPR to 55 percent, and maintaining SBA at constant levels would eliminate 4,884 maternal deaths. This would imply a 40 percent decline in the number of maternal deaths from the current estimate. In the third and optimal option, we assume that SBA increases to 80 percent and the CPR rises simultaneously to 55 percent. This would reduce the number of maternal deaths by 60 percent, i.e., from 12,351 to 4,997, thus saving 7,354 maternal lives.

Figure 6.1: Impact of family planning on number of maternal deaths in Pakistan

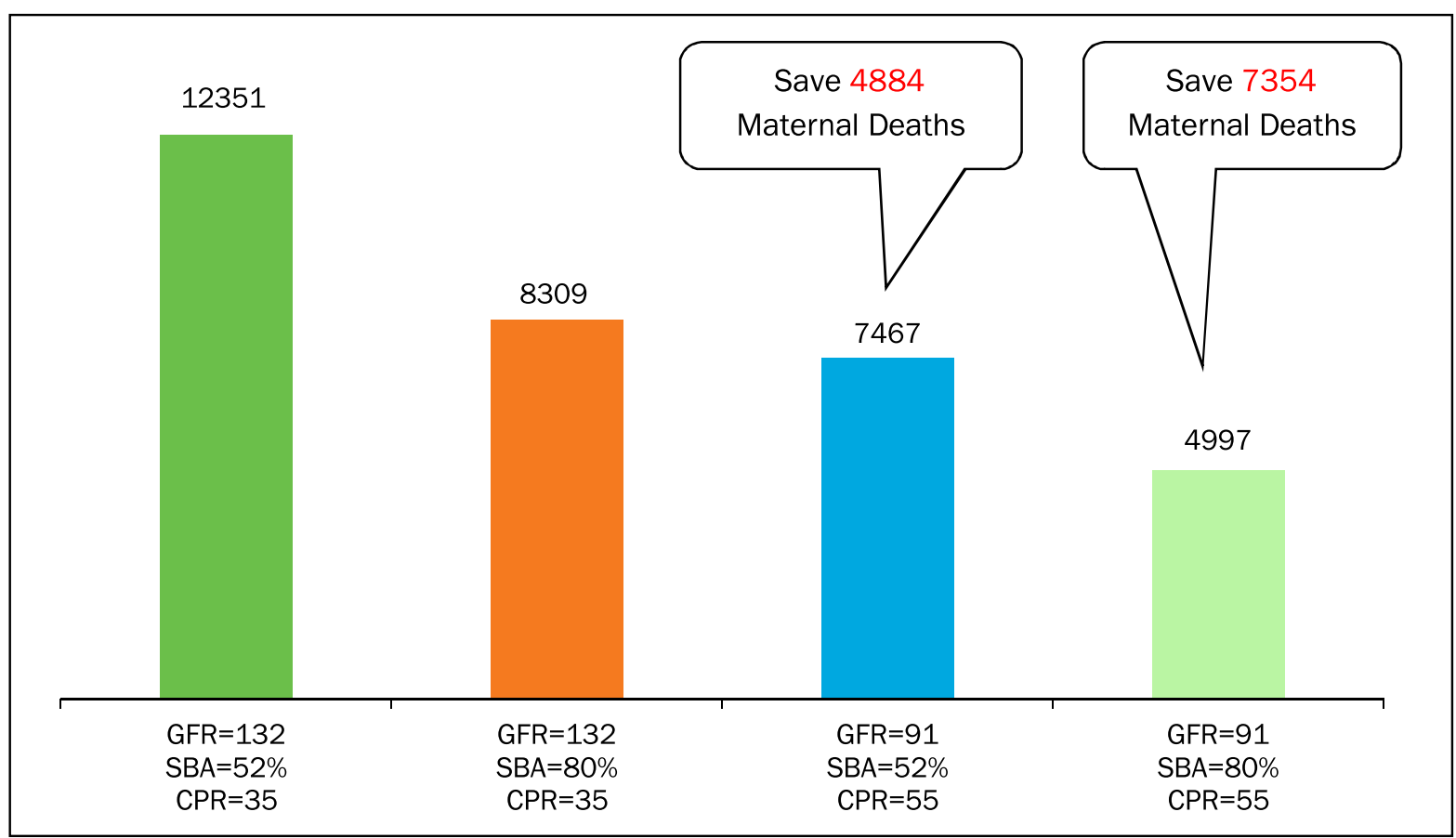

Source: PDHS 2012-13 and simulations based on Maternal Mortality 2000: Estimates developed by WHO, UNICEF and UNFPA, WHO, and Liu et al. (2008)

We apply the same three scenarios at the provincial level to estimate the impact of eliminating the unmet need for family planning on maternal mortality for each province (see Figure 6.2).

\subsubsection{Punjab}

If SBA in Punjab were to increase to 80 percent from its current level of 52 percent, and the CPR remained at its current level of 41 percent, the number of maternal deaths would fall from 6,027 to 4,082 , saving 1,945 maternal lives. Maternal deaths would, therefore, decline by 32 percent. Assuming the scenario in which we eliminate the unmet need for family planning (17 percent) by increasing the CPR to 59 percent and we maintain SBA at its current level of 52 percent, we would have 2,711 fewer maternal deaths, i.e., a 45 percent decline. In the optimal situation, we assume that SBA increases to 80 percent while the CPR rises to 59 percent. In this situation, the number of maternal deaths would fall by 63 percent, i.e., from 6,027 to 2,232 , thus saving 3,795 maternal lives in Punjab alone. 


\subsubsection{Sindh}

In the first scenario, we assume that SBA in Sindh increases to 80 percent from its current level of 61 percent and the CPR remains at its current level of 30 percent. This would reduce the number of maternal deaths from 2,807 to 2,138 - a 24 percent decline - thus saving 669 maternal lives. In the second scenario, we eliminate the unmet need for family planning in Sindh (20 percent) by increasing the CPR to 51 percent, and keep SBA constant at 61 percent. This would eliminate 931 maternal deaths, representing a 33 percent decline. In the optimal scenario, we increase SBA to 80 percent and the CPR to 51 percent. The number of maternal deaths falls to 1,430 from 2,807 , saving 1,377 maternal lives and representing a 49 percent decline.

Figure 6.2: Impact of family planning on maternal mortality by provinces

Punjab

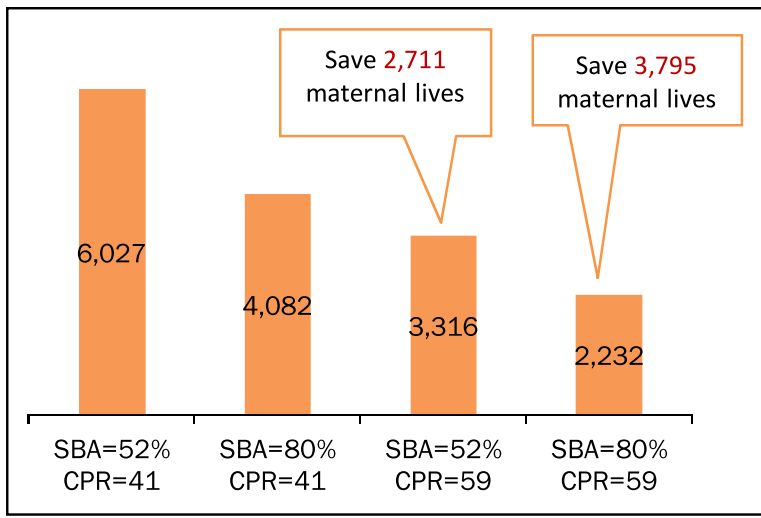

Khyber Pakhtunkhwa

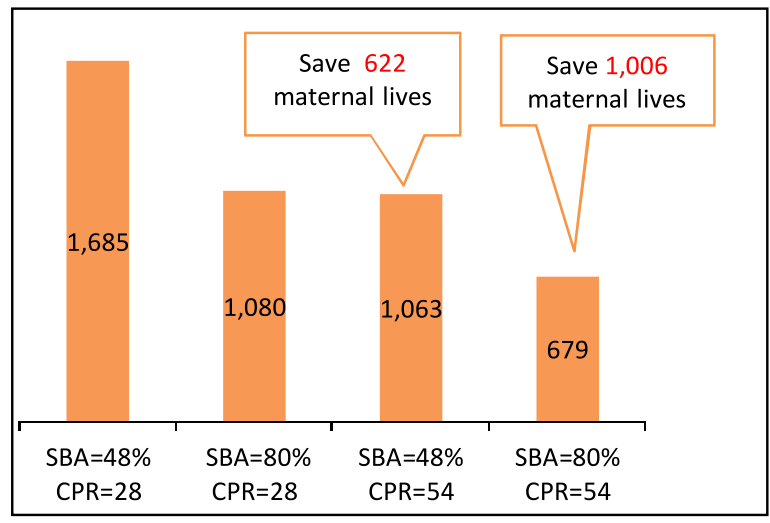

Sindh

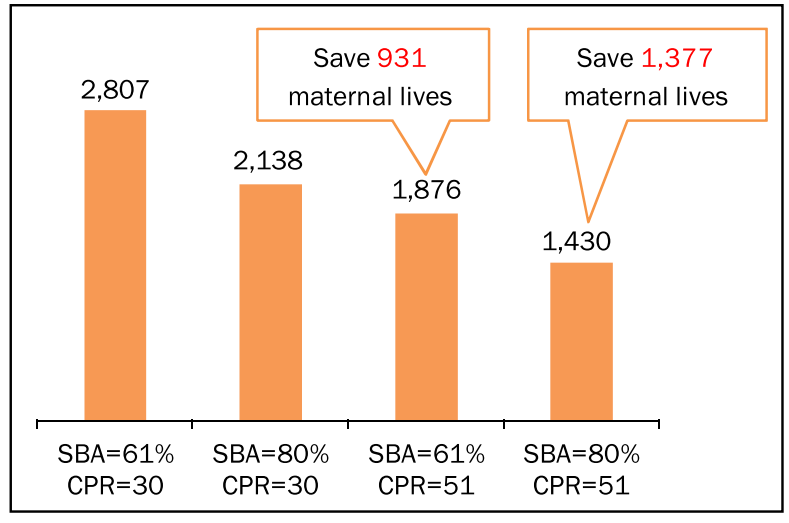

Balochistan

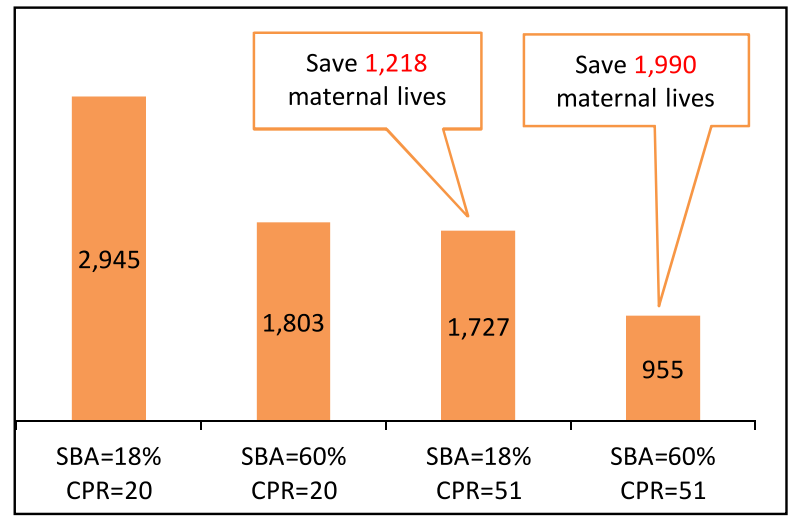

Source: PDHS 2012-13 and simulations based on Maternal Mortality 2000: Estimates developed by WHO, UNICEF and UNFPA, WHO, and Liu et al. (2008) 


\subsubsection{Khyber Pakhtunkhwa (KP)}

The results of this exercise are, potentially, even stronger for KP. Increasing SBA to 80 percent would prevent about 36 percent of all maternal deaths in the province: the number of maternal deaths would fall to 1,080 from 1,685, thus saving 605 maternal lives. In the second scenario, eliminating the unmet need for family planning (26 percent) alone would save 622 maternal lives. Finally, in the optimal situation, eliminating the unmet need for family planning while increasing SBA to 80 percent would reduce the number of maternal deaths from 1,685 to 679 - a 60 percent reduction in maternal deaths.

\subsubsection{Balochistan}

The case of Balochistan is critical: recent evidence shows that reproductive health indicators (ANC and SBA) have actually decreased in the last six years. Consequently, the estimated MMR has increased in this period. Our simulation exercise, therefore, presents an even stronger case for policymakers in Balochistan to improve the province's maternal mortality record.

In the first scenario, increasing the level of SBA to 60 percent $^{3}$ alone would prevent about 39 percent of all maternal deaths in the province. The number of maternal deaths would decline from 2,945 to1803, saving 1142 maternal lives. In the second scenario, addressing the unmet need for family planning in Balochistan (31 percent) by increasing the CPR to 51 percent would save 1218 maternal lives - a 41 percent reduction in maternal deaths. In the third optimal situation, eliminating the unmet need for family planning while increasing SBA to 60 percent would reduce the number of maternal deaths from 2,945 to 955 . This would save 1,990 maternal lives.

\subsection{Saving Infant Lives}

As in the case of saving maternal lives, there is an opportunity to reduce the number of infant and child deaths in Pakistan by accelerating family planning efforts. Over the last few decades, child and infant survival has improved moderately, largely due to better childhood immunization and nutrition. However, approximately 0.41 million infants and 0.5 million children under the age of five still die each year in Pakistan.

It is important to note that family planning is a key - and as yet untapped - policy option for reducing infant and child mortality in Pakistan. In particular, birth spacing can prove to be one of the strongest interventions capable of improving child survival rates. By preventing closely spaced births, family planning can save a substantial number of infants and children under five.

The methodology adopted to calculate the potential impact of increased contraceptive prevalence on infant and child mortality is described in Chapter 2. We develop two family

\footnotetext{
3 In Balochistan, we assume that SBA will increase to 60 percent because it is already lower than in other provinces; it has also declined by 5 percent in the last six years.
} 
planning effort scenarios. The first assumes that we are able to meet the unmet need for family planning for each province. The second assumes that we can meet half the unmet need for family planning in each province.

Figure 6.3 shows that eliminating the unmet need for family planning significantly reduces the number of infant and children aged 1-4 deaths in Pakistan. For instance, if we increase the CPR to 55 percent (eliminating the unmet need for family planning at 20 percent), there would be almost 140,357 fewer infant deaths and 72,985 fewer children aged 1-4 deaths, accounting for a 34 percent decline in the former and a 87 percent decline in the latter. The impact of increased family planning use on infant and child mortality for each province is illustrated in Figure 6.4.

Figure 6.3: Impact of family planning on infant and children (aged 1-4) deaths in Pakistan

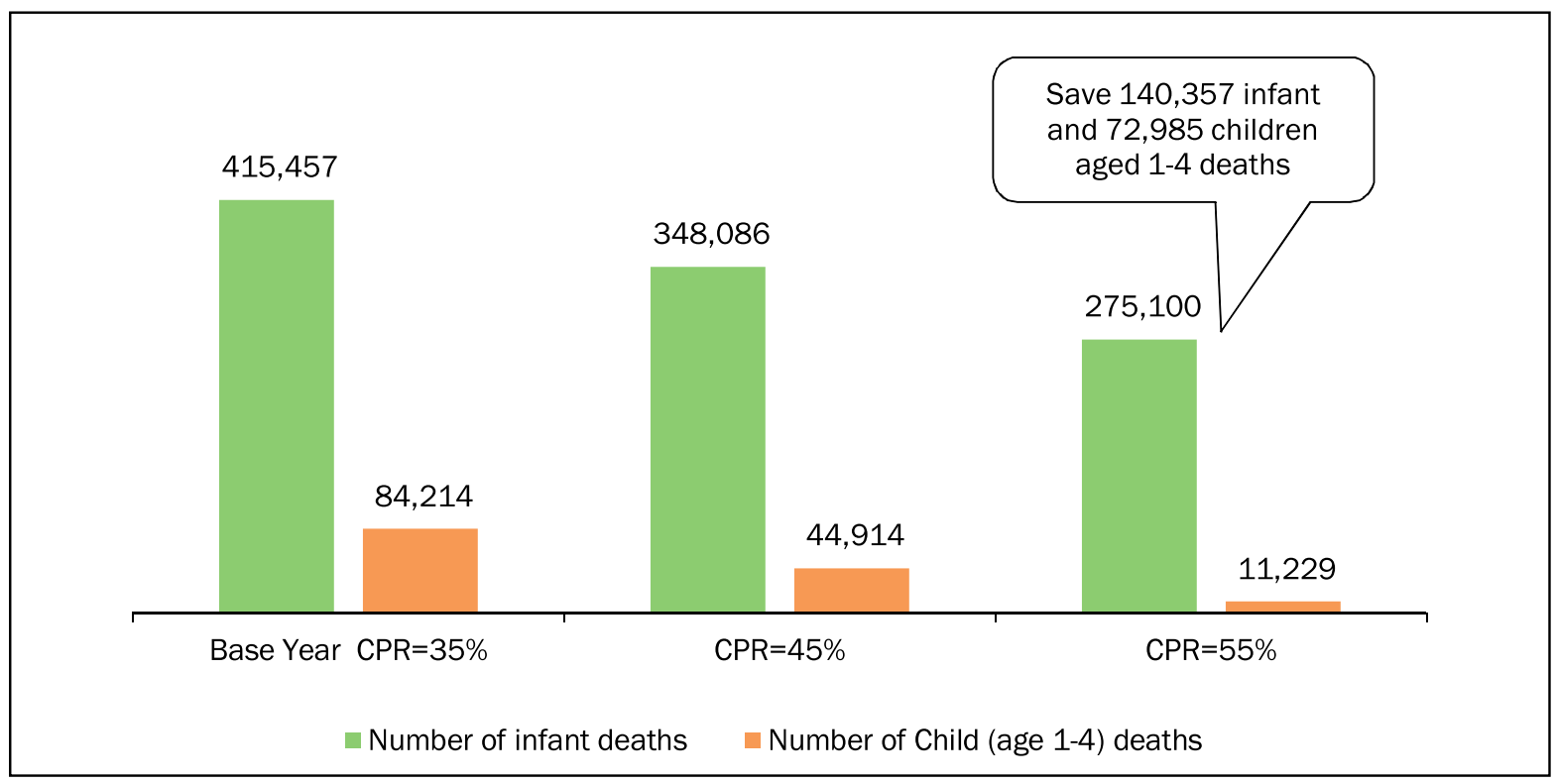

Source: PDHS 2012-13 and simulation based on FAMPLAN model.

\subsubsection{Punjab}

In Punjab, approximately 281 thousand infants and 54 thousand children aged 1-4 die each year. Despite its significant progress in infant and child immunization and improving infant and child mortality, Punjab still has one of the highest child mortality rates. In the first scenario, we assume that contraceptive use rises to 50 percent; this decreases the number of infant deaths from 281 thousand to 242 thousand, saving 39000 infant lives. The proportion of infant deaths would thus decline by 14 percent. Child deaths (aged 1-4) would fall from 54 thousand to 35 thousand, saving 19000 child lives. The proportion of child deaths would thus decline by 35 percent.

If we were to eliminate the unmet need for family planning (18 percent) by increasing the CPR to 59 percent, this would lead to 73 thousand fewer infant deaths, accounting for a 26 percent decline in infant deaths. Children age 1-4 deaths in this scenario would fall from 54 thousand to 
13 thousand, saving 41 thousand child lives. The number of child deaths would thus decline by 76 percent.

\subsubsection{Sindh}

If contraceptive use in Sindh increased to 40 percent, the number of infant deaths would fall from 97,000 to 80,000 , saving 17,000 infant lives. Children aged 1-4 deaths would fall from 24,924 to 15741 , saving 9183 child lives. In the second scenario, we eliminate the unmet need for family planning in Sindh by increasing the CPR to 51 percent. This would imply 34,000 fewer infant deaths and 18,365 fewer children aged 1-4 deaths. The proportion of infant and child deaths would, therefore, decline by 35 percent and 74 percent, respectively.

Figure 6.4: Impact of family planning on infant and child mortality by province

Punjab

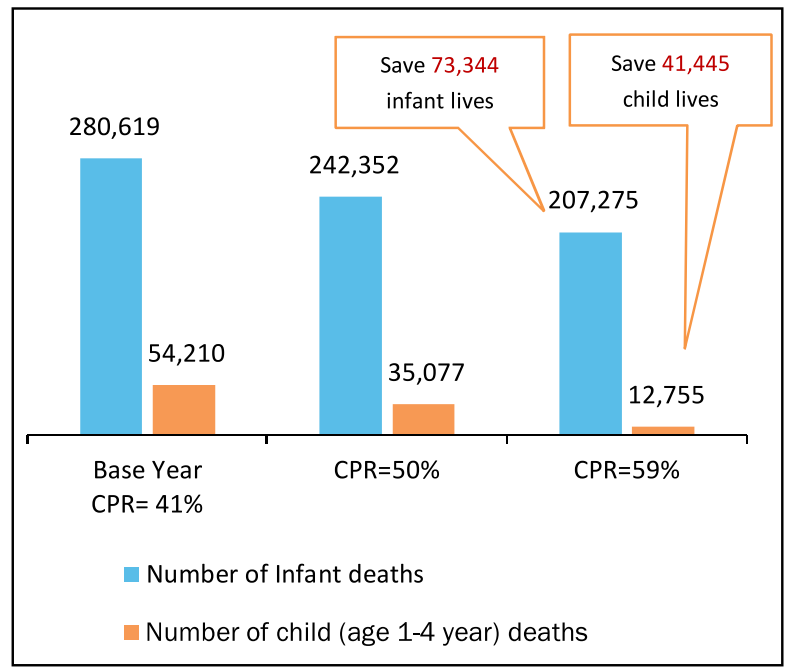

Khyber Pakhtunkhwa

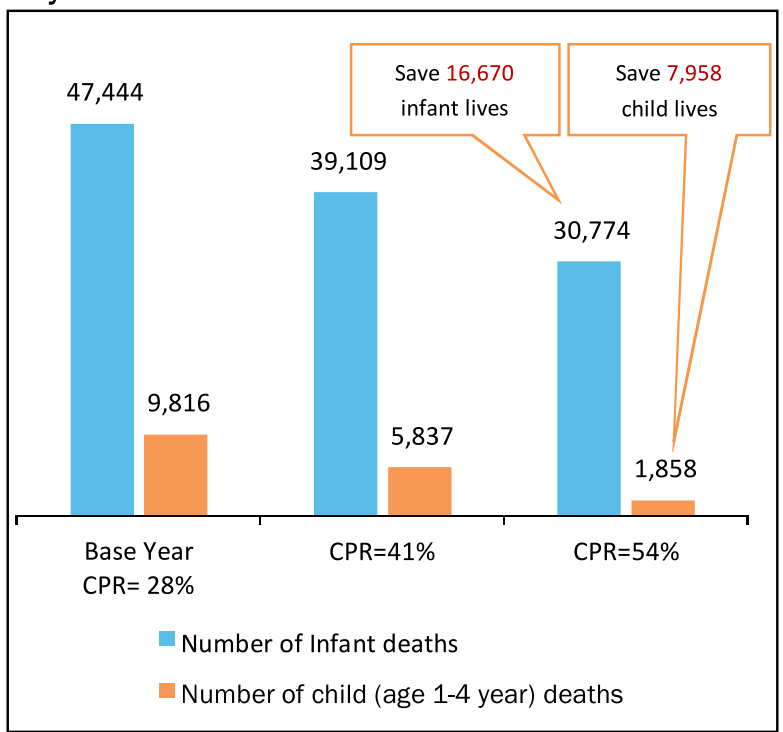

Sindh

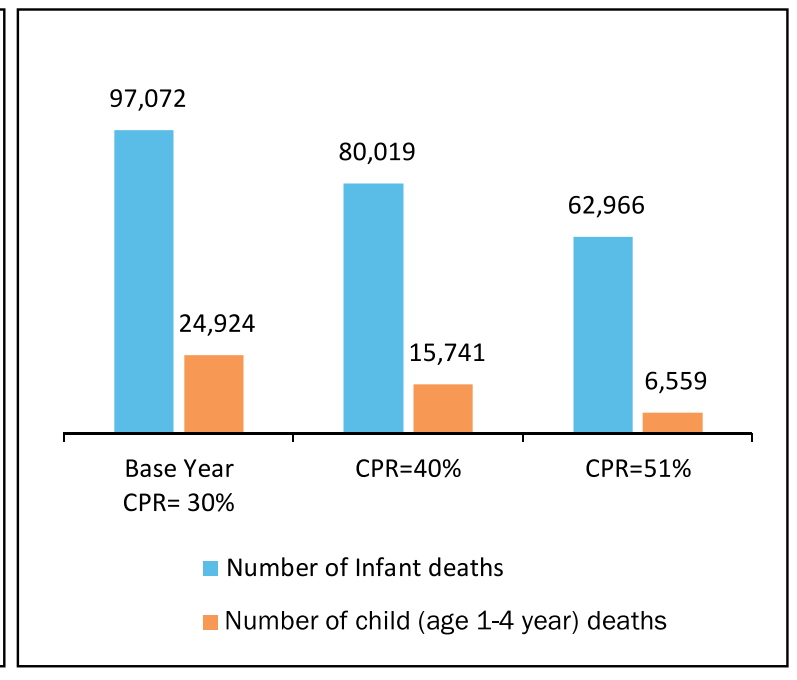

Balochistan

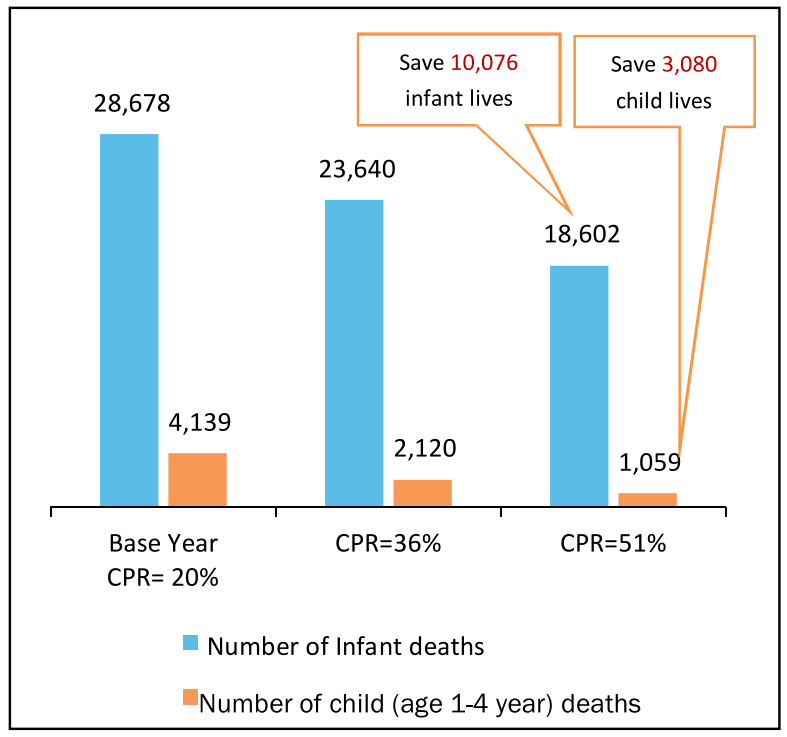

Source: PDHS 2012-13 and simulation based on FAMPLAN model. 


\subsubsection{Khyber Pakhtunkhwa (KP)}

Improved family planning efforts and higher contraceptive use are likely to have a significant impact in terms of reducing infant and child mortality in KP. In the first scenario, we increase the CPR to 41 percent, as a result of which infant deaths fall from 47,444 to 39,109 (a decline of 18 percent). Child (aged 1-4) deaths fall from 9,816 to 5,837 (a 40 percent reduction in child deaths).

Increasing contraceptive use to 54 percent (assuming that we can address the unmet need for family planning) alone could save 16,670 infant lives. The proportion of infant deaths would thus decrease by 35 percent. The number of children aged 1-4 deaths would fall from 9,816 to 1,858 thus saving 7,958 child lives (a decline of 81 percent).

\subsubsection{Balochistan}

In the first scenario, an increase in the level of contraceptive use to 36 percent would decrease the number of infant deaths from 28,678 to 23,640 , saving 5,038 infant lives. This would account for an 18 percent decline in infant deaths. The number of child deaths (aged 1-4) would decrease from 4,139 to 2,120 , thus declining by 49 percent. In the second scenario, addressing the unmet need for family planning and increasing contraceptive use to 51 percent would save 10,076 infant lives. The number of infant deaths would thus decline by 35 percent. The number of children aged 1-4 deaths under this scenario would decrease from 4,139 to 1,059 , saving 3,080 child lives. The proportion of child deaths would then decline by 74 percent. 



\section{The Role of Family Planning in Economic Wellbeing}

The main aim of this chapter is to speculate about the relationship between fertility and poverty and assess whether children and members of high-fertility households experience adverse economic effects. In particular, we explore whether they are likely to be more vulnerable to poverty. The idea is to focus on the household-level impacts of fertility change during 20002010 that have affected household composition and size. We will try to assess whether differential fertility behaviour across poorer and richer households translates into household propensities to spend on consumption and conversely to save. We assume that these changes affect household consumption and expenditure patterns and consequently, savings at the household level. To draw on economic data and link it with household demographics and behaviours, the study uses micro-data from the nationwide PSLMS data for various years conducted by the Pakistan Bureau of Statistics. The rationale for choosing these two datasets was that the surveys contain comprehensive information on income indicators (consumption) as well as on the social indicators needed for this study. Moreover, both were conducted by the same organization and, therefore, are similar in methodology and structure.

\subsection{Establishing the Link between Fertility, Family Planning and Poverty}

This section reviews the empirical evidence on fertility, family planning and economic groupings. Since the 1980s, evidence has confirmed the family planning-related benefits of reductions in fertility and population growth (Cleland et al., 2006). In Pakistan, there are significant differences in fertility rates by women's socioeconomic status. On average, poorest women had a TFR of 4.9 births per woman, compared with 2.9 births among rich women in Pakistan (PDHS 2012/13). Substantial differences in TFR for poor and rich women are also seen across all provinces (Figure 7.1). The largest differences between rich and poor fertility levels are seen in Sindh (2.8 children) and smallest differentials in KP (1.4 children).

Figure 7.1: TFR by poverty status by province

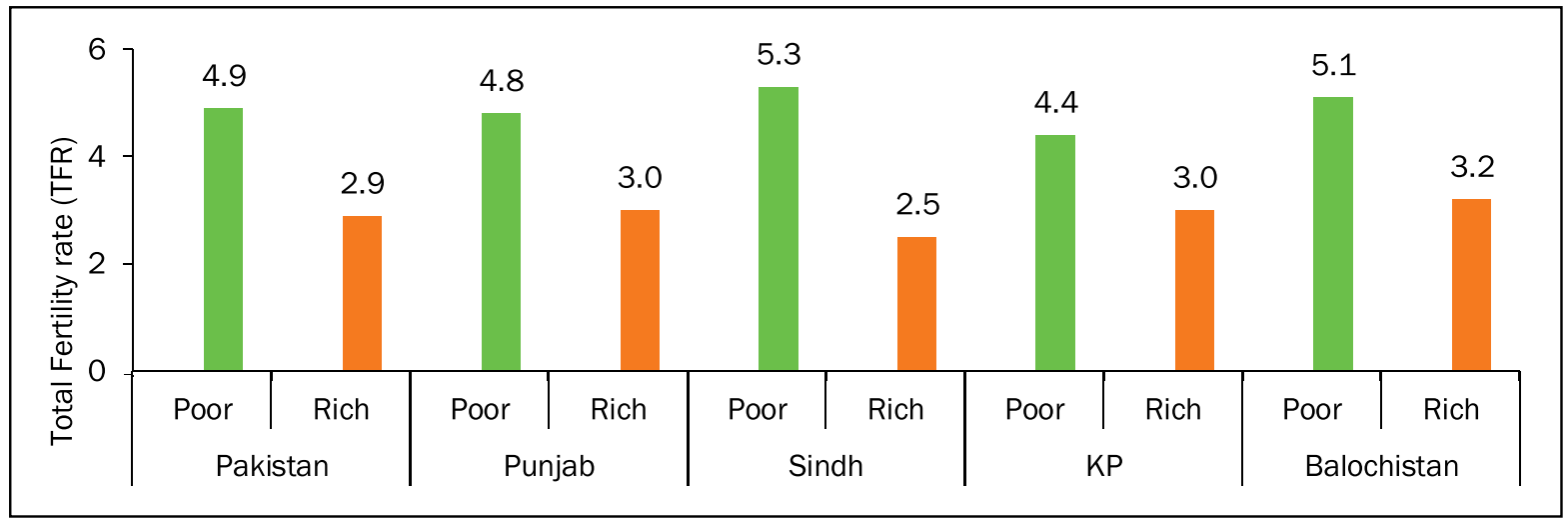

Source: PDHS 2012-13 
Many economists have contended that this behaviour is rational on the part of poor parents who perceive the need for more earners in the form of children (Pritchett 1994), implying that family planning cannot succeed in very poor countries. Cleland et al. (2006) clearly demonstrate, however, that family planning promotion has succeeded in very poor countries and that much of the fertility difference between rich and poor population stems not from successful reproductive choices but from the absence of such an option for the poor.

The unmet need for contraception and unwanted childbearing is, invariably, higher among poor couples than wealthy couples (Cleland et al., 2006). Again, the results for Pakistan support this claim: Figure 7.2 shows the differential use of contraception across the wealth quintiles in the provinces. The gap between the poorest and richest women is striking in Sindh, KP, and Balochistan, where the CPR for the richest women is almost more than double that for the poorest women. In Punjab, where the CPR is the highest, we see that the gap between the poorest and richest women is narrower.

Figure 7.2: Contraceptive prevalence rates by three wealth quintiles by province

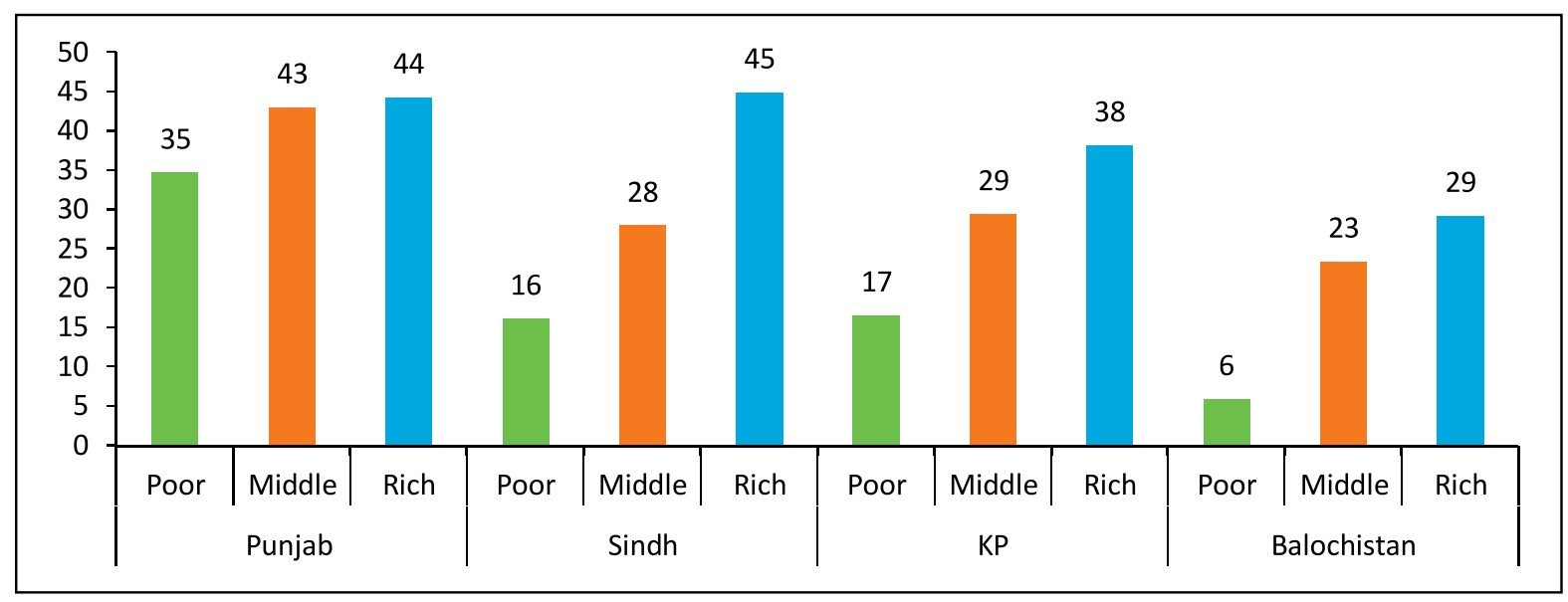

Source: PDHS 2012-13

When referring to universal access to contraceptive services and the unmet need for family planning in Pakistan, the first image that comes to mind is that of poor women in greater need and distress. Indeed, Pakistan's unmet need for contraception is much higher than that of other countries in the region (Bangladesh in 2001: 13.5; India in 2005/06: 13.9) and poor women have a much higher unmet need (Singh and Darroch, 2012). From any perspective, poor women are at the greatest disadvantage in terms of access to the services they most need.

Figure 7.3 presents the unmet need for family planning by women's socioeconomic status at the provincial level. Except in Punjab, the unmet need for family planning among poor women is significantly higher than among the richest women. This reconfirms the idea that, as services spread to a wider economic spectrum of women and contraceptive prevalence differentials improve (as in Punjab), unmet need differentials narrow. Conversely, when contraceptive prevalence levels stagnate (as in Balochistan) and the poorest women have virtually little or no access to family planning services, unmet need is very high at 46 percent. 
Figure 7.3: Unmet need for family planning by women's socioeconomic status by province

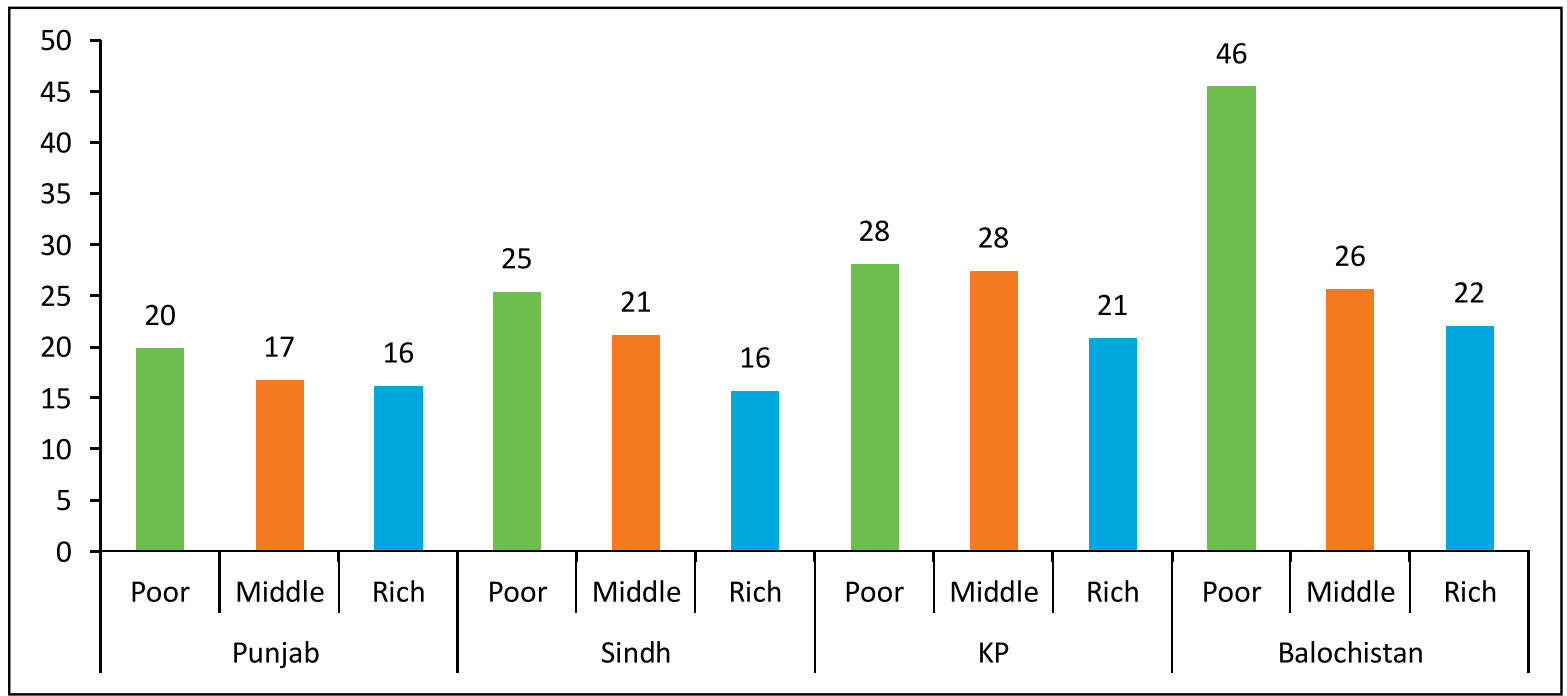

Source: PDHS 2012-13.

\subsection{The Impact of Fertility Decline on Overall Age Structure}

The demographic transition is projected to yield positive effects for the economy through a demographic dividend (Sathar et al., 2013), with Pakistan deriving some economic benefits from changes in its age structure, starting in the 1990s and continuing until 2040 (Bloom, 2013). Kelly and Schmidt (2001) demonstrate that fertility decline is the primary impetus to changes in age composition that, in turn, generate the demographic dividend. However, there is now sufficient research indicating dissimilarities between the East Asian experience and Pakistan's demographic transition. The results of recent analysis now caution that substantial investments in an educated labour force and a speedier decline in fertility are required for Pakistan to reap the benefits of a demographic dividend (Sathar et al., 2013). While the demographic dividend is not the focus of this study, we do intend to link the differentials in fertility decline across economic groups with changes in age structures at the household level. 
Figure 7.4: Population pyramids for the poorest and richest households at the provincial level, 2010-11
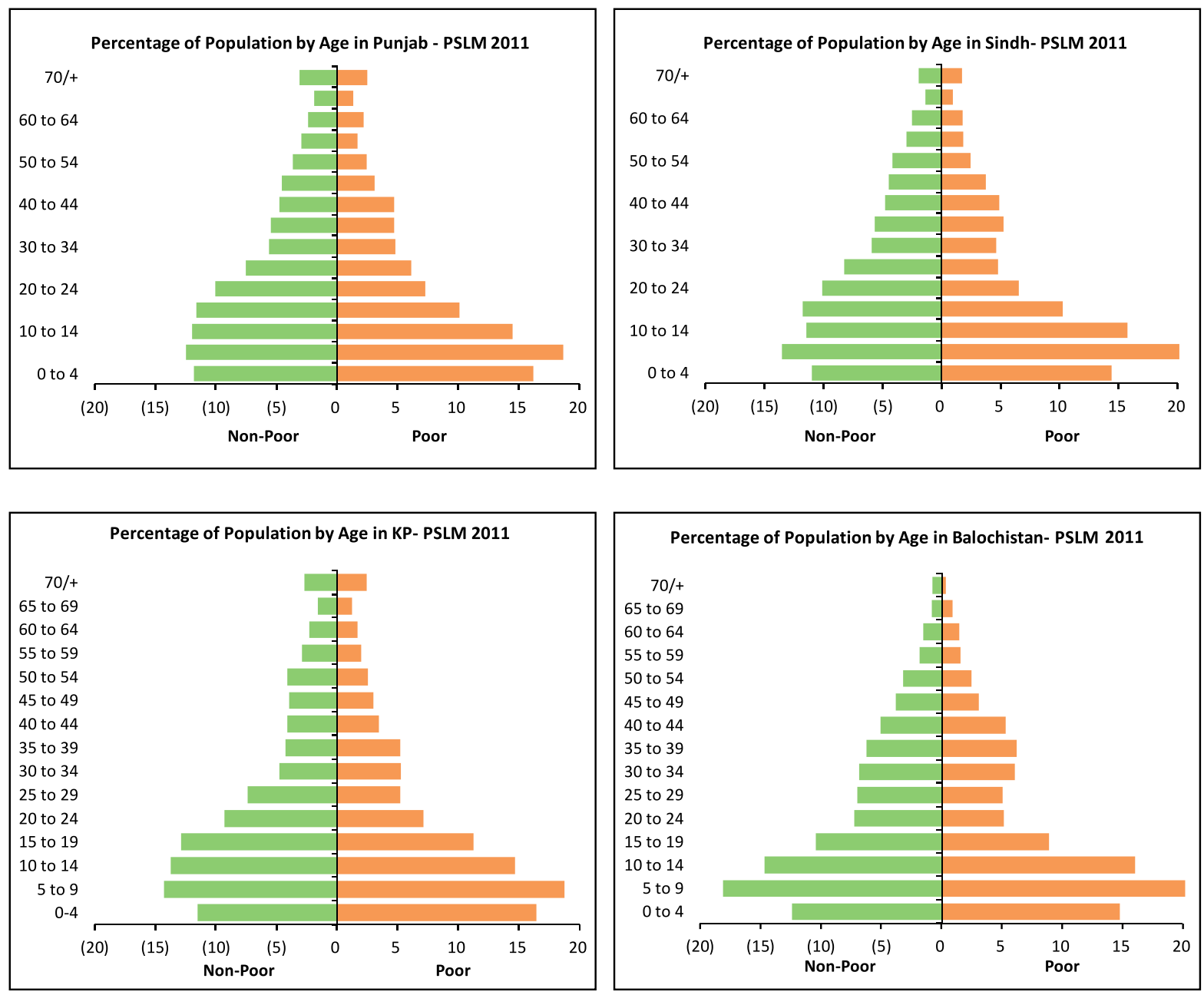

Source: PSLMS 2010-11. 
Contrasting age structures and different dependency ratios are seen on either side of the age pyramids for the four provinces in Figure 7.4. The contrast in the age structures for Punjab is most evident; it shows a broadening of the age pyramid for the non-poor and the continuing young age structure reflected for poor households. Sindh follows closely with a contrast between poor and non-poor age structures. KP and particularly Balochistan have less of a contrast in the age structures of poor and non-poor reflecting the later declines in fertility as compared to Punjab and Sindh.

Differences in household sizes of the rich and poor households were already evident in 2001 (Table 7.1). But the changes between 2001 and 2010 present an interesting perspective. Overall household size has declined by 0.6 persons in this period. By comparing household size across the provinces thorough the division of poor and non-poor households, we see changes occurring across both. Also the change has been driven by the decline in the number of children under 15 in all provinces.

The largest decline in household size has occurred in Sindh - about 1.2 people and 0.8 children under 15 in the last ten years. In the other provinces, the decline is between 0.4 and 0.6 persons on average. There are significant differences evident between poor and non-poor households in Punjab, Sindh and KP. Surprisingly, the differences in numbers of children under 15 between the poorest and richest households in Sindh and KP are larger than that of Punjab.

Table 7.1: Average household size, mean number of children under 15, and dependency ratios by poverty status, at national and provincial levels. 2001-02 and 2010-11

\begin{tabular}{|c|c|c|c|c|c|c|c|c|c|}
\hline \multirow{2}{*}{$\begin{array}{l}\text { Poverty } \\
\text { Status }\end{array}$} & \multicolumn{3}{|c|}{ Household Size } & \multicolumn{3}{|c|}{ Children Under 15} & \multicolumn{3}{|c|}{ Dependency Ratio } \\
\hline & $2000 / 01$ & $2010 / 11$ & Change & $2000 / 01$ & $2010 / 11$ & Change & $2000 / 01$ & $2010 / 11$ & Change \\
\hline Pakistan & 7.0 & 6.4 & -0.6 & 3.0 & 2.5 & -0.5 & 1.14 & 0.99 & -0.15 \\
\hline Poor & 8.5 & 8.2 & -0.3 & 4.2 & 4.1 & -0.1 & 1.50 & 1.50 & 0.00 \\
\hline Non-poor & 6.4 & 6.2 & -0.2 & 2.5 & 2.3 & -0.2 & 1.00 & 0.93 & -0.07 \\
\hline Punjab & 6.5 & 6.2 & -0.4 & 2.8 & 2.3 & -0.4 & 1.15 & 1.00 & -0.15 \\
\hline Poor & 7.9 & 7.9 & 0.0 & 3.9 & 3.9 & 0.0 & 1.53 & 1.50 & -0.03 \\
\hline Non-poor & 6.1 & 6.0 & -0.1 & 2.3 & 2.2 & -0.2 & 1.01 & 0.94 & -0.07 \\
\hline Sindh & 7.5 & 6.4 & -1.2 & 3.2 & 2.4 & -0.8 & 1.04 & 0.89 & -0.15 \\
\hline Poor & 9.7 & 8.3 & -1.3 & 4.7 & 4.3 & -0.4 & 1.38 & 1.52 & +0.14 \\
\hline Non-poor & 6.7 & 6.2 & -0.5 & 2.6 & 2.2 & -0.4 & 0.91 & 0.82 & -0.09 \\
\hline $\mathrm{KP}$ & 7.7 & 7.2 & -0.5 & 3.6 & 2.9 & -0.7 & 1.30 & 1.09 & -0.21 \\
\hline Poor & 8.9 & 9.3 & +0.4 & 4.6 & 4.7 & +0.1 & 1.59 & 1.52 & -0.07 \\
\hline Non-poor & 7.0 & 6.9 & -0.0 & 3.0 & 2.7 & -0.3 & 1.15 & 1.04 & -0.11 \\
\hline Balochistan & 7.6 & 7.1 & -0.6 & 3.5 & 3.3 & -0.2 & 1.12 & 1.15 & +0.03 \\
\hline Poor & 9.0 & 8.1 & -0.9 & 4.5 & 4.3 & -0.2 & 1.33 & 1.51 & +0.18 \\
\hline Non-poor & 7.0 & 6.9 & -0.1 & 3.1 & 3.1 & 0.0 & 1.04 & 1.09 & +0.05 \\
\hline
\end{tabular}

Source: Pakistan Integrated Household Survey (PIHS) 2000-01 \& PSLMS 2010-11 
Declining dependency ratios emerge in the last ten years for Punjab, Sindh, and KP but not for Balochistan. The richest households in Punjab and Sindh have undergone a change since they have experienced the largest decline in fertility over the last two decades. Resultantly they have a smaller proportion of children under 15 and a large working-age population. Changes in the age structure for poor and rich households in KP and Balochistan are relatively smaller compared to Punjab and Sindh. While the beginnings of the contrast are evident in KP, there is a hardly any difference in the proportion of children under 15 between the poorest and richest households in Balochistan.

The Coale-Hoover hypothesis suggests that some of the impressive rise in the Asian saving rates can be explained by equally impressive decline in the dependency burden (Williamson, 2001, pp.106-136). Savings are also affected by household fertility- higher fertility appears to lead to lower household savings rates. Savings income ratios (Table 7.2) have decreased substantially over the last five years in Pakistan from 2005 to 2010; from 6.7 percent to 4.9 percent (data at national level is not shown). This is no doubt linked to the economic stagnation of the last few years. The provincial differentials in savings ratios are also very marked -with the exception of Punjab, saving income ratios have declined over the last five years in the other three provinces.

Also as expected, household size appears to have a negative impact on the household savings. Even in poor households those with fewer children have higher savings ratios across all the provinces. This pattern of savings income ratio and negative ratio implies that children in poorer households suffer from the draw-down of expenditures on food and basic amenities. They are less likely to have overall savings and investments overall.

Table 7.2: Household Savings Income Ratio by poverty status $\&$ by number of children at the provincial level in Pakistan: 2005-2010

\begin{tabular}{lcccccc}
\hline & \multicolumn{3}{c}{ PSLMS 2005-06 } & \multicolumn{3}{c}{ PSLMS 2010-11 } \\
\cline { 2 - 6 } Province & $0-2$ & $3 \&+$ & Total & $0-2$ & $3 \&+$ & Total \\
\cline { 2 - 6 } Punjab & & & & & \\
Poor & 11.5 & 4.8 & 6.3 & 5.1 & 1.7 & 2.5 \\
Non-Poor & 10.2 & 5.4 & 8.1 & 8.9 & 5.3 & 7.4 \\
$\quad$ Total & 10.3 & 5.2 & 7.8 & 8.7 & 4.6 & 6.9 \\
Sindh & & & & & & \\
Poor & 2.4 & 1.0 & 1.2 & -7.7 & -12.2 & -11.2 \\
Non-Poor & 7.4 & 3.6 & 5.7 & -0.3 & -4.3 & -1.2 \\
Total & 7.2 & 2.9 & 5.0 & -0.6 & -5.5 & -2.7 \\
KP & & & & & & \\
Poor & 2.3 & 1.2 & 1.4 & 0.3 & -4.5 & -3.7 \\
Non-Poor & 7.3 & 6.2 & 6.7 & 5.3 & -1.7 & 1.8 \\
$\quad$ Total & 6.8 & 4.7 & 5.5 & 5.1 & -2.14 & 1.3 \\
Balochistan & & & & & & \\
Poor & 9.4 & 0.7 & 3.5 & -1.5 & -3.0 & -2.8 \\
Non-Poor & 4.3 & 6.3 & 5.3 & 3.2 & NA & NA \\
Total & 6.2 & 3.3 & 4.5 & 2.9 & NA & NA \\
\hline
\end{tabular}

Source: PSLMS; NA = Not Applicable due to few number of cases 


\section{Recommendations}

The provincial governments must recognize the numerous benefits of investing in an accelerated family planning programme. The health sector stands to benefit the most, but family planning can also lead to a reduction in poverty levels and help increase economic growth prospects. This is a call for all four provinces to commit finances to and prioritize programmes aimed at improving access to family planning services in the immediate term, thereby leading to an accelerated programme.

The report's primary recommendation is that all health outlets should provide family planning services. This is already one of the commitments made at the London Summit 2012 and was announced by the Prime Minister on 11 July 2011 (World Population Day). The most basic issue is the lack of optimal provision of family planning services in the public health sector, which has adversely affected the outcomes of the poorest families, thereby increasing poverty and exacerbating inequality. Once the Health departments take on this responsibility and the political and bureaucratic leadership assigns it the highest level of priority and ensure accountability for monitoring progress in this area, success in raising contraceptive prevalence levels is bound to be achieved.

The mandatory delivery of such services at health department outlets must ensure regular contraceptive supplies and the availability of trained staff to provide counselling and services such as IUD insertion, implants, and surgery. Not only should the requisite facilities be available, but staff should also avail opportunities to provide such services, particularly during the postpartum, postnatal, post-abortion, and antenatal periods when women need other care.

Additional commitments include an emphasis on the LHWP, which should revert to family planning as a priority, enabling LHWs to return to their original mandate of providing family planning services. An earlier third-party evaluation has pointed out that LHWs have moved away from making household visits and providing family planning services (OPM, 2009).

As shown clearly in the maps below, the coverage of the Population Welfare Department and its main outlet the FWCs is limited. However the Department does play a major role in training through its regional Training Institutes and of providing specialized family planning services in RHS A and B centres throughout the country. Expanding access to services among the poor is possible, particularly through outlets managed by the departments of health and PPHI, which are located in rural and remote areas. The static outlets of the Health departments particularly the BHUs and RHCs can certainly expand access to services if they do in fact provide family planning advice and supplies. Most compelling is the outreach of the LHWs particularly in the rural and remote areas which would ensure greater access to family planning services and advice. While there is potential for the private sector to also step up its delivery of family planning services, our recommendations are aimed at the public sector to increase access for the poor and rural women who cannot afford private sector services. 
FALAH (Family advancement for Life and Health) and other programmes that have striven to improve the delivery of family planning services through the public sector have demonstrated the potential for a rapid increase in the uptake of family planning. An annual uptake of 2.5 percentage points in the CPR occurred over a four-year period as a result of FALAH interventions in working with LHWs and health department staff, ensuring contraceptive availability, and improving interpersonal communication, including with men (Mahmood, 2012). This is similar to Bangladesh's experience of intensive service provision at the doorstep, which brought about dramatic changes in the country two decades ago (Bongaarts et al., 2012).

Family planning use uptake is strongly correlated with the availability of contraceptives and personnel who are equipped to provide counselling and family planning services to female clients. Contraceptive availability remains a troubling issue although recently there have been efforts to streamline regular provision. Currently, the DELIVER project is striving to improve the distribution of contraceptives and USAID has provided a supply. The provinces will, however, need to make provision for stocks post-2015. While current supplies of almost all contraceptive methods are available, the stocks available with LHWs and at BHUs and RHCs have dwindled.

Finally, there needs to be interpersonal communication support at the community level through LHWs, while other means of conveying important information should be developed for uncovered areas. It is absolutely necessary for women but also men to receive direct information about what contraceptive choices are available, their sources, side effects, and how to manage them. This is best done in a group or a one to one setting in the community. 
Map of Lasbela district showing FWCs, MOH static clinics and LHWs

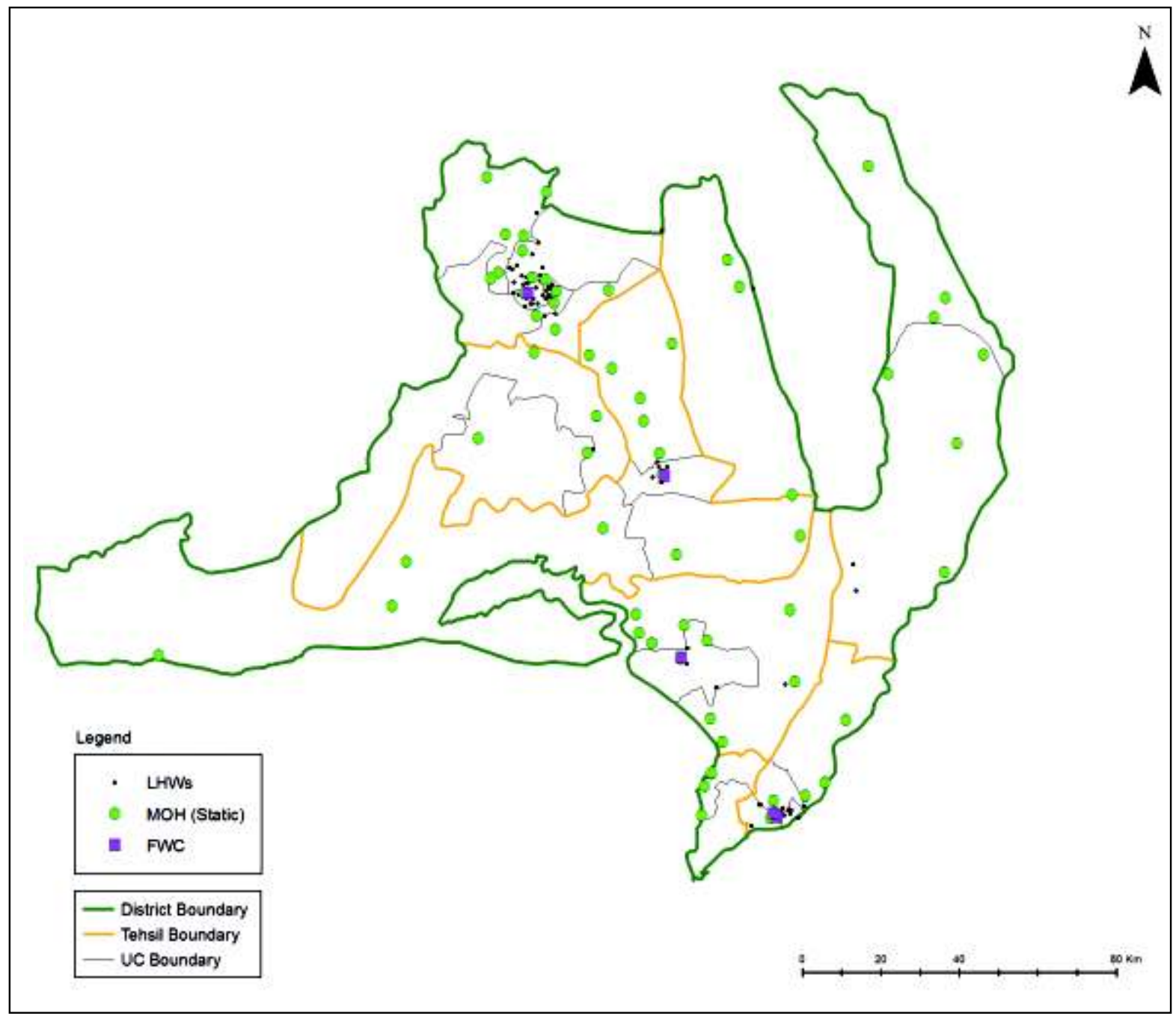

Souce: FALAH GIS Mapping survey, 2008. 
Map of Charsadda district showing FWCs, MOH static clinics and LHWs

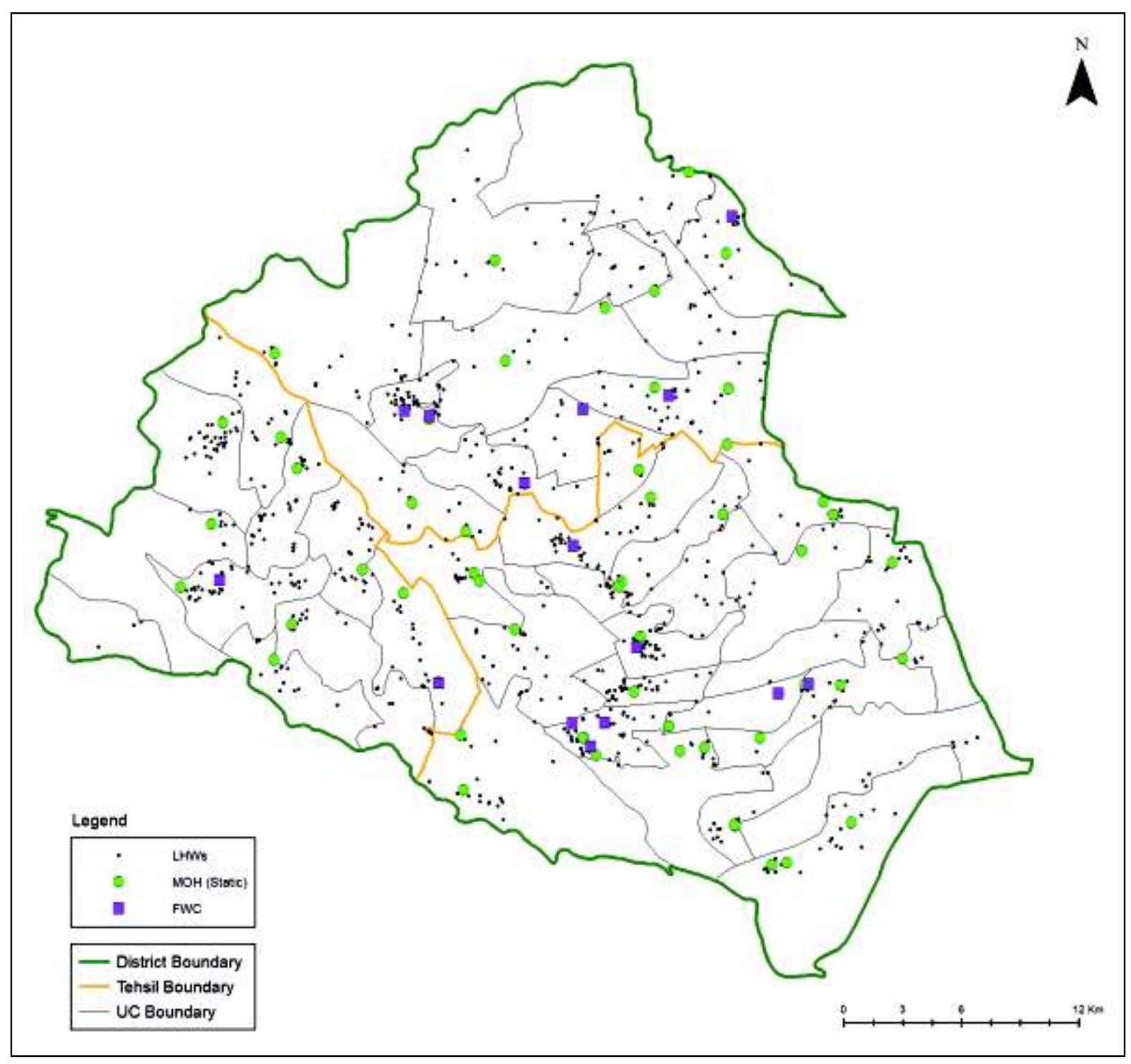

Souce: FALAH GIS Mapping survey, 2008. 
Map of D.G. Khan District showing FWCs, MOH static clinics and LHWs

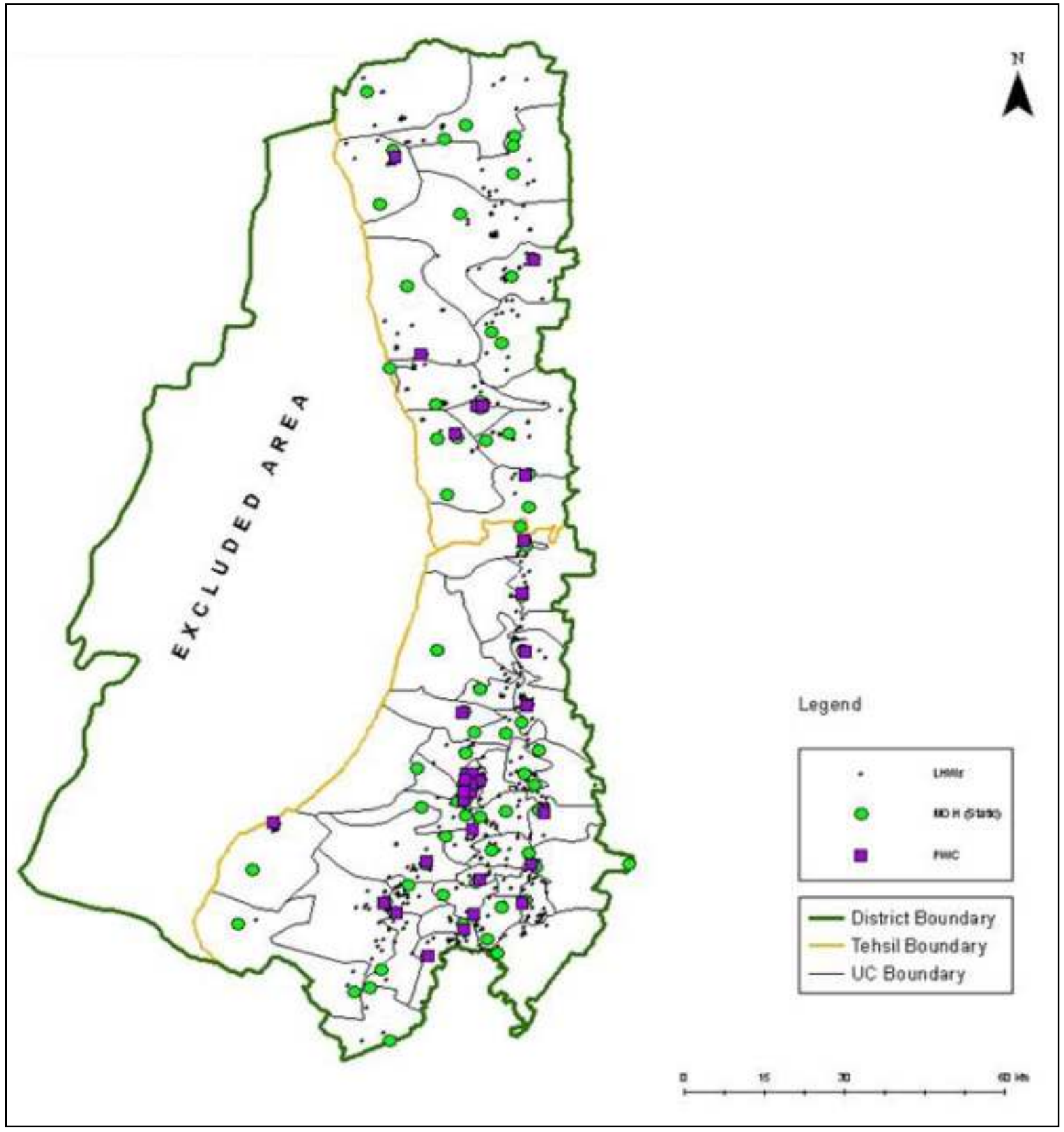

Souce: FALAH GIS Mapping survey, 2008. 
Map of Thatta district showing FWCs, MOH static clinics and LHWs

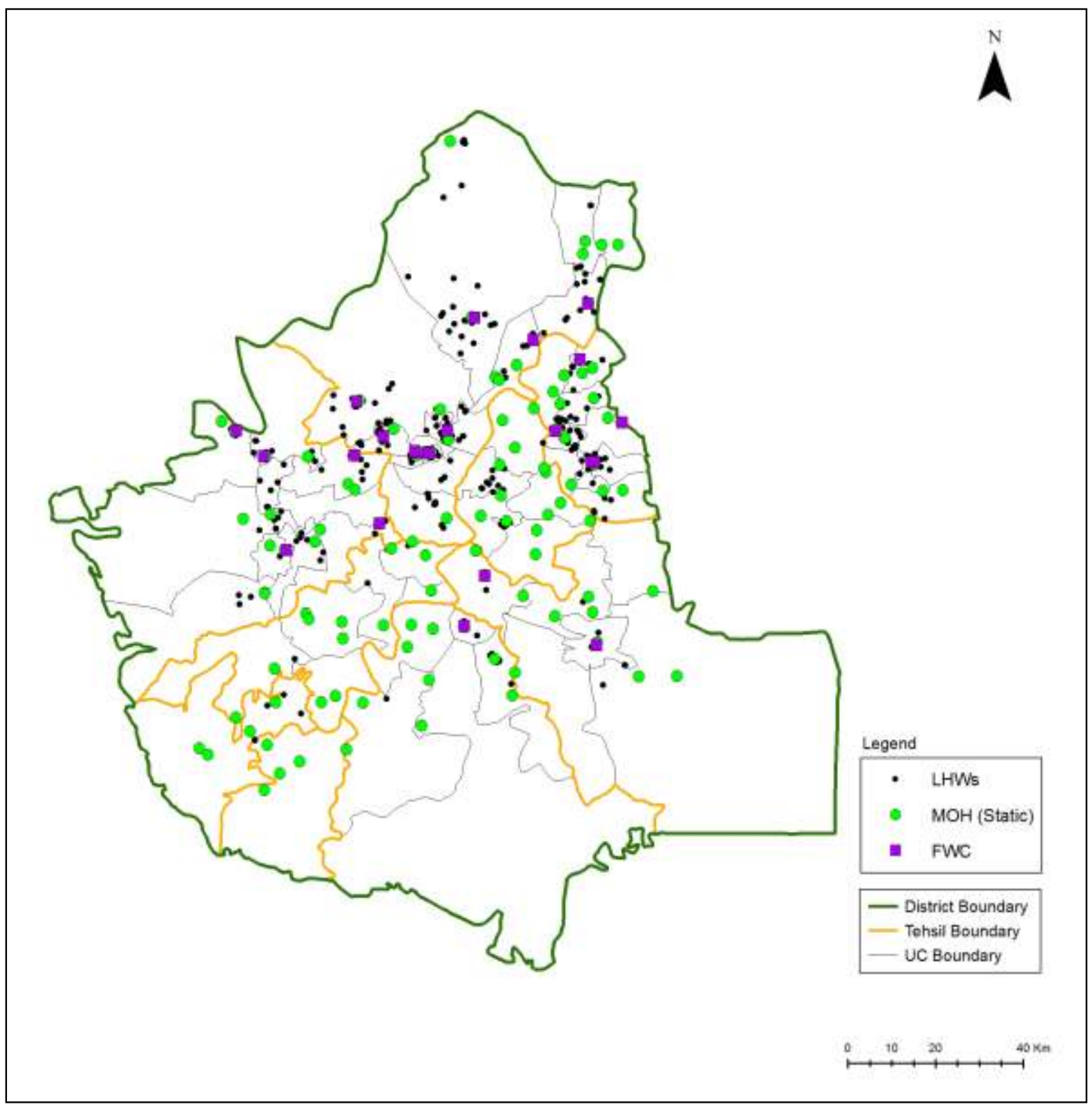

Souce: FALAH GIS Mapping survey, 2008. 


\section{Conclusions}

Millions of men and women in Pakistan - both adolescents and adults - are unable to achieve their reproductive and fertility aspirations or enjoy their reproductive and sexual health rights because they face numerous social, cultural, and economic barriers to accessing reproductive health and family planning services. The experience of developing countries suggests that, as countries struggle to diminish poverty and attain the MDGs, they must also focus on the rapid increase in population and its far-reaching consequences on infant and maternal health and development indicators.

All provinces of Pakistan are going through a period of unprecedented rapid demographic change. A huge expansion in population numbers along with a rapidly changing age structure in each province has a substantial impact on maternal and infant mortality. Provincial population projections demonstrate continuing population growth at a rapid pace for the next few decades. Population growth is determined by three major components: unwanted fertility, high desired family size and population momentum. Estimates suggest that eliminating unwanted fertility will have a large impact on Pakistan's population growth in the future. A ten percent decline in population can be achieved by 2050 by reducing unwanted fertility. A common approach to reducing unwanted fertility is to provide effective family planning services. The impact of population momentum can be mitigated by delaying the age at first birth, which is again directly correlated with the use of family planning.

The young age structure of the population poses specific challenges to reducing maternal and infant mortality. Young mothers have a higher risk of developing complications during pregnancy and maternal mortality is higher among adolescents. Delaying age at first birth and ensuring a sufficient birth interval between two births has a huge impact on lowering neonatal, infant and maternal mortality. Providing voluntary and effective family planning services enables adolescent girls to achieve their ideal family size and provides the opportunity to delay their first birth.

Pakistan is unlikely to meet its MDG 4 and 5 , despite having made some progress in lowering its MMR. Infant and child mortality rates appear to have stalled, particularly in the recent past but there are still huge gaps in the provision of both maternal and (particularly) childcare. We argue that these are necessary but not sufficient conditions to lower both maternal and infant mortality to the targets set by the MDGs. Greater effort is required both to fill these gaps and explore the case for family planning.

We have argued that the majority of women and men in all four provinces have expressed a desire for fewer and better-spaced children. However, the use of contraception to pace and limit childbirths remains low, with significant variations across and within provinces. This leaves huge room to increase the CPR in a short time by accelerating family planning efforts throughout Pakistan.

Family planning and birth spacing is an effective and untapped route towards achieving MDGs 4 and 5, as well as several other MDGs. Most countries that have achieved rapid economic growth 
have also had strong family planning programmes that help women avoid unplanned pregnancies and have the smaller families they prefer.

We have demonstrated that an accelerated family planning programme would benefit each of the four major provinces by helping to meet the aspirations and rights of women and men in terms of their fertility preferences. An effective family planning programme should focus on eliminating the high levels of unmet need (18 percent in Punjab to 31 percent in Balochistan) to achieve the CPR of about 60 percent commonly found throughout South Asia and other Muslim countries.

The rise in contraceptive prevalence to 58 percent in Punjab, 50 percent in Sindh, 54 percent in $\mathrm{KP}$, and 51 percent in Balochistan would help collectively save 5486 maternal and 136,000 infant lives. It would also reduce the stress on each of the provincial health departments of providing emergency obstetric care, emergency obstetric and new born care, ANC, and delivery and immunization services for millions of deliveries, new-borns, infants, and children. The provincial governments could then focus on improving the quality of services they currently provide and channel resources to more vulnerably located populations.

Last but not least, eliminating unmet need will empower women, freeing them from repeated, closely spaced pregnancies, and allowing them to take on employment and other productive activities and lead healthier lives.

Men who have expressed a desire for smaller families and better-spaced children are now feeling the pinch of providing their children with quality education and health. Higher levels of contraceptive prevalence will ease this pressure and allow men to use their household resources more effectively in investing better in their children's future. The effective and accelerated rise in family planning will reduce the unwanted fertility rate, thereby reducing fertility rates and population growth. Investing in family planning is, therefore, nothing but a winwin proposition. 


\section{References}

Abbasi-Shavazi, M. J., \& McDonald, P. (2006). The fertility decline in the Islamic Republic of Iran: 1972-2000. Asian Population Studies, 2(3), 217-237.

Ahmed, S., Li, Q. F., Liu, L., \& Tsui, A. (2012). Maternal deaths averted by contraceptive use: An analysis of 172 countries. The Lancet, 380, 111-125.

Alan Guttmacher Institute. (2002). Family planning can reduce high infant mortality levels (Issues in Brief, No. 2). Retrieved from http://www.guttmacher.org/pubs/ib_2-02.pdf

Ali, M., Hotta, M., Kuroiwa, C., \& Ushijima, H. (2005). Emergency obstetric care in Pakistan: Potential for reduced maternal mortality through improved basic EmOC facilities, services, and access. International Journal of Gynaecology and Obstetrics, 91, 105-112

.Aassve, Arnstein \& Engelhardt, Henriette \& Francavilla, Francesca \& Kedir, Abbi \& Kim, Jungho \& Mealli, Fabrizia \& Mencarini, Letizia \& Pudney, Stephen \& Prskawetz, Alexia, 2005. "Poverty and fertility in less developed countries: a comparative analysis," ISER Working Paper Series 2005-13, Institute for Social and Economic Research.

Arif, G.M. and F. Bilquees. (2006). "Chronic and Transitory Poverty in Pakistan: Evidence from Longitudinal Survey,"MIMAP Technical Paper Series No. 1, Pakistan Institute of Development Economics. Islamabad.

Azmat, S. K., Hameed, W., Ishaque, M., Mustafa, G., \& Ahmed, A. (2012). Post-abortion care family planning use in Pakistan. Pakistan Journal of Public Health, 2(2), 4-9.

Bloom, D. E., \& Canning, D. (2003). Contraception and the Celtic tiger. Economic and Social Review, 34(3), 229-247.

Bloom, D. E., \& Canning, D. (2006). Booms, busts and echoes: How the biggest demographic upheaval in history is affecting global development. Finance and Development, 43(3), $8-13$.

Bloom, D. E., Canning, D., Fink, G., \& Finlay, J. E. (2009). Fertility, female labour force participation, and the demographic dividend. Journal of Economic Growth, 14(2), 79101.

Bloom, D., (2013). “Foreword.” Foreword. Capturing the Demographic Dividend in Pakistan. The Population Council: Wily Online Library.

Bongaarts, J., Cleland, J., Townsend, J. W., Bertrand, J., \& Gupta, M. (2012). Family planning programs for the 21st century. New York, NY: Population Council.

Bongaarts, J., Sathar, Z. A., \& Mahmood, A. (2013). Population trends in Pakistan. In Z. Sathar, R. Royan, \& J. Bongaarts (Eds.), Capturing the demographic dividend in Pakistan (pp. 13-23). Hoboken, NJ: Wiley \& Blackwell.

Cates, W., Jr, Karim, Q. A., EL-Sadr, W.,Haffner, D.W., Kalina-Zikusoka, G., Rogo, K., Petruney, T., Averill, E. M. D. (2010). Family planning and the Millennium Development Goals. Science, 329(5999), 1603.

Centre for Poverty Reduction and Social Policy Development and Pakistan Planning Commission. (2010). Pakistan Millennium Development Goals report 2010: 
Development amidst crisis. Islamabad: Authors. Retrieved 15 July 2013 from http://undp.org.pk/images/publications/mdgr2010.pdf

Chowdhury, M. E., Botlero, R., Koblinsky, M., Saha, S. K., Dieltiens, G., \& Ronsmans, C. (2007). Determinants of reduction in maternal mortality in Matlab, Bangladesh: A 30-year cohort study. The Lancet, 370, 1320-1328.

Cleland, J., Bernstein, S., Ezeh, A., Faundes, A., Glasier, A., Innis, J., (2006). “Family planning: the unfinished agenda", The Lancet, 368(9549): 1810-1827.

Cleland, J., Conde-Agudelo, A., Peterson, H., Ross, J., \& Tsui, A. (2012). Contraception and health. The Lancet, 380, 149-156.

Conde-Agudelo, A., \& Belizán, J. M. (2000). Maternal morbidity and mortality associated with interpregnancy interval: Cross sectional study. British Medical Journal, 321, 12551259.

Conde-Agudelo, A., Rosas-Bermudez, A., \& Kafury-Goeta, A. C. (2007). Effects of birth spacing on maternal health: A systematic review. American Journal of Obstetrics and Gynaecology, 196(4), 297-308.

Collumbien, M., Gerressu, M., \& Cleland, J. (2004). Non-use and use of ineffective methods of contraception. In M. Ezzati, A. D. Lopez, A. Rodgers, \& C. J. L. Murray (Eds.), Comparative quantification of health risks: Global and regional burden of disease attributable to selected major risk factors (pp. 255-320). Geneva: World Health Organization.

Desai, M. (1992). "Population and poverty in Africa," African Development Review, 4(2): pp. 63-78.

Eastwood, R. and M. Lipton (1999). "The Impact of Changes in Human Fertility on Poverty," Journal of Development Studies, 36(1): pp. 1-30.

Falbo, T., Kim, S. H., \& Chen, K. (2008). The effects of siblings, parental socioeconomic status, adolescent aptitude, educational attainment, and wealth on health in later life. Paper presented at the Population Association of America's annual meeting. Retrieved from http://paa2008. princeton.edu/abstracts/80026.

Feenay, G., \& Alam, I. (2003). New estimates and projections of population growth in Pakistan. Population and Development Review, 29(3), 483-492.

Stover, John., Heaton, Laura., \& Ross, John. (2006). A Computer Program for Projecting Family Planning Requirements (FamPlan), Spectrum System for Policy Models. Retrieved from http://www.jhsph.edu/departments/international-health/centers-andinstitutes/institute-for-internationalprograms/_documents/manuals/FamPlanManual.pdf

Gilmore, K., \& Gebreyesus, A. (2012). What will it take to eliminate preventable maternal deaths? The Lancet, 380, 87-88.

Gipson, J. D., Koenig, M. A., \& Hindin, M. J. (2008). The effects of unintended pregnancy on infant, child, and parental health: A review of the literature. Studies in Family Planning, 39(1), 18-38.

Habumuremyi, D. P., \& Zenawi, M. (2012). Making family planning a national development priority. The Lancet, 380, 78-80. 
High Impact Practices in Family Planning (HIP). (2012). Post-abortion family planning: Strengthening the family planning component of post-abortion care. Retrieved from www.fphighimpactpractices.org/hip-briefs

Hemmi, N. (2003). “The poverty trap with high fertility rates," Economics Bulletin, 9(6): pp. 1-4.Gordon, D., Pantazis, C., and P.Townsend (2006), " Child Rights and Child Poverty in Developing Countries," Summary Report to UCICEF, UK.

Hobcraft, J., McDonald, J. W., \& Rutstein, S. O. (1983). Child-spacing effects on infant and child mortality. Population Index, 49, 585-618.

Hogen, M. C., Foreman., K.J., Naghavi, Mohsen., Ahn, Y.S., Wang, Mengru., Makela, S.M., Lopez, A.D., Lozano, Rafael \&Murray, J. L. (2010). Maternal mortality for 181 countries, 19802008: A systematic analysis of progress towards Millennium Development Goal 5. The Lancet, 375(9726), 1609-1623.

Huntington, D., Hassan, E. O., Attallah, N., Toubia, N., Naguib, M., \& Nawar, L. (1995). Improving the counselling and medical care of post-abortion patients in Egypt. Studies in Family Planning, 26(6), 350-362.

Huntington, D., \& Piet-Pelon, N. J. (Eds.). (1999). Post-abortion care: Lessons from operations research. New York, NY: Population Council.

Jain, A. K. (2011). Measuring the effect of fertility decline on the maternal mortality ratio. Studies in Family Planning, 18, 247-260.

Jayachandran, S., \& Lleras-Muney, A. (2008). Life expectancy and human capital investments: Evidence from maternal mortality declines (Working Paper No. 13947). Cambridge, MA: National Bureau of Economic Research.

Jejeebhoy, S. (1995). Women's education, autonomy, and reproductive behaviour: Experience from developing countries. Oxford: Clarendon Press.

Joshi, S. (2012). Reproductive health and economic development: What connections should we focus on? Washington, DC: Population Reference Bureau.

Kelley, A.C. \& Schmidt, R.M. (2001) Economic and demographic change: a synthesis of models, findings, and perspectives, in: N.Birdsall, A.C. Kelley \& S. Sinding (eds.) Population Matters: Demographic Change, Economic Growth, and Poverty in the Developing World, New York, Oxford University Press,67-105.

The Lancet (series on family planning). (2012). 380(9837), 75-186.

Liu, L., Becker, S., Tsui, A., \& Ahmed, S. (2008). Three methods of estimating births averted nationally by contraception. Population Studies, 62(2), 191-210.

Maralani, V. (2008). The changing relationship between family size and educational attainment over the course of socioeconomic development: Evidence from Indonesia. Demography, 45(3), 693-717.

McCarthy, J. (1997). The conceptual framework of the PMM network. International Journal of Gynaecology and Obstetrics (Suppl.), 59, S15-S21.

McCarthy, J., \& Maine, D. (1992). A framework for analyzing the determinants of maternal mortality. Studies in Family Planning, 23(1), 23-33. 
Moreland, S., \& Talbird, S. (2006). Achieving the Millennium Development Goals: The contribution of fulfilling the unmet need for family planning. Washington, DC: USAID.

Nana-Fabu, S. (2001). "High Fertility and Development in Cameroon" Journal of Social Development in Africa, 16(1). pp. 1-20

National Institute of Population Research and Training, Mitra and Associates, and ICF International. (2013). Bangladesh demographic and health survey 2011. Dhaka: Authors.

National Institute of Population Studies and Macro International Inc. (1992). Pakistan demographic and health survey 1990-91. Islamabad: Authors.

National Institute of Population Studies.(2001). Pakistan reproductive health and family planning survey 2000-01. Islamabad: Author.

National Institute of Population Studies and Macro International Inc. (2008). Pakistan demographic and health survey 2006-07. Islamabad: Authors.

National Institute of Population Studies and Macro International Inc. (2014). Pakistan demographic and health survey 2012-13. Islamabad: Authors.

Okijie, C. (1989). "Women Status And Fertility And Fertility In Bender States If Nigeria: A Comparative Study of Selected Communities," Report submitted to Rockefeller Foundation, New York.

Pritchett, L. (1994). Desired fertility and the impact of Population policies. Population and DevelopmentReview, 20(1), 1-55.

Pakistan Bureau of Statistics (2001). Pakistan Social and Living Standards Measurement Survey 2000-01. Pakistan Bureau of Statistics, Government of Pakistan, Islamabad.

Pakistan Bureau of Statistics.(2010). Pakistan social and living standards measurement survey 2008-09. Islamabad: Author.

Pakistan Bureau of Statistics (2011). Pakistan Social and Living Standards Measurement Survey 2010-11. Pakistan Bureau of Statistics, Government of Pakistan, Islamabad.

Pakistan Bureau of Statistics.(2013). Pakistan social and living standards measurement survey 2011-12. Islamabad: Author.

Population Action International. (2010). The key to achieving the MDGs: Universal access to family planning and reproductive health. Washington, DC: Author.

Population Council. (2004). Unwanted pregnancy and post-abortion complications in Pakistan: Findings from a national study. Retrieved from http://www.popcouncil.org/pdfs/Unwanted_Pregnancy.pdf

Population Council. (2013). Post-abortion Care in Pakistan: A National Study. Retrieved from http://www.popcouncil.org/uploads/pdfs/2013RH_PakistanPAC.pdf

Punjab, Bureau of Statistics. (2011). Multiple indicator cluster survey (MICS) Punjab. Lahore: Author.

Randall, E. (2012). Family planning programmes review. Retrieved 12 July 2013 from http://www.populationmatters.org/documents/programmes_review.pdf 
Razzaque, A, Vanzo , J.Da., Rahman., M., Gausia, K., Hale, L., Khan, M.A., Mustafa, A. H. (2005). Pregnancy spacing and maternal morbidity in Matlab, Bangladesh. International Journal of Gynaecology and Obstetrics, 89(1), S41-S49.

Ross, J. A., \& Blanc, A. K. (2012). Why aren't there more maternal deaths? A decomposition analysis. Journal of Maternal and Child Health, 16, 456-463.

Roudi-Fahimi, F. (2002). Iran's family planning program: Responding to a nation's needs (MENA Policy Brief). Washington, DC: Population Reference Bureau.

Rutstein, S. O. (2008). Further evidence of the effects of preceding intervals on neonatal, infant and under-five-years mortality and nutritional status in developing countries: Evidence from demographic and health surveys (Demographic and Health Surveys Working Paper No. 41). Calverton, MD: Macro International Inc.

Sathar, Z. A. (2013). Family planning: A missing priority in Pakistan's health sector? The Lancet, 381(9884), 2140-2141.

Sathar, Z., Royan, R., and Bongaarts, J. (2013). "Capturing the Demographic Dividend in Pakistan" Editors, the Population council and UNFPA.

Schultz, T. P. (2009). How does family planning promote development? Evidence from a social experiment in Matlab, Bangladesh, 1977-1996. Paper presented at the Population Association of America's meeting, Detroit, MI.

Schultz (2005). "Effects of Fertility Decline on Family Well Being: Opportunities for Evaluating Population Programs," unpublished paper.

Sedgh, G., Singh, S., Shah, I., Åhman, E., Henshaw, S. K., \& Bankole, A. (2012). Induced abortion: Incidence and trends worldwide from 1995 to 2008. The Lancet, 379(9816), $625-632$.

Seyfried, L. (2011). Family planning and maternal health: The effects of family planning on maternal health in the Democratic Republic of Congo. Master's thesis, Georgetown University, Washington, DC.

Shah, N., Hossain, N., Shoaib, R., Hussain, A., Gillani, R., \& Khan, N. H. (2009). Sociodemographic characteristics and the three delays of maternal mortality. Journal of the College of Physicians and Surgeons Pakistan, 19(2), 95-98.

Shavit, Y., \& Pierce, J. L. (1991). Sibship size and educational attainment in nuclear and extended families: Arabs and Jews in Israel. American Sociological Review, 56, 321330.

Shiffman, J. (2000). Can poor countries surmount high maternal mortality? Studies in Family Planning, 31(4), 274-289.

Singh, S., \& Darroch, J. E. (2012). Adding it up: Costs and benefits of contraceptive servicesEstimates for 2012. New York, NY: Guttmacher Institute and United Nations Population Fund (UNFPA)

Schultz, P. (2005). Effects of fertility decline on family wellbeing: Opportunities for evaluating population programs. Unpublished paper. 
Smith, R., Ashfold, L., Gribble, J., \& Clifton, D. (2009). Family planning saves lives (4th ed.). Washington, DC: Population Reference Bureau.

Starrs, M. A. (2006). Safe Motherhood Initiative: 20 years and counting. The Lancet, 368(9542), 1130-1132.

Steelman, L. C., Powell, B., Werum, R., \& Carter, S. (2002). Reconsidering the effects of sibling configuration: Recent advances and challenges. Annual Review of Sociology, 28, 243269.

Stover, J., \& Ross, J. (2010). How increased contraceptive use has reduced maternal mortality. Maternal Child Health Journal, 14, 687-695.

Tripney, J., Schucan Bird, K., Kwan, I., \& Kavanagh, J. (2010). The impact of post-abortion care family planning counselling and services in low-income countries: A systematic review of the evidence (Technical report). London: EPPI Centre.

USAID. (2011). Extending service delivery and USAID: Mainstreaming healthy timing and spacing of pregnancy: A framework for action. Retrieved from http://www.pathfind.org/site/DocServer/ESD_Legacy_Mainstreaming_HTSP.pdf?docID $=18752$

USAID. (2013). The role of family planning in reducing poverty. Retrieved 12 July 2013 from http://transition.usaid.gov/our_work/global_health/pop/news/issue_briefs/fp_redpove rty.pdf

USAID Health Policy Initiative. (2009). Family planning and the MDGs: Saving lives, saving resources. Washington, DC: USAID.

United Nations. (1993). Women's status and fertility in Pakistan: Recent evidence. New York, NY: UN Department of Economic and Social Information and Policy Analysis.

United Nations, Department of Economic and Social Affairs. (2009). World population prospects: The 2008 revision. New York, NY: Author.

United Nations, Department of Economic and Social Affairs. (2012). World population prospects: The 2012 revision. New York, NY: Author.

United Nations Development Program, (2013). Pakistan Millennium Development Goals Report 2013. Planning Commission, Government of Pakistan.

Vlassoff, M., Hossein, A., Maddow-Zimet, I., Singh, S., \& Bhuiyan, H. U. (2012). Menstrual regulation and post-abortion care in Bangladesh: Factors associated with access to and quality of services. New York, NY: Guttmacher Institute.

Wallace, H. M., Gold, E. M., \& Dooley, S. (1969). Relationships between family planning and maternal and child health. American Journal of Public Health, 59(8), 1355-1360.

WHO. (1997). Post-abortion family planning: A practical guide for program managers. Geneva: Author.

WHO, (2000). Maternal mortality in 2000: estimates developed by WHO, UNICEF and UNFPA. Retrieved from http://whqlibdoc.who.int/publications/2004/9241562706.pdf?ua=1 
WHO. (2003). Antenatal care in developing countries: Promises, achievements and missed opportunities: An analysis of trends, levels and differentials, 1990-2001. Retrieved from http://whqlibdoc.who.int/publications/2003/9241590947.pdf?ua=1

WHO. (2007). Report of a WHO technical consultation on birth spacing. Geneva: Author.

WHO. (2011). Unsafe abortion: Global and regional estimates of incidence of unsafe abortion and associated mortality in 2008 (6 $6^{\text {th }}$ ed.). Geneva: Author.

WHO. (2012). Family planning: A health and development issue - a key intervention for the survival of women and children. Geneva: Author.

WHO, UNICEF, UNFPA, and World Bank. (2000). Maternal mortality in 2000: Estimates developed by WHO, UNICEF, UNFPA and the World Bank. Geneva: Authors.

WHO, UNICEF, UNFPA, and World Bank. (2012). Trends in maternal mortality, 1990 to 2010: Estimates developed WHO, UNICEF, UNFPA, and the World Bank. Geneva: Authors.

Winikoff, B., \& Sullivan, M. (1987). Assessing the role of family planning in reducing maternal mortality. Studies in Family Planning, 18(3), 128-143.

Williamson, G.J (2001), “Demographic change, economic growth and inequality" in N. Birdsall, A. Kelley and S. Sinding (Eds.). Population Matters: Demographic Change, Economic Growth, and Poverty in the Developing World. New York: Oxford University Press: pp. 106-136

Zosa-Feranil, I., Green, C., \& Cucuzza, L. (2009). Engaging the poor on family planning as a poverty reduction strategy. Washington, DC: Futures Group, Health Policy Initiative. 

